University of Rhode Island

DigitalCommons@URI

Open Access Master's Theses

2017

\title{
Quantifying Behavioral Impacts on Electric Vehicle Efficiency
}

Daniel Kowlasky

University of Rhode Island, dan_kowalsky@my.uri.edu

Follow this and additional works at: https://digitalcommons.uri.edu/theses

Recommended Citation

Kowlasky, Daniel, "Quantifying Behavioral Impacts on Electric Vehicle Efficiency" (2017). Open Access

Master's Theses. Paper 1139.

https://digitalcommons.uri.edu/theses/1139

This Thesis is brought to you for free and open access by DigitalCommons@URI. It has been accepted for inclusion in Open Access Master's Theses by an authorized administrator of DigitalCommons@URI. For more information, please contact digitalcommons-group@uri.edu. 


\section{QUANTIFYING BEHAVIORAL IMPACTS ON ELECTRIC VEHICLE EFFICIENCY}

BY

DANIEL KOWALSKY

A THESIS SUBMITTED IN PARTIAL FULFILLMENT OF THE

REQUIREMENTS FOR THE DEGREE OF

MASTER OF SCIENCE

IN

SYSTEMS ENGINEERING

UNIVERSITY OF RHODE ISLAND 
MASTER OF SCIENCE IN SYSTEMS ENGINEERING

OF

DANIEL KOWALSKY

APPROVED:

Thesis Committee:

Major Professor Gretchen A. Macht

Manbir Sodhi

Christopher Hunter

Nasser H. Zawia

DEAN OF THE GRADUATE SCHOOL

UNIVERSITY OF RHODE ISLAND

2017 


\begin{abstract}
The impact of human behavior on vehicle efficiency has been vastly explored for internal combustion engine (ICE) vehicles. However, human behavioral impacts on vehicle efficiency have not yet transitioned to include battery electric vehicles (BEVs). Understanding the impact of human behavior that achieves BEV efficiency is essential globally, as BEVs begin to retain a significant portion of the automotive market share. BEV sales trends in the US have seen consistent growth since 2010, amounting to over 200,000 units sold by 2015. Globally, the total amount of BEVs and plug-in hybrid electric vehicles (PHEVs) is expected to be 40-70 million by 2025. In light of the growth estimates, defining behavior that induces efficient energy consumption when driving BEVs is essential as these vehicles have a traveling distance constrained to 60-120 miles and can require 1-8 hours to attain a fully charged battery at commercial charging stations.

With firm traveling distances and long charging times, defining human behavioral impacts on BEV efficiency will allow drivers to get the most range out of their vehicle. In order to develop categories of BEV drivers in terms of efficiency, an empirical experiment was conducted to determine if clustering drivers on their energy consumption profiles invokes significant categories. The driving attributes that defined the clusters were extracted to compare whether or not efficient BEV driving is similar to eco-driving in ICE vehicles. Furthermore, BEV drivers can suffer from anxiety that stems from limited traveling distance, a phenomenon known as range anxiety. However, there exist other sources of anxiety-related human driving behavior, three of which can be measured using the driving behavior survey (DBS). The three anxiety measures from the DBS were contrasted against the BEV efficiency clusters found from this research, to determine if the anxiety factors defined by the DBS were responsible for efficient BEV driving.

The results from this research found two significantly different clusters of BEV driving efficiency, which were defined as efficient and inefficient BEV driving. In comparison to eco-driving in ICE vehicles, both aggressive speed and acceleration were found to be
\end{abstract}


contributing factors to BEV efficiency. The results from the DBS proved that anxiety was not a contributing factor to BEV efficiency, as both clusters had similar answers.

The information accumulated through this research can be used to guide new BEV drivers to adopt sustainable driving behaviors, which can help maximize their traveling distance on a single charge. Behavioral contributions to efficiency stemmed mostly from reduction of traveling speed; however, consumption based on elevation and road class selection were also quantified. Drivers can use this information to plan their driving routes to minimize energy usage. Modeling techniques that assume a single rate of energy consumption for the population should include behavioral rates defined by this research. Defining behavioral classes of BEV efficiency is essential as BEV sales are on the rise and drivers and manufactures can both use this information to improve efficiency of these vehicles. 


\section{ACKNOWLEDGMENTS}

First and foremost, I would like to thank my major professor Dr. Gretchen A. Macht for her invaluable guidance in completing this research. Without her unrelenting commitment to make this research both feasible and valuable, the work completed would not have been possible. It has been a privilege to have worked with her over the past year, and those who choose to work with her in the future will quickly learn the passion she has for helping students succeed. I look forward to hearing about her continued success as a professor at the University of Rhode Island.

I would also like to thank my inside committee member Dr. Manbir Sodhi for aiding in developing the framework for this research. I would also like to thank him for inspiring me to continue on to the graduate program at the University. I would not be here today without the help of Dr. Sodhi.

Lastly, I would like to thank Dr. Christopher Hunter, who served as my outside committee member. He has made great additions to this thesis that make the research even more relevant in the realm of transportation. 


\section{TABLE OF CONTENTS}

ABSTRACT ..................... ii

ACKNOWLEDGMENTS . . . . . . . . . . . . . . . . iv

TABLE OF CONTENTS . . . . . . . . . . . . . . . . vi

LIST OF TABLES . . . . . . . . . . . . . . . . . . . vii

LIST OF FIGURES . . . . . . . . . . . . . . . . . . . viii

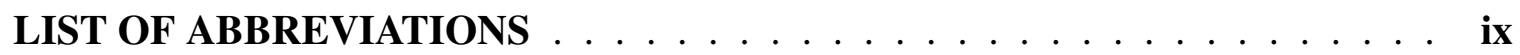

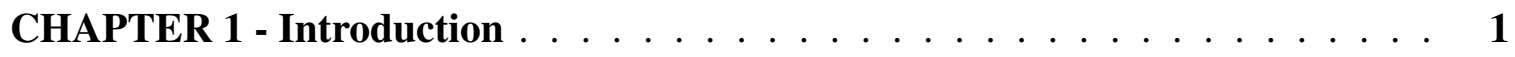

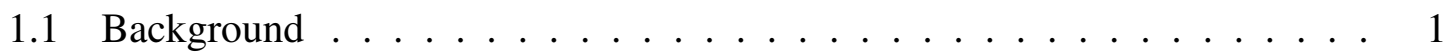

1.2 Research Goals . . . . . . . . . . . . . . . . . 3

CHAPTER 2 - Literature Review . . . . . . . . . . . . . . . . . 5

2.1 Driving Behavior Background ............... 5

2.2 Behavioral Impact on ICE Vehicles . . . . . . . . . . . . . . . 6

2.3 Behavioral Impacts on BEVs . . . . . . . . . . . . . . . . . 10

CHAPTER 3 - Methodologies . . . . . . . . . . . . . . . . . . 16

3.1 Methods of Experimentation . . . . . . . . . . . . . . 16

3.2 Methods of Data Collection and Analysis . . . . . . . . . . . . . . 24

3.2.1 BEV Driving Data ..................... 24

3.2.2 Survey Data . . . . . . . . . . . . . . 35

CHAPTER4 - Results and Discussion . . . . . . . . . . . . . 38

4.1 Raw Data Analysis . . . . . . . . . . . . . . . . 38

4.1.1 Analysis of SOC Consumed . . . . . . . . . . . . 38 
4.1.2 Road Type Analysis . . . . . . . . . . . . . . . . . . . . . . . . . . 39

4.1 .3 Elevation Analysis . . . . . . . . . . . . . . 40

4.2 Cluster Analysis . . . . . . . . . . . . . . . . . . 43

$4.2 .1 \quad$ Results $\ldots \ldots \ldots \ldots \ldots \ldots \ldots \ldots \ldots$

4.2 .2 Cluster Validation . . . . . . . . . . . . . . . . 45

4.2.3 Analysis of Aggressive Driving Attributes . . . . . . . . . 50

4.2.4 Regression of BEV Driving Factors $\ldots \ldots \ldots \ldots$

4.3 Questionnaire Results . . . . . . . . . . . . . . . . . . 56

4.4 Summary $\ldots \ldots \ldots \ldots \ldots \ldots \ldots \ldots \ldots$

CHAPTER5 - Conclusion $\ldots \ldots \ldots \ldots \ldots \ldots \ldots \ldots \ldots$

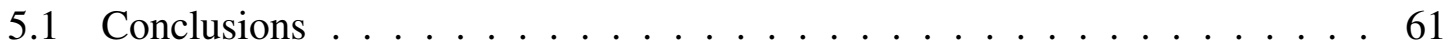

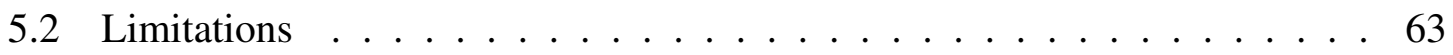

5.3 Future Work . . . . . . . . . . . . . . . . . . . . 64

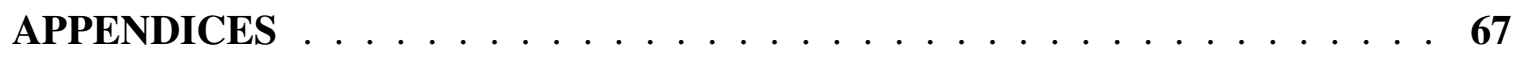

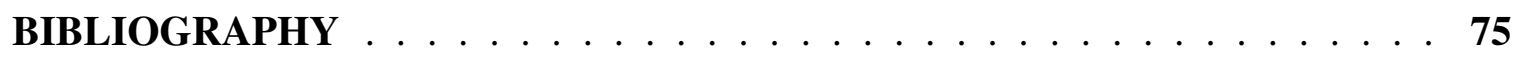

\section{LIST OF TABLES}

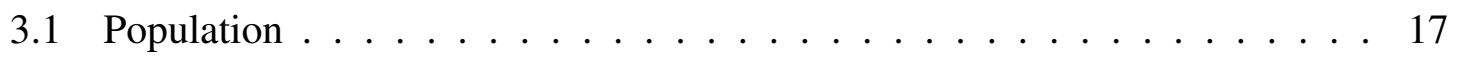

3.2 Experimental Design Summarization . . . . . . . . . . . . . 17

3.3 OSM Road Classes [69] . . . . . . . . . . . . . . . . . . . 18

3.4 e-Golf Recuperation Modes [70] . . . . . . . . . . . . . . . . . . . 21

3.5 Anxiety Based Driving Factors … . . . . . . . . . . . . 37

4.1 Cluster Statistics . . . . . . . . . . . . . . . . . . . . . 47

4.2 Hierarchical Regression Results _ . . . . . . . . . . . . . 55

4.3 Principal Component Analysis Variance $\ldots \ldots \ldots \ldots$ 
4.4 Factor Loadings for the DBS $\ldots \ldots \ldots$

4.5 Driving Estimation for BEV Driving Behavior . . . . . . . . . . 60

\section{LIST OF FIGURES}

1.1 Alternative Fuel Vehicles Sales $[4] \ldots \ldots \ldots \ldots$

2.1 ICE Efficiency $[46] \ldots \ldots \ldots \ldots \ldots$

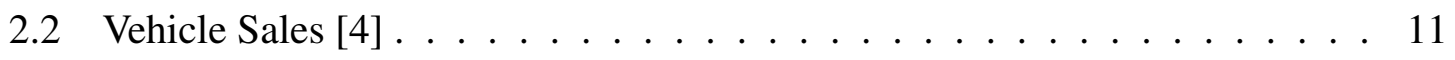

2.3 ICE Vs. BEV Internal Systems [52] $\ldots \ldots \ldots \ldots \ldots \ldots \ldots$

3.1 Route Visual . . . . . . . . . . . . . . . . . . . . . . . . . 19

3.2 Altitude on Experimental Route $\ldots \ldots \ldots \ldots$

3.3 Recuperation Mode Testing . . . . . . . . . . . . . . . . 22

3.4 Main Data Logging Devices $\ldots \ldots \ldots \ldots$

3.5 SocketCAN Terminal Output $\ldots \ldots \ldots \ldots \ldots \ldots$

3.6 SOC Comparison $\ldots \ldots \ldots \ldots \ldots \ldots \ldots \ldots \ldots \ldots$

3.8 Dataset Matching Procedure $\ldots \ldots \ldots \ldots \ldots$

3.9 Distributed SOC Measurements . . . . . . . . . . . . . . . . 33

4.1 Subjects Usage of Energy During Experiment … . . . . . . . . . . 39

4.2 Rate of SOC depletion by Road Type . . . . . . . . . . . . . . . 40

4.3 Rate of SOC depletion by Grade $\ldots \ldots \ldots \ldots$. . . . . . . . . 42

4.4 Clustering Results . . . . . . . . . . . . . . . . . . 44

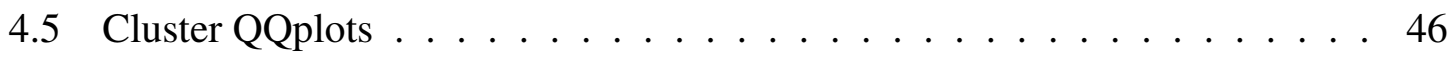

4.6 Rate of SOC depletion by Road Class $\ldots \ldots \ldots$

4.7 Cluster Speed . . . . . . . . . . . . . . . . . . . . . . . 51

4.8 Cluster Deviation from Speed Limit $\ldots \ldots \ldots \ldots \ldots$

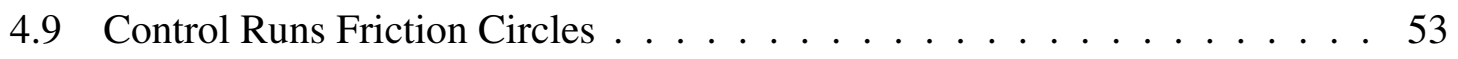

4.10 Points Outside Safe Driving Region by BEV Cluster . . . . . . . . . . 54

4.11 DBS 21 Anxiety Scores by Cluster . . . . . . . . . . . . 56 
4.12 Scree Plot of Eigenvalues . . . . . . . . . . . . . . . . . . 57 


\section{LIST OF ABBREVIATIONS}

\begin{tabular}{|c|c|}
\hline ANG & Anxiety-Based Aggressive/Hostile Behaviors \\
\hline $\mathrm{BEV}$ & Battery Electric Vehicle \\
\hline CAN & Controller Area Network \\
\hline CAUT & Exaggerated Safety/Caution Behaviors \\
\hline DBS & Driving Behavior Survey \\
\hline DBQ & Driving Behavior Questionnaire \\
\hline $\mathrm{DEF}$ & Anxiety Based Performance Deficits \\
\hline DSQ & Driving Skills Questionnaire \\
\hline EPA & Environmental Protection Agency \\
\hline $\mathrm{EV}$ & Electric Vehicle \\
\hline GPIO & General-Purpose Input/Output \\
\hline GPS & Global Positioning Satellite \\
\hline HVAC & Heating, Ventilation, and Air Conditioning \\
\hline ICE & Internal Combustion Engine \\
\hline $\mathrm{kWh}$ & Kilowatt Hours \\
\hline MPG & Miles per Gallon \\
\hline MPH & Miles per Hour \\
\hline NMEA & The National Marine Electronics Association \\
\hline OBD & On-Board Diagnostics \\
\hline OSM & OpenStreetMaps \\
\hline PID & Parameter ID \\
\hline PHEV & Plug-in Hybrid Electric Vehicle \\
\hline RPM & Revolutions per Minute \\
\hline SOC & State of Charge \\
\hline VW & Volkswagen \\
\hline
\end{tabular}




\section{CHAPTER 1 - Introduction}

\subsection{Background}

Human behavior is naturally complex, as behavior is not tangible matter that can be simply measured, but rather a system that changes dynamically in different environments [1]. Beyond studying behavior subjectively, when humans become intertwined with auxiliary systems, complexity grows as the combination of systems forms a hierarchy [2]. Quantifying this hierarchical system with respect to transportation networks is known as driving behavior. Driving behavior is the effect of the interactions between the human, the vehicle, and the roadway system, where identical causes produce variable effects from driver to driver [3].

The field of driving behavior is not new research. As roadway networks became increasingly dense, due to the non-stop growth of registered vehicles [4], the focus of driving behavior research was to define traits that evoke risky behavior which results in traffic accidents and fatalities $[5,6,7]$. In conjunction with increasing vehicles on the roads, problems arose with a growing amount of pollution from internal combustion engine (ICE) vehicles. ICE vehicles are responsible for $45 \%$ of harmful pollutants emitted every year in the US alone [8]. With respect to human behavior, eco-driving methods were defined as ways to improve ICE efficiency, through the reduction of aggressive driving [9]. The majority of eco-driving protocols call for controlled rates of speed and acceleration; however, further maintenance and comfort settings also inhibit ICE vehicle efficiency [10].

However, as the world's fossil fuel supply lingers [11], the cost to find, extract, and refine oil will continue to grow as supply dwindles [2]. To circumvent a limited supply of energy, alternative fuel vehicles began hitting the market, with increasing sales from year to year. Figure 1.1 illustrates sales for plug-in hybrid electric vehicles (PHEV), and battery electric vehicles (BEV), since their significant market entry at the beginning of 2010. BEVs are fully electric vehicles, meaning that they are powered only by means of an electric 


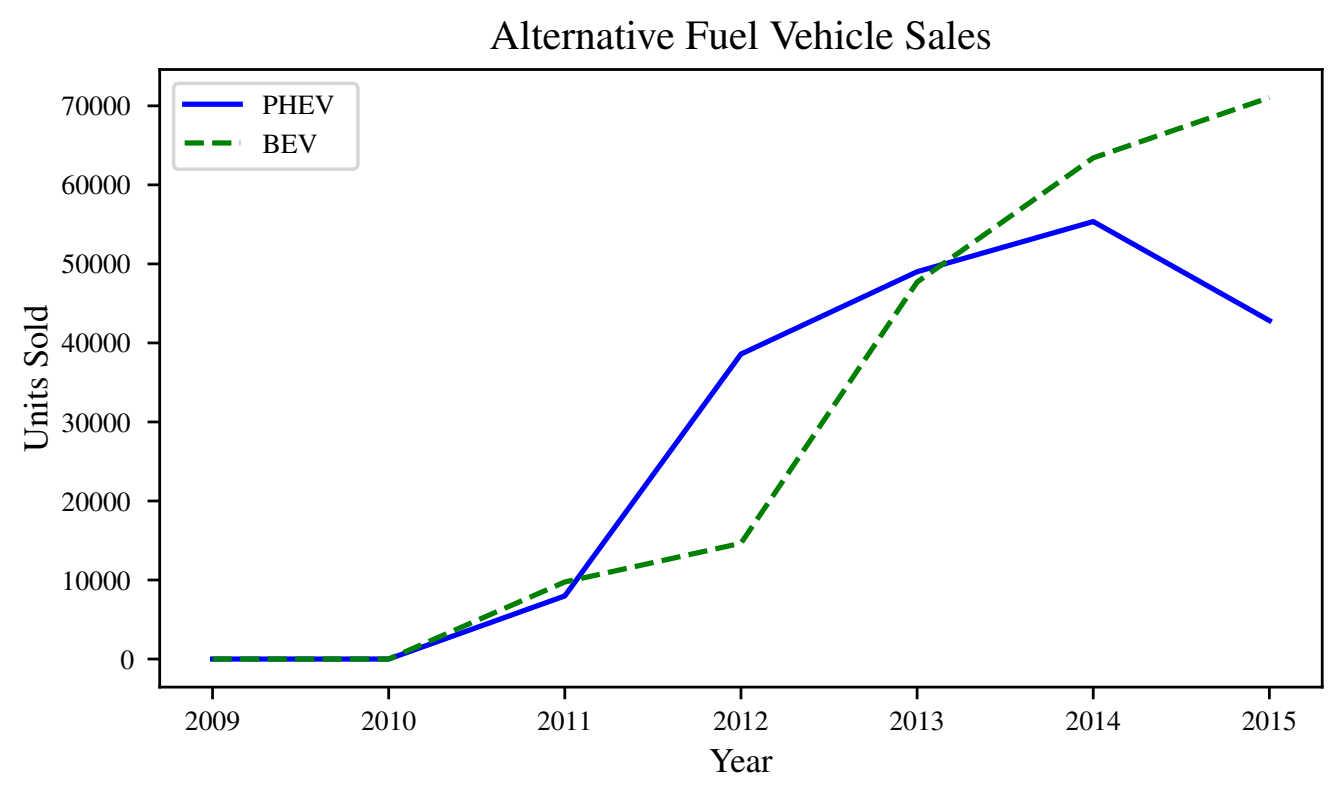

Figure 1.1: Alternative Fuel Vehicles Sales [4]

motor and must be charged at an electronic charging station in order to regain energy for travel [12]. A PHEV is also powered by an electric motor, but has an additional gasoline powered engine used to charge the vehicle's battery pack for extended range [13]. Since a $\mathrm{BEV}$ is constrained to electricity as its only source of fuel, traveling long distances becomes difficult, as range is generally limited to $60-120$ miles [14]. Once a majority of energy is used for travel, BEVs must be recharged. Recharging the vehicle becomes challenging, as charging times range from 1-8 hours to fully recharge the battery at commercial charging stations $[14,15]$. Long charging times paired with limited range means BEV drivers have to construct precise driving schedules.

In addition to planning charging events, a BEV driver also needs to consider how much energy they will personally consume. A Mitsubishi i-MiEV has an estimated range of 90 miles [16], but studies with subjects driving the same route had variable usage of energy consumption, ranging from $11 \%$ to $15.5 \%$ of the total battery capacity [17]. While the variation in energy consumption profiles between drivers could have diverged due to roadway congestion $[10,12,18]$, variables such as traveling speed are known to affect the 
energy consumption of a BEV [16]. While aggressive driving could have been assumed to be the reason behind inefficient BEV driving, further proof was necessary to support this hypothesis, as BEVs and ICE vehicles are independent systems.

\subsection{Research Goals}

The contribution of this research will serve to quantify the different categories of BEV efficiency, in conjunction with individualistic driving behavior. To complete this analysis, an experiment was set up to collect data on thirty drivers over the course of a 26-mile route. The route chosen for the experiment was held constant for each driver. Over the course of this route, data was collected via electronic sensors to study BEV driving behavior.

One of the key difficulties for drivers considering switching from an ICE vehicle to BEV is limited range [19]. This notion is known as "range anxiety" which is a measure of anxiety traits that are heightened when the maximum distance a vehicle can travel becomes further constrained, where drivers can be trapped in a vehicle with no battery power and no way to recharge the battery [20]. In an effort to further quantify the effect anxiety has on driving behavior, participants in the experiment took the Driving Behavior Survey (DBS). The DBS is a questionnaire that has been used to find three levels of anxiety-based driving behavior [21]. If anxiety-based driving behavior was found to be a contributing factor to BEV efficiency, range anxiety could be further detrimental to the efficiency of a BEV driver [22].

Therefore, the following specific research questions were addressed:

- Do drivers consume different amounts of energy when driving the same path?

- Does grouping BEV drivers based on their energy consumption profile aid in understanding why some BEV drivers use more energy than others?

- Is anxiety-based driving responsible for inefficient BEV driving? 
- Since eco-driving, with respect to ICE vehicles, is assumed to stem from aggressive displays of speed and acceleration, is efficient BEV driving behavior similar to ecodriving?

To answer these specific research questions, this thesis was broken up into following chapters. Chapter 2 provides an outline of the literature encompassing driving behavior, in terms of how behavior is defined, analyzed, and interpreted. An in-depth discussion of the factors essential to eco-driving was explored. Then, BEV efficient driving styles were compared and contrasted to those essential to eco-driving.

Chapter 3 describes the methodologies utilized in this research. Rationale for using the experimental design, along with the process of selecting and recruiting drivers, was defined. Networking into the vehicle's controller area network (CAN) was used to extract measurements from the vehicle's battery pack [23]. A separate global positioning satellite (GPS) was used to collect location and velocity information. Since smartphone accelerometers have been successfully used to obtain three-dimensional acceleration data [24], an iPhone 6s was used to capture this information. The last section of Chapter 3 covers the methods used to cluster drivers based on their energy consumption profiles, and how the DBS was used to test if anxiety is affecting BEV efficiency within the clusters found.

Chapter 4 covers the analysis and discussion of the data. The analysis includes how energy consumption was affected by road classifications, as well as the difference in energy usage among the drivers who participated in the experiment. Results of clustering drivers on their energy consumption profiles were completed, along with an analysis of aggressive driving behavior. Chapter 4 concludes with the analysis of the DBS, discussing driving anxiety's impact on BEV driving.

The last chapter, Chapter 5, concludes the results obtained from this research. Analysis of the impact of the BEV driving clusters was outlined. Recommendations for further research in the realm of BEV driving and BEV driving behavior were discussed. 


\section{CHAPTER 2}

\section{Literature Review}

\subsection{Driving Behavior Background}

Driving behavior is defined as the intermediate connection between humans and the situational outcomes that happen when driving vehicles [3]. When studying driving behavior, research strives to quantify these situations and extract patterns that exist within a segmented population. There exist three key avenues for segmenting drivers with respect to behavior. The three methods are population demographics, psychological traits, and pattern recognition from electronic sensors. However, when it comes to studying human behavior our initial perceptions of a population's performance may be distinctive, but the latent construct of behavioral patterns that define an individual can only be unearthed through the science of behavior [1].

In the process of developing a framework to organize humans with respect to their driving behavior, many initial hypotheses focused on traditional population demographics. These categories include age, sex, and driving experience [25, 26, 27], and are typically used to subsegment the entire population into notions of driver categories. Sometimes these population divisions produce significant results. Age and sex show significantly different driving behavior when measuring the gap-acceptance in making left turns [27], and through questionnaires focused on traffic violations and accident risk assessment [28]. However, these divisions are not always clear indicators of driving behavior classes. This can be seen in an experiment to quantify braking behavior at intervals of driving experience, which

yielded insignificant results [25]. Success in applying various population demographics in driving behavioral studies exemplifies how a predetermined view of behavior can be used to quantify driving categories. However, the predetermined intuition of these behavioral 
patterns falls short in some avenues of analysis because human behavior is complex [1] and cannot always be defined by physical traits.

To overcome the complexity that exists in the driving behavior of humans, research has also expanded to incorporate psychological measures. Background knowledge on these traits is usually generated via questionnaires that seek to statistically group drivers based on a group's response pattern $[21,29]$. Other research has used data from vehicles embedded with electronic sensors to cluster patterns of driving data into known psychological traits [30]. Electronic sensor data is also used for general clustering of driving behavior, by clustering drivers on comparable patterns $[5,31]$.

Exploration of how behavioral patterns vary with respect to driving behavior is further used to understand their impact on roadway systems. Overall, behavioral research in this domain is primarily focused on traffic safety $[5,6,7]$. Even though traffic safety is a fundamental component of driving behavior research, engineers today are being tasked with alternative avenues of design and analysis by employing green engineering practices. Green engineering involves quantifying the risk of pollutants through product use and manufacture, in an effort to minimize excessive use of resources [32]. Beyond the design of vehicles, green engineering can be used to reduce ICE vehicle emissions production through analysis of driving behavior. The efficiency of an ICE vehicle correlates with the behavior of different drivers [33]. The application of green engineering to ICE vehicles is known as eco-driving. Eco-driving, also known as ICE efficiency, is affected by aggressive driving behaviors, most commonly noted as aggressive speed and acceleration [34]. There are, however, more factors that are detrimental to ICE efficiency, and understanding those factors will help illustrate how behavioral driving affects efficiency.

\subsection{Behavioral Impact on ICE Vehicles}

It has been estimated that ICE vehicles are responsible for $45 \%$ of pollutants emitted in the US [8]. As of 2015 there were more than 263 million registered vehicles on U.S. 
roads, where alternative vehicles (BEVs, hybrids, and PHEV) accounted for approximately $1.5 \%$ of those vehicles [4]. From a green engineering perspective, determining factors to curb emissions from the use of ICE vehicles is the first logical step in developing a more sustainable society. Through the lens of behavioral driving, curbing emissions of an ICE vehicle can be done through eco-driving practices. Eco-driving is defined as the reduction of aggressive driving behaviors, which leads to increased fuel economy [9].

One way to achieve efficient driving of ICE vehicles is to stabilize gear shifting behavior. In a study that simulated gear shifting relative to speed, it was found that an aggressive style of gear shifting can increase fuel consumption and $\mathrm{CO}_{2}$ production by up to $30 \%$ [35]. To apply non-aggressive gear shifting, vehicle operators would need to up shift between the revolutions-per-second (RPM) range of 2000-2500 [36]. When an ICE vehicle is up shifted sooner, wasted energy used to propel vehicles on lower gears at faster speeds can be avoided.

A second method to exercise eco-driving principles is to control one's rate of acceleration and deceleration [36]. Ideally, drivers would seek to control braking and acceleration behavior when driving in variable traffic congestion levels [37, 38]. ICE vehicles make use of both automatic and manual transmission, so engine braking can be used to slow down vehicles when approaching a stop signal or entering roadways with traffic congestion. The engine braking method utilizes smoother deceleration, which can aid in reducing speed appropriately, without going below the optimal speed, which would then require more unnecessary acceleration [18]. Reducing the rate of acceleration boils down to maintaining consistent speeds, which ultimately increases fuel economy of an ICE vehicle [37]. Choice of traveling speed, however, also affects efficiency. When traveling speed is compared against fuel efficiency, a negative parabolic trend occurs [10]. For example, a V6 2007 Honda Civic exhibits minimal efficiency at speeds of 30 and 90 miles per hour (MPH) and optimal efficiency around $61 \mathrm{MPH}$ [39]. What this means for eco-driving efficiency is that road type selection is important when seeking ICE efficiency [10, 37]. 
Other known factors affecting ICE efficiency include excessive idling, which can account for a quarter to a half gallon of fuel per hour [40], and upkeep in regular maintenance, by tuning the engine, keeping appropriate tire pressure, and selection of engine oil [10]. Additionally, the mass of the vehicle can impact overall efficiency, because of the energy requirements necessary to increase momentum [10]. Lastly, usage of cooling by means of heating, ventilation, and air conditioning (HVAC) systems can reduce mileage by $5-25 \%$ [41]. However, heating is not affected in the same manner because ICE vehicles heat is generated from waste engine heat, where no additional energy is used to heat the vehicle's cab.

While all of the factors affecting ICE efficiency can be determined through mathematical modeling or mechanical systems simulation, understanding the human behavioral interaction with ICE vehicles for efficiency can only be achieved through experimentation. Since mass is an important aspect of ICE efficiency, buses are affected not only by their size, but also by their capacity of travelers [42]. Buses can be more efficient in a sense that per rider, their emissions are lower than driving individual vehicles because buses are a form of carpooling [10]. However, other factors still play a role in determining a bus driver's efficiency. From an experiment tracking three bus drivers, on five different bus routes, it was found that each driver used a different amount of fuel on the same route. There also existed consistency among the drivers, where one driver always used the least amount of fuel, another used the most, and the last driver was always in between the two [43].

However, utilizing buses as a mode of transportation is not nearly as common in the US as it is in European countries [44]. As it pertains to studying driving behavior with respect to eco-driving of passenger vehicles, most research is focused on testing whether or not individuals' driving behavior can be altered to improve efficiency [36, 37, 45]. The reason that individualistic patterns of eco-driving may not have been exhaustively researched is because aggressive driving behavior was stated to be the reason for inefficiency [9]. The gap 
in research could also stem from the US eliminating eco-driving programs which informed drivers on how to improve their efficiency [9].

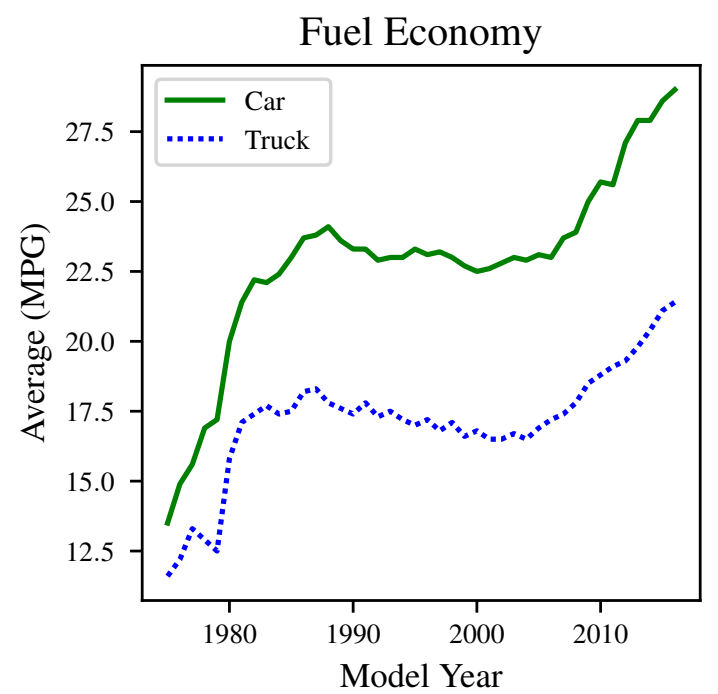

(a) Fuel Economy Trends

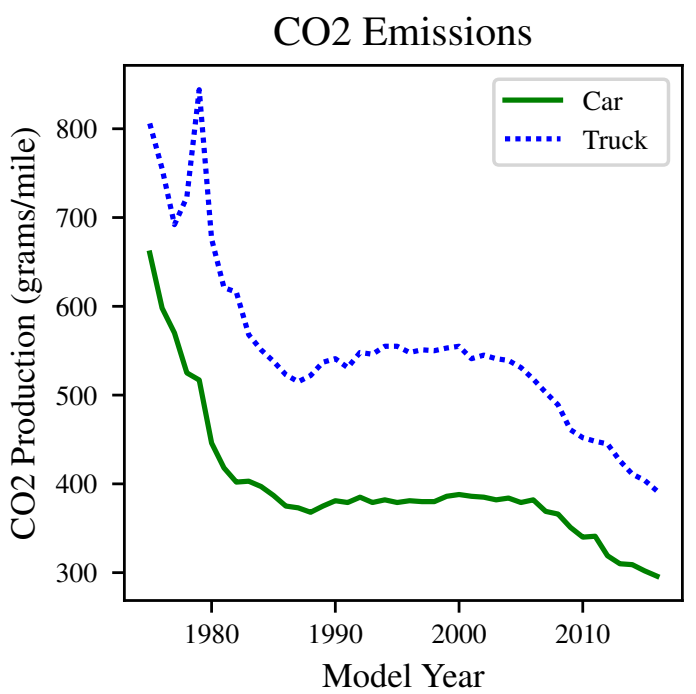

(b) Emissions Tends

Figure 2.1: ICE Efficiency [46]

Another issue with eco-driving is permanent adoption of the habits, when there exist minimal negative effects from drivers fading back to their standard habits. One experiment found seven out of eight subjects adopted eco-driving habits over the course of 6 months after taking an eco-driving course [36]. However, since adoption of these habits can be affected by driving situations and personal motivations [47], without a more complete sample size adoption of eco-driving for the long term has not completely been researched. It may also be challenging mentally to adopt eco-driving habits because ICE vehicles have been seeing an upward trend in efficiency. The Environmental Protection Agency (EPA) tracks the fuel economy and the rate of emissions from all vehicles in the US [46]. The EPA's data, seen in Figure 2.1a, shows an uptrend in the average fuel economy of cars (green) and trucks (blue). This increase in fuel efficiency also correlates with a downtrend in the rate of $\mathrm{CO}_{2}$ emissions, displayed in Figure 2.1b. Since 2000, efficiency in miles per gallon (MPG) of cars and trucks has increased by $29 \%$ and $27 \%$ respectively. The increasing trend of efficiency is due to governmental policies that set standards for fuel economy and production 
of emissions [48]. As of 2016, the average fuel economy of cars was around 29 MPG. By the year 2020, the National Highway Traffic Safety Administration has set standards for cars to achieve 35 MPG. Individual vehicle manufacturers are responsible for meeting set standards; otherwise the manufacturer is fined for failing to meet expected efficiency [48].

With an upward trend in efficiency, adoption of eco-driving behaviors indefinitely will be even more challenging for society as ICE vehicles become more efficient on the manufacturers' end. However, it may in turn be the perfect time to begin applying similar behavioral studies to the next generation of vehicles. In 2010, the International Energy Agency estimated that if there could be around 84 million PHEVs and BEVs by year 2035, carbon emissions could be reduced by around 900 Megatons $[49,50]$. While that number may be difficult to reach, the rate of BEV sales over the last five years continues to increase in the US, from 9,750 units in 2011 to 71,044 units in 2015 (see Figure 2.2). To prepare for this rising green technology, it will be essential to understand driving behavior's impact on BEV efficiency before these vehicles retain a larger market share, as compared to studying behavior of ICE vehicles which is being done retrospectively.

\subsection{Behavioral Impacts on BEVs}

To apply behavioral techniques to BEVs, as has been done with ICE vehicles through eco-driving, will first require knowledge of how BEV efficiency is influenced. While both vehicles look similar, their internal systems are substantially different. The motor of an ICE vehicle has hundreds of moving parts, as compared to a BEV which only has an encompassing motor [51]. A rough schematic of the essential components for each vehicle is depicted in Figures 2.3a and 2.3b. The most fundamental difference, however, is the fuel source for each vehicle. For ICE vehicles, the engine is powered by gasoline, which is stored in the fuel tank, as seen in Figure 2.3a. The fuel source for the BEV, labeled as the traction battery pack in Figure 2.3b, is an electronic battery. While these vehicles have the same external skeletons, the interconnections that define their powertrain system are 


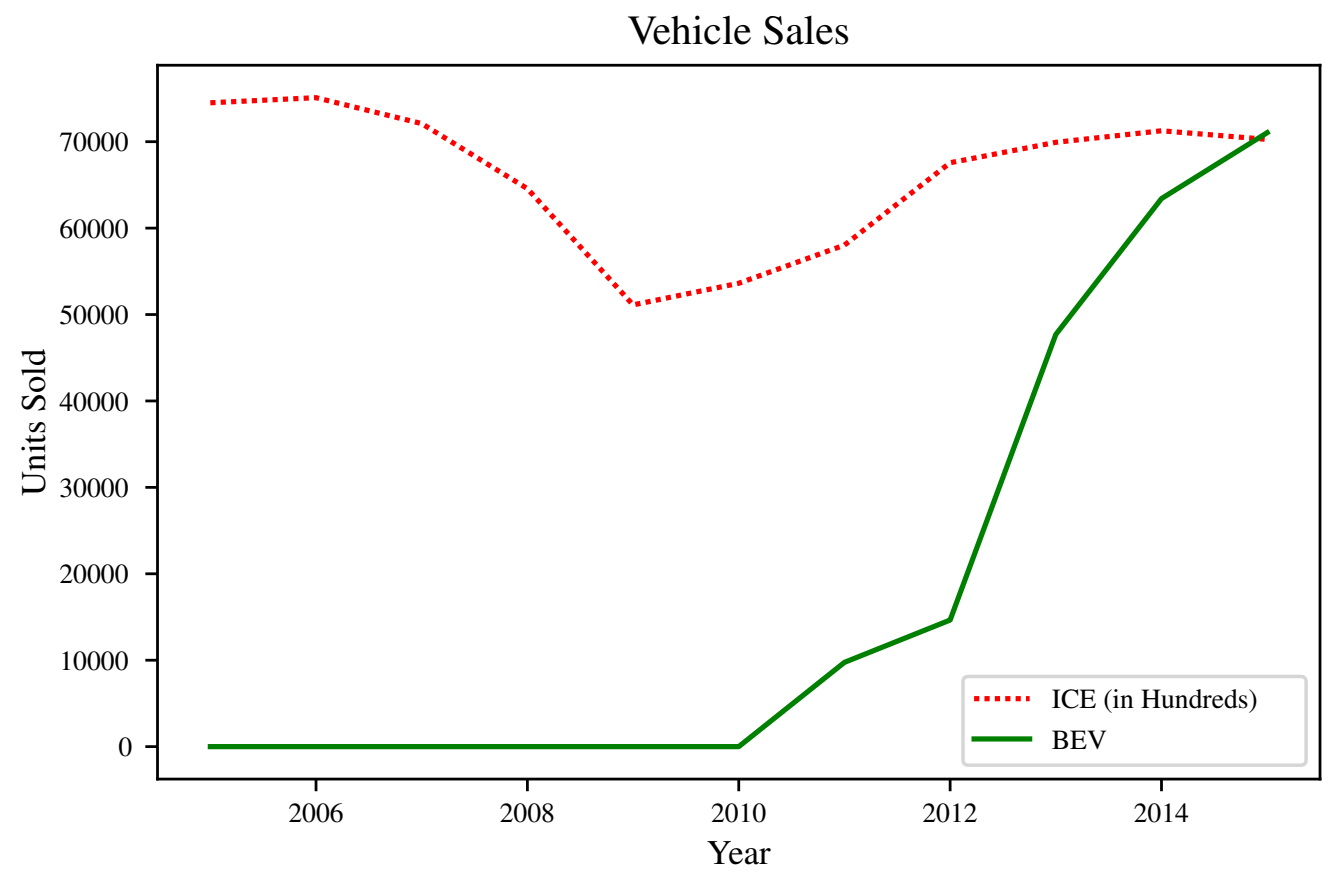

Figure 2.2: Vehicle Sales [4]

completely different, making them unique systems [2]. In studying ICE efficiency, a focus on the variables that affect the rate of fossil fuel consumption is monitored $[36,37]$. For a $\mathrm{BEV}$, a focus on the variables that affect the rate of sate of charge (SOC) depletion, must be studied to determine the impact of human behavior.

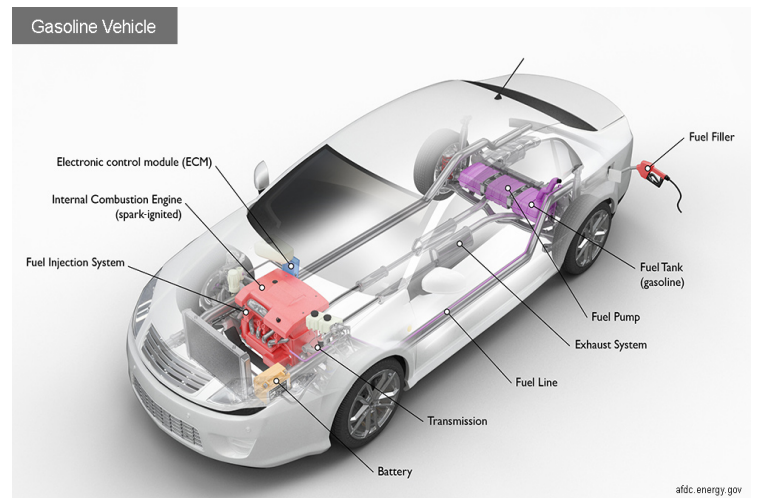

(a) ICE Vehicles Main Components

\section{All-Electric Vehicle}

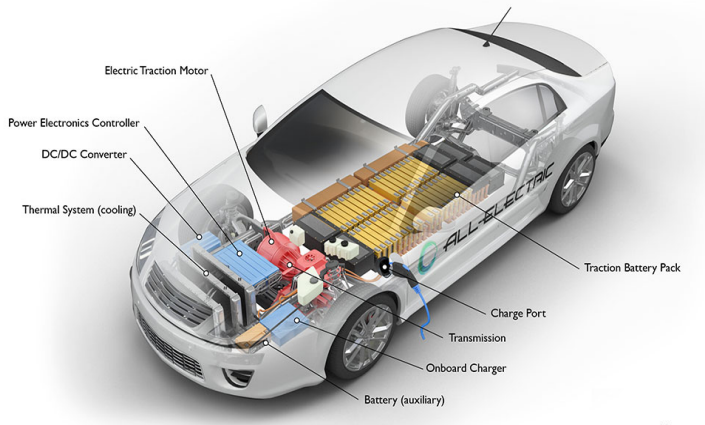

(b) BEV Vehicles Main Components

Figure 2.3: ICE Vs. BEV Internal Systems [52] 
The first variable affecting the rate of energy consumption, and one of the most important, is vehicle speed. An experiment was conducted using a Mitsubishi i-MiEV and a Nissan ${ }^{\circledR}$ LEAF®. A single driver, operating each of the cars at speeds of 37.2, 43.5, 49.7, 55.9, 62.1, and 68.3 MPH, found an exponential relationship between speed and rate of energy consumption [16]. This curve is much different when compared to the speed vs. fuel consumption curve of an ICE vehicle, which follows a negative parabolic trend [10]. In terms of efficiency, an ICE vehicle is efficient around $45 \mathrm{MPH}$, and a BEV is efficient around $15 \mathrm{MPH}$ [12]. Since efficiency follows two completely different trends with respect to speed for ICE vehicles and BEVs, road type selection between the two is completely different.

Energy savings via road type selection for BEVs was found by collecting data over an extended period of time from a professor's daily commute. Initially there were four possible ways to get between the two places (home and work). The three main routes used were comprised of back roads and intercity roads, while the fourth route used a highway for travel. The time savings from using the highway were minimal compared to the other three routes; however, the other three routes saved about $1 \mathrm{kWh}$ of battery capacity over 100 miles [53]. Utilization of alternative routes can be thought of as leverage points, where the length of time may not be a significant factor, but the rate of discharge of the BEV can be beneficial to the driver [54].

Road grade is another important factor in route selection. BEVs have the ability to regenerate energy while braking. The regenerative braking system allows vehicles to harness the power lost while braking, by reversing the direction the motor turns [55]. It is estimated that in urban areas, the recuperation from braking could increase the range of a BEV by $15-20 \%[12,55]$. The effect of power used by a BEV versus the traveling grade was studied, and showed that a positive increase in grade always has a significant amount of power consumption, while a decreasing grade results in minimal energy consumption or energy collection from the regenerative brakes [53]. In contrast, ICE vehicles' efficiency suffers 
from elevation changes, because they cannot recover energy on decreasing road grades. In fact, a study found that an ICE vehicle traveling the same distance on a flat route and a route with variable elevation had fuel savings of $15-20 \%$ on the flat route [56].

Regenerative braking can also increase efficiency in other scenarios, such as driving in variable traffic congestion, because of the deceleration. A study was conducted on various levels of traffic congestion, where measurements were recorded during free flow traffic, mild congestion, moderate congestion, and high congestion. When a freeway switches from free flow to mild/moderate congestion, BEVs take advantage of slower speeds and regenerative braking though deceleration for improved efficiency [12]. When compared to an ICE vehicle, which is not efficient at slow speeds, the rate of fuel consumption increases [10]. Another problem in high traffic congestion is that if traffic comes to a full stop, ICE efficiency is reduced because of excessive idling [40]. A BEV's motor, on the other hand, does not turn without pressing the accelerator; thus, no energy is consumed from the motor when idling.

Another factor affecting a BEV's rate of energy consumption is the auxiliary power used by systems such as steering, radio, HVAC, and other onboard electronics that derive power directly from the BEVs battery. Since in a typical ICE vehicle these amenities are powered via an alternator, their effect on fuel consumption is not as detrimental as it is to BEV drivers who have to account for the charge they will use on a trip. For a Nissan® LEAF®, it has been estimated that the power needed to support the accessories is $0.2 \mathrm{~kW}$, while the power needed to sustain the HVAC system is around $6 \mathrm{~kW}$ [57]. The HVAC system affects efficiency of BEVs at both ends of the extreme temperature spectrum [57], where the trend of efficiency is parabolic. When using the HVAC system, a BEV is extremely inefficient at temperatures below $0^{\circ} \mathrm{F}$ and above $100^{\circ} \mathrm{F}$, and is most efficient around temperatures of $50-70^{\circ} F$ [58]. Overall, HVAC systems have been found to reduce range by up to $40 \%$ [59]. 
For the most part, the variables that affect ICE efficiency are different from those that alter a BEV's efficiency. This is because ICE vehicles and BEVs interact with transportation networks differently. For ICE vehicles, it has been suggested that aggressive driving behavior is directly linked to ICE efficiency [9]. While this assumption may hold true for BEVs in the case of the exponential use of energy at higher speeds [16], aggressive driving is also affected by rapid rates of acceleration [34]. All BEVs take advantage of regenerative braking and recover energy during deceleration [53], making the overall assumption that aggressive driving is the sole representation of BEV efficiency challenging to prove without experimentation.

However, what is known about BEVs with respect to driving behavior is that consumption of energy differs between drivers. An experiment having ten drivers drive a BEV on the same route resulted in variable usage of energy among the participants [17]. Another study's findings showed variation in the rate of SOC consumption among a group of 25 drivers, where the least efficient driver consumed $2.8 \% \mathrm{SOC} / \mathrm{mile}$ and the most efficient driver used $1.5 \% \mathrm{SOC} / \mathrm{mile}$ [60]. Since it can be interpreted that behavior has an effect on the rate at which energy is depleted, it has been stated that future works should study the behavioral patterns that lead to excessive energy consumption [17]. Research defining behavioral impacts on BEV efficiency can have a greater impact on society as compared to studying eco-driving with respect to ICE vehicles, because limited traveling range may force drivers to adopt efficient driving styles for the long term.

One of the most common drawbacks from society adopting BEVs is their limited range [19], as most BEVs are restricted to a traveling distance of 60-120 miles [14]. However, most BEVs on the market have been found to meet a large percentage of individuals' travel needs $[61,62]$. A study supplying BEVs to 40 participants for daily driving found that 94\% of participants had enough range with the BEV to meet their needs [63]. However, issues with a BEVs limited range are still present. This phenomena is known as "range anxiety," which is defined as"the fear of becoming stranded with a discharged battery in a 
limited range vehicle" [20]. For BEVs, range anxiety can be mitigated through optimally designing a transportation network with an appropriate amount of charging stations [64]. However, since charging times can range from one to eight hours at commercial charging stations [14, 15], and with optimal networks still in the research phase [64], understanding the behavioral component can help BEV drivers learn to get the most out of their vehicles' range to reach destinations and charging stations.

Since range anxiety can be overcome through BEV driving experience [62], and since studies point to high interest in BEV usage [65], studying the impacts of BEV behavioral driving can help plan for a transition to a BEV future. There is a strong possibility that there will be between 9-20 million electric vehicles (EVs) by 2020 and between 40-70 million EVs in the world by 2025 [66]. By quantifying the impact of BEV driving behaviors, current BEV drivers can learn to practice efficient driving behavior and new BEV drivers can be educated to help make a seamless transition into the future. 


\section{CHAPTER 3}

\section{Methodologies}

In order to appropriately define classes of BEV drivers with respect to efficiency, various methods were deployed to collect and analyze data. This chapter begins with the methods used to develop an experiment where subjects drove a BEV for the bulk of data collection. Thens the systems used to electronically collect data from driving and use of questionnaires were discussed. Finally, the methods chosen to analyze the data will were covered.

\subsection{Methods of Experimentation}

This section will cover all of the methods used to design and run an experiment to capture data relevant to BEV driving behavior. For this experiment, a sample of subjects was recruited to drive a BEV on a predetermined route. The design of this experiment needed to include a population large enough to witness different driving behavior among individuals. Along with population size, the route chosen needed to be particularly long enough to collect enough change events in SOC. The experimental design was approved by the University of Rhode Island's Institutional Review Board (IRB). The documentation for the experiment can be found using the IRB reference number HU1617-055.

For this experiment, a sample of inexperienced BEV drivers was utilized. To amass a sample of experienced BEV drivers would have presented a recruiting challenge. In

Rhode Island, as of 2015, there were only 421 registered BEVs and PHEVs. This would account for $0.0421 \%$ of the state's population [67]. However, use of an inexperienced sample of BEV drivers was of greater benefit to this research. It was found that through experimental interventions, an inexperienced BEV driver will opt to change their driving behavior to improve efficiency [53]. With BEV sales increasing year to year [4] and an expected total sales of 40-79 million PHEVs and BEVs by the year 2025 [49, 50], the 
impact from studying the driving behaviors of inexperienced BEV drivers was of greater benefit to society, as there is a limited pool of experienced BEV drivers and their habits will need to be quantified to improve their BEV driving efficiency.

Table 3.1: Population

\begin{tabular}{|c|c|c|c|c|}
\hline \multicolumn{3}{|c|}{ Age Stats } & \multicolumn{2}{c|}{ Sex (population \%) } \\
\hline Mean & Stdv & Range & Male & Female \\
\hline 24.55 & 3.74 & $(19,36)$ & $55 \%$ & $45 \%$ \\
\hline
\end{tabular}

Recruiting of participants was done through the University. Advertisements were developed in the form of email blasts and flyers. Flyers used for recruitment can be found in Appendix A. Subjects who opted to participate in the research completed a consent form (see Appendix B), in compliance with the IRB's rules for experimentation involving human subjects. The results for the subjects age and sex can be seen in Table 3.1. The subjects' in this experiment were not conclusive with respect to age range, which only means that there cannot be analysis with respect to driving experience. However, 30 participants completed the experiment. This sample size follows trends seen in other driving behavioral research, which are outlined in Table 3.2.

Table 3.2: Experimental Design Summarization

\begin{tabular}{|c|c|l|c|}
\hline Sample Size & Distance per Driver (miles) & Constants & Source \\
\hline 45 & 1 mile & Route, Weather, and Time & {$[33]$} \\
\hline 40 & 16 miles & $\begin{array}{l}\text { Route, Vehicle, Samples From Es- } \\
\text { tablished Classes, and Time }\end{array}$ & {$[7]$} \\
\hline 23 & Unknown & $\begin{array}{l}\text { One Aggressive and One Non- } \\
\text { Aggressive Sample }\end{array}$ & {$[31]$} \\
\hline 13 & 243 miles & Route, Vehicle, Weather, and Time & {$[30]$} \\
\hline 10 & 8 miles & Route and Vehicle & {$[68]$} \\
\hline
\end{tabular}

In general, route selection for studying driving behavior has been held constant in previous research, as seen in the constants column of Table 3.2. For this research, the route driven by the subjects was also held constant. The importance of holding the route con- 
stant was necessary for this research, because assessing total energy consumed over the route was an essential step in defining behavioral patterns. The only way to make these comparisons was to hold route characteristics that affect the rate of SOC depletion, such as elevation changes [12] and road types [53], constant. However, the experimental route did include those characteristics, as it was necessary to interpret how these factors affect BEV driving behavior.

Since road type selection is a component of BEV efficiency [53], the route adopted for experimentation covered various road classifications. To make distinctions between one road and another, the road classification practices presented by OpenStreetMaps (OSM) were used. OSM is an open source, community-built database of roadway information [69]. The descriptions of the different road classes are available in Table 3.3. The road classes from OSM were all plotted in southern Washington County, RI, as seen in Figure 3.1a.

Table 3.3: OSM Road Classes [69]

\begin{tabular}{|c|l|}
\hline Road Class & Description \\
\hline Expressway & $\begin{array}{l}\text { Has directional traveling lanes, typically separated by a } \\
\text { physical barier where access is limited to on- and off-ramps }\end{array}$ \\
\hline $\begin{array}{c}\text { Principal } \\
\text { Arterial }\end{array}$ & $\begin{array}{l}\text { Roadways responsible for connecting urban centers to sur- } \\
\text { rounding regions }\end{array}$ \\
\hline $\begin{array}{c}\text { Minor } \\
\text { Arterial }\end{array}$ & Provide connectivity to Principal Arterials and communities \\
\hline $\begin{array}{c}\text { Major } \\
\text { Collector }\end{array}$ & Responsible for connecting Local roads to Arterials \\
\hline $\begin{array}{c}\text { Minor } \\
\text { Collector }\end{array}$ & $\begin{array}{l}\text { Similar to Major Collectors, except they are generally } \\
\text { shorter with slower rates of travel }\end{array}$ \\
\hline
\end{tabular}

The chosen route, depicted in Figure 3.1b, was eventually selected as the route of choice. The route covers every OSM road class, except for Motorways. In the region where the experiment took place, that road class did not exist, as is not seen by the missing color red in Figure 3.1a. In the experimental route, participants started at the University and 


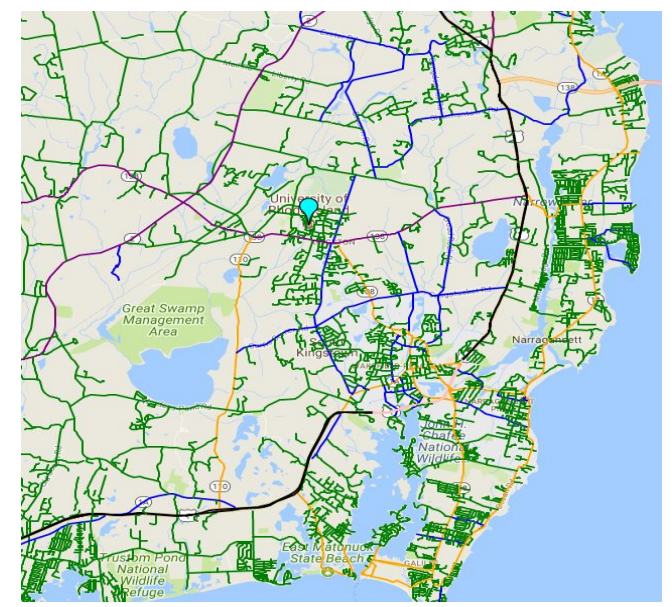

(a) Roads by Class

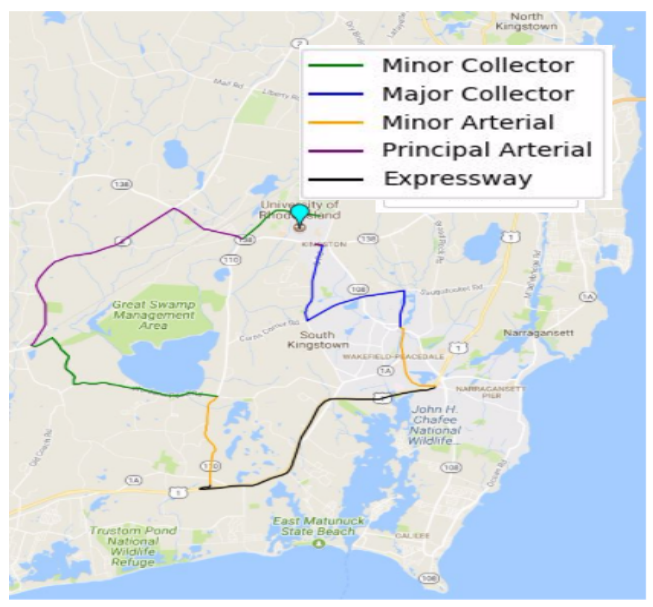

(b) Experimental Route

Figure 3.1: Route Visual

ended at the University, and for the most part stayed consistently on the same road type. The average distance on a given road class was 5.29 miles, with a standard deviation of 0.91 miles. Two road types that were split between two segments of the route were Minor Arterial (orange) and Minor Collector (yellow). On the Minor Collector road class, the total distance for the first portion was 1.68 miles and the second portion was 4.31 miles long. For road class Minor Collector, the first portion was 2.25 miles long and the second portion was 1.82 miles long. Even with those splits, there was still a large enough distance on each split to compare to the intervals of change in percent battery capacity, as this happened, on average, every half mile.

While maintaining road types was integral, the change in elevation along each road type was also considered. Since the area in southern Washington County had a high variation in elevation, the design of the experimental route was planned on roadways that displayed variable elevation changes. Figure 3.2 is a plot of the elevation over the different road classes from start to finish on the experimental route. Measurements of altitude were taken every $1 \mathrm{ft}$ on the route and plotted over time. Almost every road type had at least one sizable change in both positive and negative altitude, with the exception of the Tertiary class which had a constant uphill elevation. 


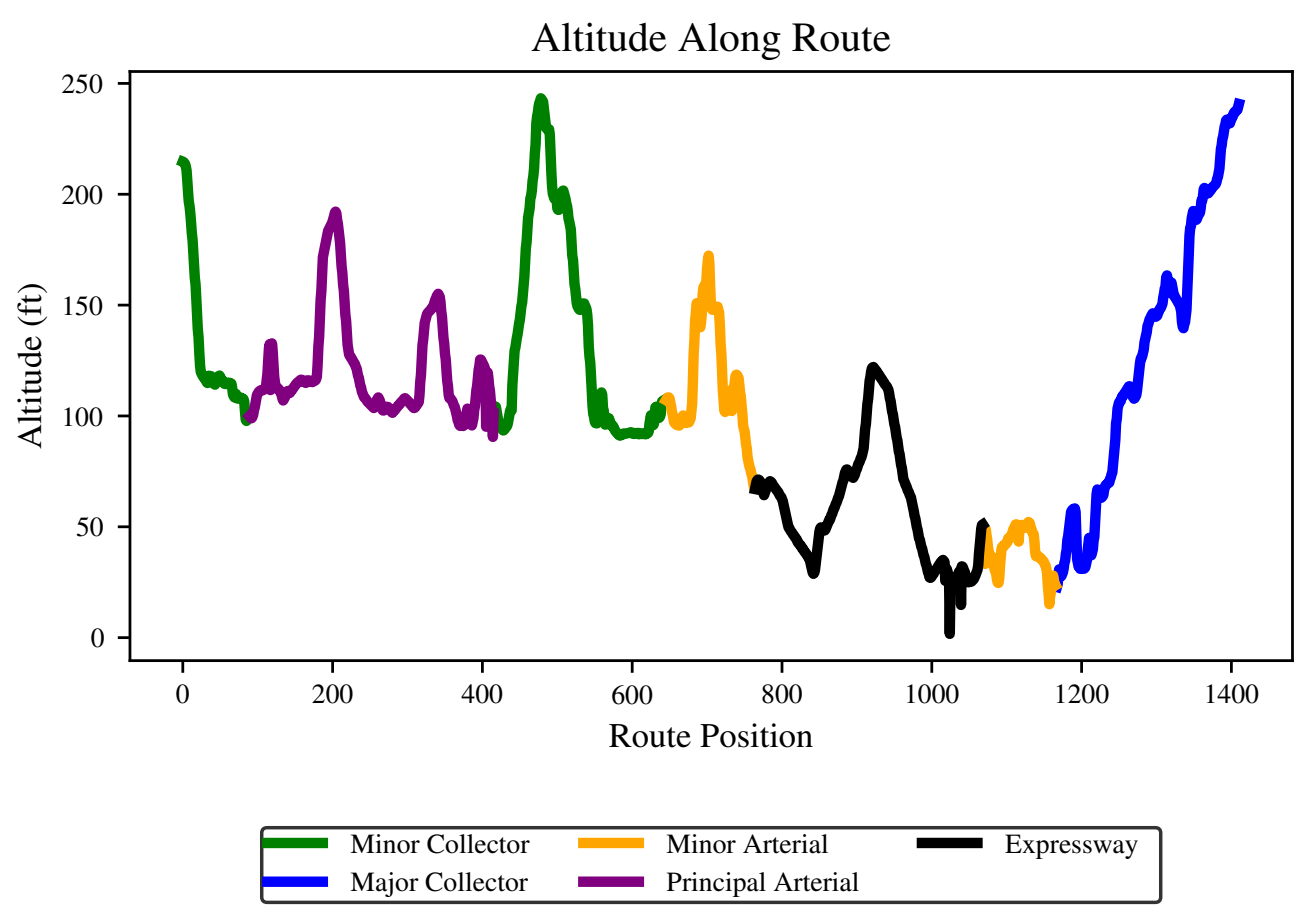

Figure 3.2: Altitude on Experimental Route

Beyond the experimental route, other conditions were held constant for each driver in the experiment. The first constant was weather. The experiment was not held on rainy days, by pre-scheduling experimental drives on days where the weather forecast did not show rain. In the event that a driver was scheduled for a morning with rain, they were rescheduled for another day, or later in the day if the forecast was expected to be sunny for more than four hours. The second component of the experiment held constant was the time of day. This was done to attempt to control traffic congestion, as the experiment was conducted in the late morning to early afternoon. However, traffic could not be fully controlled as these data are not publicly available. The third portion held constant was the climate control temperature. Since the HVAC system draws power directly from the battery pack, drivers who chose to change climate control settings would have used a different amount of energy on that factor alone, as HVAC setting can reduce overall range by up to $40 \%$ [59]. While this could have been important for characterizing a driver's energy consumption profile, adjustments to HVAC would have also correlated with factors such 
as outside temperature, which could not have been controlled for this experiment. For this reason, the climate control was set to an ambient $68^{\circ} \mathrm{F}$. The fourth constant enforced that the windows of the BEV remained closed. Keeping the windows open would have increased aerodynamic drag, resulting in reduced fuel economy [10]. While the choice of driving with open windows or having the climate control set to a specific temperature are behavioral driving decisions, the are both dependent on weather conditions, which could not have been held exactly constant in the experiment. For this reason, window position and the HVAC system settings were controlled. The fourth variable held constant in the experiment was the researcher who rode along the experimental drive. This was necessary to keep communication and navigation patterns consistent.

The last variable held constant in the experimental drive was the brake recuperation mode. The e-Golf has the possibility to recuperate energy at four different levels, which are outlined in Table 3.4. While braking in a BEV always recuperates some amount of energy, these modes apply a degree of braking power when the driver's foot is removed from the accelerator. Modes D1-B in Table 3.4 range from light braking to very high braking, meaning that once the driver removes their foot from the accelerator, the brakes will be applied to the degree of the recuperation mode. Mode $\mathrm{N}$ allows drivers to experience normal braking, where the brakes are only applied when the brake pedal is pressed [70].

Table 3.4: e-Golf Recuperation Modes [70]

\begin{tabular}{|c|c|c|}
\hline Recuperation Mode & \multicolumn{2}{|c|}{ Description } \\
\hline N & When coasting, energy is only recuperated by pressing the brakes \\
\hline D1 & Light braking recuperation & Recuperation during braking, \\
coasting, and driving \\
downhill
\end{tabular}

Some brief experimentation was done driving on the different recuperation modes in a random order, by a participant not involved in the driving experiment, to test which modes consumed the least energy. The route used was different than the experimental route and 
can be seen in Figure 3.3a. This route covers 17 miles, enough to capture change events in SOC that happen, on average, every 0.5 miles. The results from this test can be seen in Figure 3.3a, where the $\mathrm{x}$ axis of the plot shows the different regenerative modes ranging from zero recuperation $(\mathrm{N})$ when coasting, to maximal recuperation $(\mathrm{B})$ when coasting. The y axis displays the total consumption of SOC in \% of battery capacity drained. From the test, a linear decrease in energy consumed was expected from modes N-B. However, both modes D2 and D3 yielded the greatest consumption of energy. Since those modes added no benefit to the driver, it was decided that they would not be the mode of choice for the experiment. Mode B performed only slightly worse than mode D1. However, this mode applied too much braking power for subjects to get used to, which could have skewed results. This left modes $\mathrm{N}$, no recuperation unless the brakes were pressed, and D1, light recuperation when coasting. For the experiment, mode D1 was elected as the constant for recuperation mode. The reason D1 was selected over mode $\mathrm{N}$ was because mode D1 provided additional benefit to the drivers in terms of energy consumption. In ICE vehicles, eco-modes are automatically activated each time the vehicle is started, to help drivers limit fuel consumption. For BEVs, this trend will most likely follow suit, as recuperation modes were designed to improve maximum range of the vehicle.

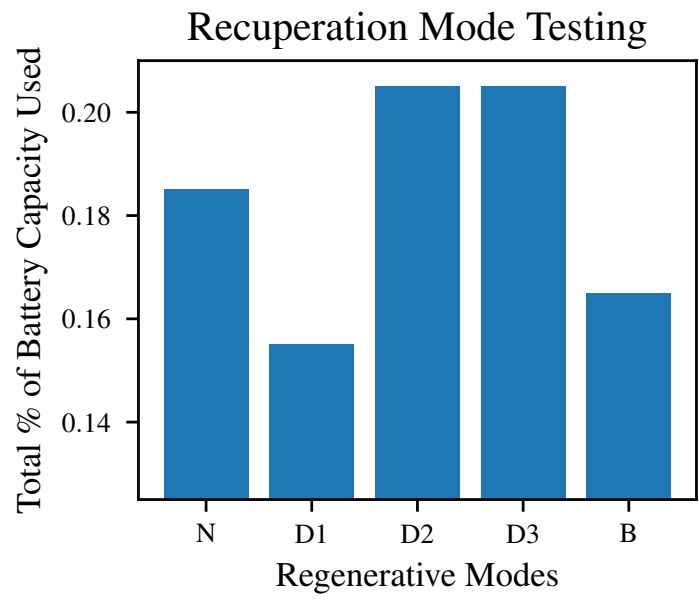

(a) Recuperation Mode Results

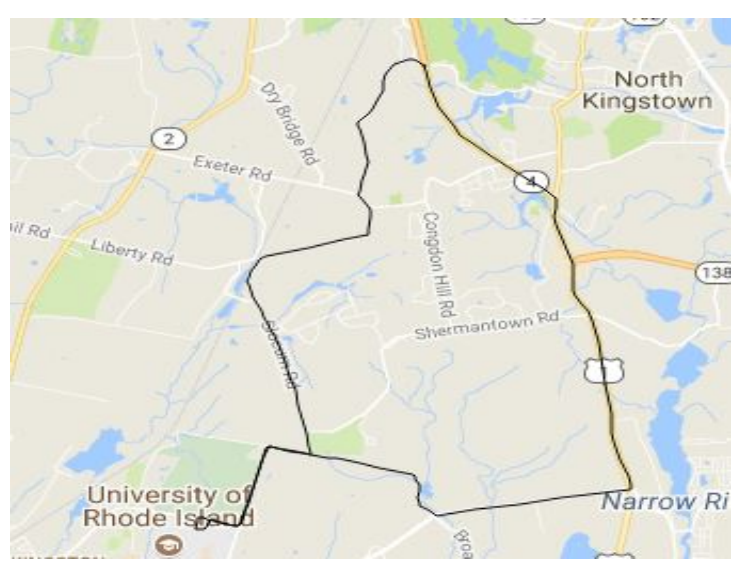

(b) Recuperation Mode Route

Figure 3.3: Recuperation Mode Testing 
Before subjects began driving, they were instructed to attempt to recreate a scenario that promoted their preferred vehicle setup. This included adjustment of the seat and mirrors, if the subject felt it was necessary. Subjects also had the choice to listen to the radio, or their own music. Since this option was given to everyone, the center console display was always left on, to retain a similar level of energy draw, from those components, from the battery.

Since the participants were first time BEV drivers, they were each given a brief introduction to the car before starting the experimental drive. This included how to visualize their energy consumption, which could be done in two ways. The first was by looking at the SOC gauge from Figure 3.6a. This analogue gauge ranges from 0 to 1 , representing the percentage of power remaining in the battery pack. The second way subjects were informed of how to view their energy consumption was through the $\mathrm{kWh}$ analogue gauge. This gauge displays the $\mathrm{kWh}$ draw from the battery instantaneously, increasing when pressing the gas and regenerating when the brakes were pressed. Once the participants went through this demo, the vehicle was switched into the D1 recuperation mode and subjects drove a half a mile to get comfortable in the vehicle. At this point, the only instruction given to subjects was route guidance. At the completion of the experimental drive, subjects were given a link to SurveyMonkey ${ }^{\circledR}$, where subjects would complete the driving behavior survey (DBS).

The DBS was used in this research to measure the effect of anxiety on BEV driving behavior. A discussion of the DBS was covered in the last section of this chapter. However, since a portion of this experiment was focused on studying the factors of anxiety presented by the DBS, range anxiety was not measured in the experiment. In an effort to curb this type of anxiety, participants were informed that they had plenty of energy in the BEV to complete the experiment.

At the conclusion of the experiment, two additional control runs were used to capture data for further analysis. For each control run, constants in the experiment remained the same. The first control drove the BEV efficiently, while the second control drove the BEV inefficiently. For efficient driving, a focus on maintaining controlled speeds equivalent to 
the speed limit and focus on minimal consumption based on the kWh gauge was employed by the efficient control, along with non-aggressive acceleration, as this was defined to be an aspect of eco-driving for ICE vehicles [9]. The inefficient control drove the BEV using aggressive speed and acceleration, while focusing on high consumption from the $\mathrm{kWh}$ gauge. Use of additional control drives have been used in similar experimental designs to establish separation between potential behavioral clusters [31].

\subsection{Methods of Data Collection and Analysis}

This section covers the various sources of data extracted during and after the experiment. During the experiment, electronic sensors were set up throughout the vehicle, taking measurements from the vehicle's computer and some external measurement systems that recorded information, such as location and acceleration. A discussion of the questionnaire taken after the experimental drive was also covered in this section.

\subsubsection{BEV Driving Data}

The most crucial element for the completion of this research was a BEV. The vehicle selected for data collection was a 2015 VW e-Golf. This vehicle was equipped with an 85 $\mathrm{kW}$ electric motor, which is powered by a $24.2 \mathrm{kWh}$ lithium-ion battery pack. The manufacturer specified range was around 85 miles and the vehicle had a curb weight of 2.455 tons [71]. The selection process for using this vehicle stemmed from both its competitiveness with other BEVs on the market in terms of driving range, and from the fact that no other literature found had used a VW e-Golf for electric vehicle experimentation. Most research studies used a Mitsubishi i-MiEV, which has an estimated range of 90 miles [16, 17] or a Nissan® LEAF® which has an estimated range of 123 miles [16].

The first piece of data necessary for this research was the SOC of the vehicle. SOC is the percentage of battery power remaining in the battery pack before the BEV needs to be recharged. While this information is available from an analogue gauge on the dashboard, 


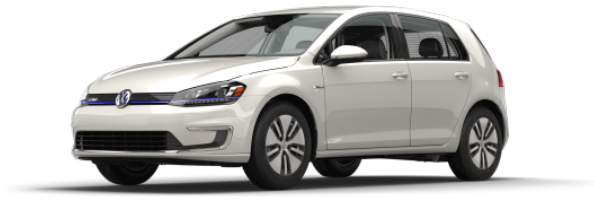

(a) 2015 e-Golf [71]

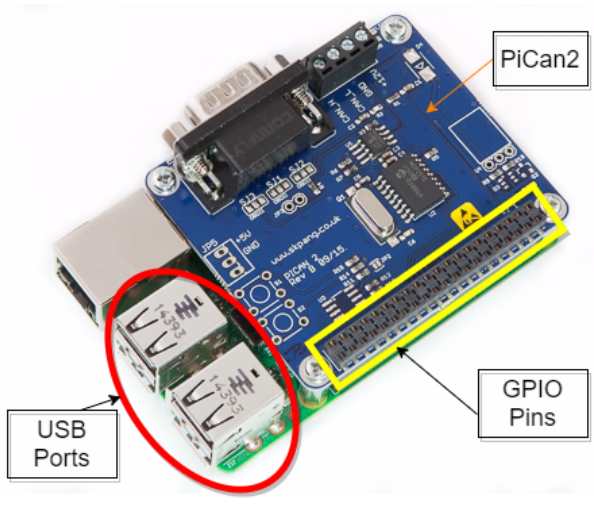

(b) Raspberry Pi and PiCAN2 [72]

Figure 3.4: Main Data Logging Devices

an external system to capture this data was necessary to read it and log it in real time. This type of information could be collected via the car's controller area network (CAN). CAN is a serial bus communication protocol, which contains the communications between a car's sensors, actuators, controllers, and other nodes tied into the system [73].

Access to CAN is usually accomplished by connecting to the on-board diagnostics terminal (OBD) [74]. The OBD is a 16-pin male connector, where different pins are responsible for different protocols or are for power supply. Pins six and fourteen, for most cars on the market, are typically CAN-High and CAN-Low, respectively [23]. Both connection points are responsible for transmitting messages to various controllers throughout the network, known as the bus, by sending a similar voltage pattern that represents a string of binary data.

There were various systems available for reading CAN information; however, for this research a Raspberry Pi 3 was selected. The Raspberry Pi is small enough that it can be placed close to the OBD port, without getting in the way of the driver. This is necessary because CAN speed is measured relative to the length of the wires throughout the system [73]. To prevent any malfunctions in the system, the wires connecting the Raspberry Pi to the OBD were kept short. Since the operating system for a Raspberry Pi is a Linux distribution, the open source software package SocketCAN was used. SocketCAN uses the 
Berkeley Socket API and can only be run on the Linux stack [75]. SocketCAN enables the Raspberry Pi to become a node on the car's CAN. However, the Raspberry Pi cannot be wired directly to the vehicle in order to begin reading data. Another daughter board must be attached via the general-purpose input/output (GPIO) pins, highlighted in yellow in Figure 3.4b. This board is called the PiCAN2 which transformed the Pi into a CAN controller. Wires were connected from the CAN-High and the CAN-Low terminals on the PiCAN2 board, which were then linked to the terminals on the OBD port on the BEV. These wires could also have been connected to the CAN-High or CAN-Low wires at other junctions on the car, by splicing those wires and pig-tailing them together. The setup for the system can be seen in Figure 3.4b, where the Raspberry Pi 3 is the green board on the bottom, connected to the blue PiCAN2 board on top.

With the Raspberry Pi connected to the vehicle, CAN frames were read directly from the BEVs computer. The frames transmitted via the CAN wires contain segments of messages represented as binary strings. These strings are segmented into groups enabling the BEVs computer to interpret their meaning. Examples of these groups included the start-offrame bits, which let the computer know a new frame is being transmitted; end-of-frame bits that let the computer know that a new frame will begin now; and the data bits, which hold measurements from different sensors on the BEV [73]. Using SocketCAN to read this data enables programmers to split these fields automatically, without having to read raw binary strings to ascertain data from the system.

The output depicted in Figure 3.5 is the output from the Linux terminal when the CanDump command was issued [75]. The first column of values in Figure 3.5, highlighted in green, displays the name of the node assigned to the Raspberry Pi. The second column, highlighted in cyan displays the Parameter ID (PID). A PID is a data location identifier. Every CAN system has a set of unique PIDs, which are the identifiers for data stored in a frame. For example, PID A5 could store both speed and RPM. Every time the system witnesses PID A5, the controller reading that frame will know that the frame stores speed 


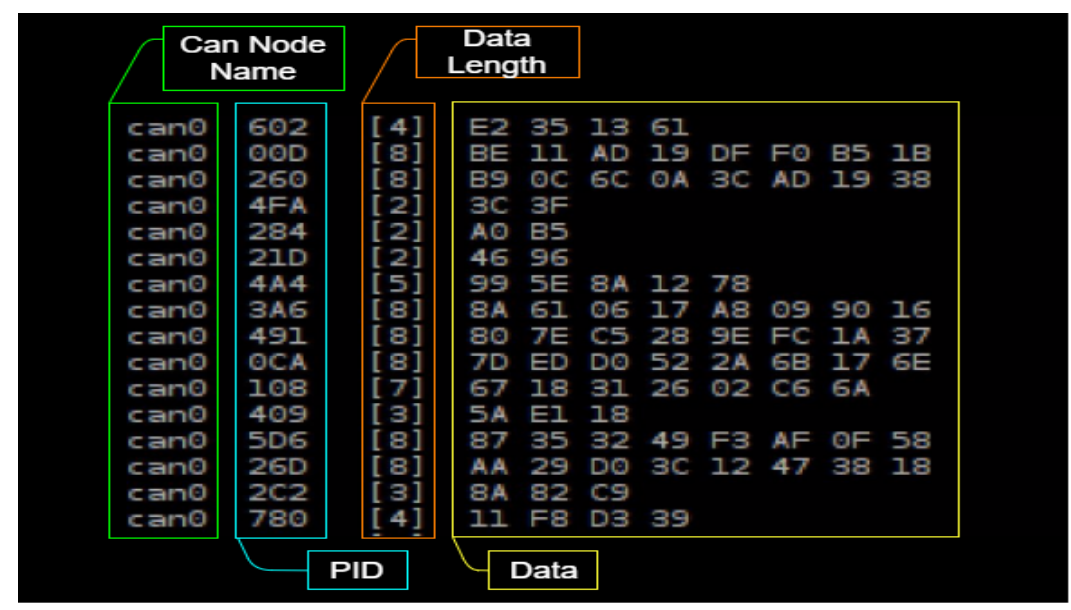

Figure 3.5: SocketCAN Terminal Output

and RPMs values. The third column, highlighted in orange, displays the byte length of the message or how many columns are to follow. The last chunk, highlighted in yellow, displays the packets of data, represented in hexadecimal format, where each column contains one byte of data, unless the third column specifies that there are fewer than 8 bytes of data. In this case the number of bytes specified in the third column represents how many columns of bytes will follow.

The data shown in Figure 3.5 mean nothing on their own. However, to the vehicle they supply the necessary information to all electronics on board to make the car function. The vehicle's internal database keeps a record of what each CAN frame means, and how it will be decoded by subsystems in the car. Obtaining the SOC data required finding the PID that identifies the data packets containing SOC measurements, by decoding the hexadecimal data packets from the yellow highlighted section in Figure 3.5. There were two possible methods for decoding the frames, known as fuzzing and visual pattern correlation [74]. Fuzzing would require manually creating CAN frames and injecting them into the system, which was possible to do in SocketCAN. If a custom frame was injected into the vehicles CAN, the vehicle would react in some manner. Simple examples of a given reaction would have been the horn honking or the speedometer jumping to a different speed. In this research, a change in the SOC gauge would have been sought after when fuzzing CAN data 
(see Figure 3.6a). While fuzzing would have been the fastest way to decode the frames, it is also very dangerous as the vehicle may act erratically which could have risked damage to the car or anyone in the car [74].

To circumvent the issues with fuzzing this research employed method two of CAN frame decoding, which was visual pattern inspection. One way to have applied this method was perform an operation on the car, and look for bytes of a given PID that changed. For example, gas pedal and brake pedal percent depression were decoded in this fashion with only the interior power switched on. The pedals were pressed, and the changing bytes were found. The benefit of only having the interior power on was that many other CAN frames were unchanged; thus, they could be filtered out, leaving only a select few frames that changed. For SOC, however, this method would not work because there was no way to rapidly discharge the battery safely without driving.

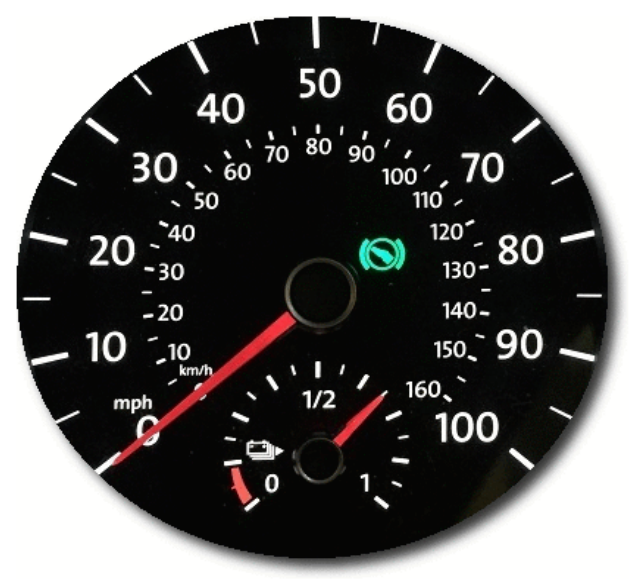

(a) SOC Gauge (Smaller Gauge) [71]

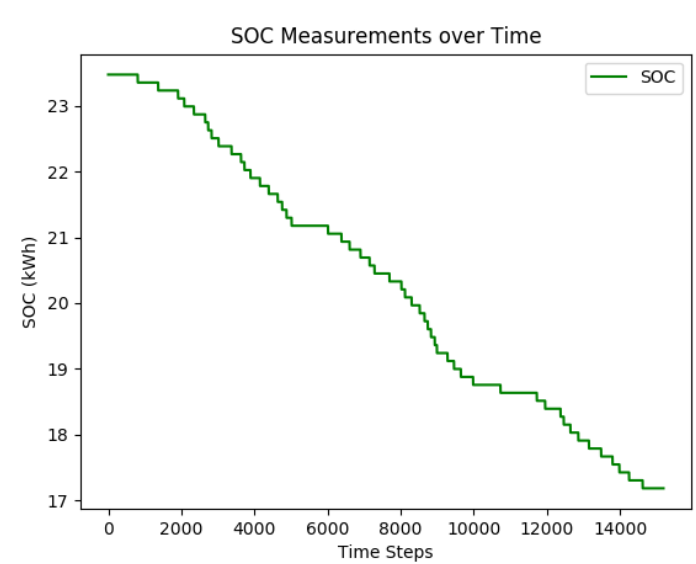

(b) Recorded SOC

Figure 3.6: SOC Comparison

To obtain SOC, the vehicle was driven and a log file of the data stored for off-line analysis. Various possible locations were determined by sifting through different combinations of bit lengths and comparing them graphically. The location of SOC was determined by data packets that had a negative slope with respect to time. While a few possibilities presented themselves, the possible locations were live-validated over the course of multiple 
drivers at various levels of SOC remaining, to witness their change in conjunction with the SOC gauge. Only one location remained and its time series values can be seen in Figure 3.6b. In the chart, the remaining charge is seen from $23.5 \mathrm{kWh}$ to around $17.1 \mathrm{kWh}$, with CAN frames logged every 50 microseconds. While the plot matched the gauge's output while driving, changes in SOC over a trip could only be recorded as a decreasing function, limiting analysis of regenerative braking. Also, the sensor that supplied the data on the CAN only updated once a large enough decrease in remaining charge was witnessed. Thus, every CAN frame received did not witness a change in SOC, as can be seen in Figure $3.6 \mathrm{~b}$, where the data presented themselves as a stepwise function.

Location of the $\mathrm{BEV}$ was a requirement of the data collection. While it was noted that CAN data for SOC does not change with a high degree of frequency, it will be beneficial to sample location information comparable to the speed put out by the CAN, so that other sources of data such as accelerometer and engine load measurements could be accurately matched to location information. For this research the Adifriut ${ }^{\circledR}$ Ultimate breakout board was acquired. This board, seen in Figure 3.7a, comes equipped with an internal GPS antenna and a detachable external antenna that was magnetically mounted to the roof of the vehicle.

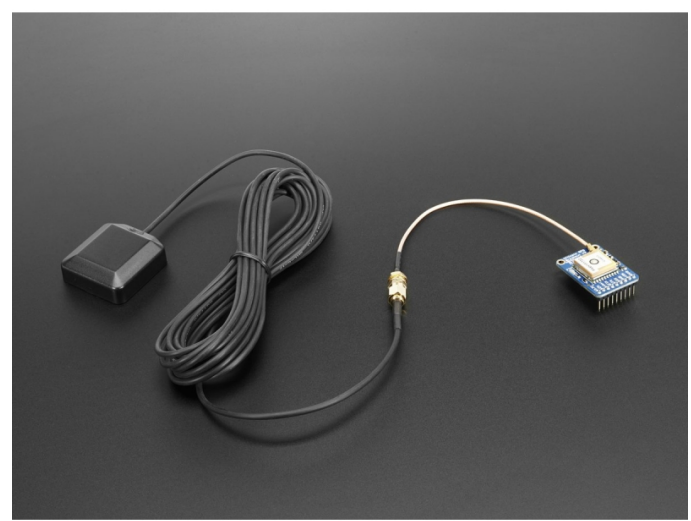

(a) Adifruit Ultimate Breakout Board

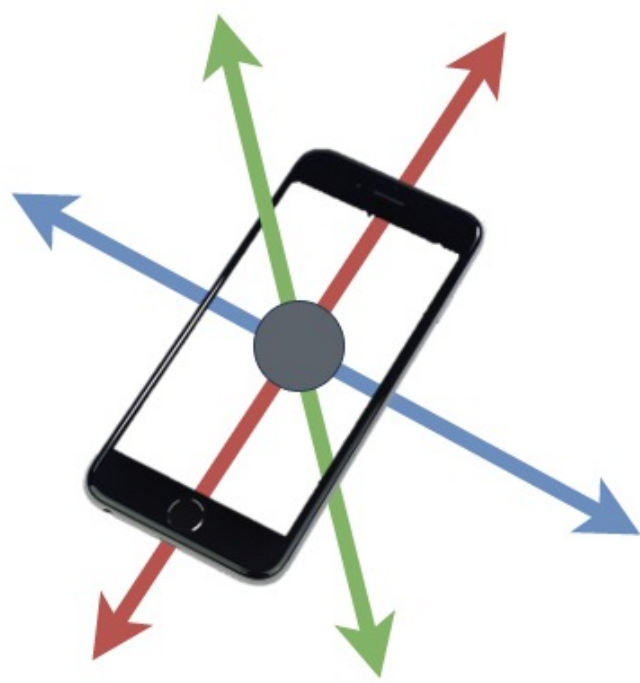

(b) Distributed SOC Measurements 
The Breakout Board has 66 channels giving it the ability to track 22 satellites at once. Most importantly, the board can sample location data at a rate of $10 \mathrm{~Hz}(10$ samples every second). This particular sampling rate was high enough to match a quality amount of the high speed CAN data. It has a positional accuracy within 1.8 meters and a velocity accuracy of $0.1 \mathrm{~m} / \mathrm{s}(0.22 \mathrm{mph})$ [76]. Since the PiCAN2 board used all 40 GPIO pins on the Raspberry $\mathrm{Pi}$, the Breakout Board was dongled to a USB port, circled in red in Figure 3.4, for easy connection to the Raspberry Pi.

Adifruit@ had built a python module for accessing the data received by the GPS. However, this module did not allow users to alter the sampling rate of the GPS, leaving the rate at $1 \mathrm{~Hz}$ (1 sample per second). To overcome this hurdle, the python module PySerial was used to send and listen to serial information. The National Marine Electronics Association (NMEA) sentences were then structured into their respective data formats. Since the only data collected from the GPS were geo-coordinates and speed, those NMEA sentences were decoded.

Another device used to collect data from the vehicles was an Apple iPhone 6s. Smartphones are equipped with accelerometers because these devices can be used to track screen orientation. Smartphones have become standard in vehicle driving based experiments $[24,68,77]$. While a smartphone accelerometer's measurements present a greater degree of noise, they produce correlated results to commercial devices [24].

The iPhone application Sensor Play was used to log data. The application allows for a sampling rate of $10 \mathrm{~Hz}$, in line with both the CAN sampling rate and the GPS sampling rate. The iPhone was positioned on the cup holder tray, and locked down to prevent movement. Since the iPhone was well oriented, readings did not need to be reoriented [77] as the iPhone was held stationary. The spatial measurements of acceleration taken from the iPhone are illustrated in Figure 3.7b. The green axis captured falling acceleration, the red axis collected longitudinal acceleration (forward and reverse), and the blue axis collected lateral acceleration (left to right). 
With all of the sensors in place and the experiment concluded, post-processing of the data ensued. Since each sensor stored data to a separate comma separated value file, they needed to be combined for analysis. This was done by finding the closest time value from each log and matching that value to the output from the CAN data. The CAN logs each contain a timestamp, expressed as a unix epoch, which is the number of elapsed seconds since January $1^{\text {st }}, 1970$. Both the GPS and the iPhone log dates in datetime UTC format (YYYY-MM-DDTHH:MM:SS.000Z). To generalize the matching procedure between the data, both the GPS time and the iPhone time were converted to unix epochs.

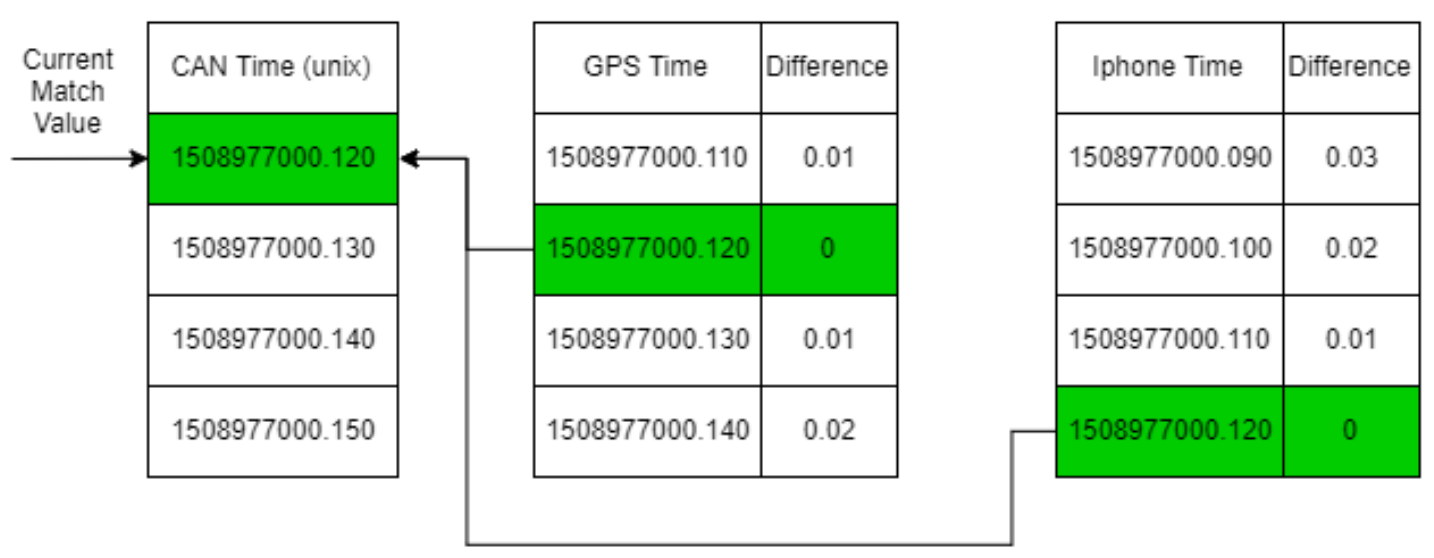

Figure 3.8: Dataset Matching Procedure

The time conversation enabled seamless matching by finding the absolute difference in time between the logs from the different sensors. This process is outlined in Figure 3.8. Iterating over each CAN measurement, starting with the first, the absolute value was calculated from the CAN timestamp to all timestamps in the GPS data set. The smallest difference in time, highlighted in green in Figure 3.8, was found and the GPS log was combined with that $\mathrm{CAN} \log$. This process was the same for matching values from the iPhone's dataset.

Once all of the datasets were fused, there were some further post-processing steps. The first was to calculate the distance between each logged event. This can be done using the 
Haversine formula from Equations 1 and 2, which equates the distance between two geocoordinates on a sphere. $R$ is the radius of earth, represented in miles, and is equal to 3,959 miles. $\varphi$ and $\delta$ are the latitude and longitude coordinate values respectively. For each coordinate value a subscript of 1 represents the previous set of coordinates (look back one row) from the combined dataset. A subscript value of 2 was equivalent to the current coordinate in the combined log file.

$$
\begin{gathered}
\text { Distance }=2 R \arcsin \left(\sqrt{\operatorname{hav}\left(\varphi_{2}-\varphi_{1}\right)+\cos \left(\varphi_{1}\right) \cos \left(\varphi_{2}\right) \operatorname{hav}\left(\delta_{2}-\delta_{1}\right)}\right) \\
h a v(\theta)=\sin ^{2}\left(\frac{\theta}{2}\right)=\frac{1-\cos (\theta)}{2}
\end{gathered}
$$

With the distance between coordinates calculated, these values were then used to distribute the measurements of SOC backward, from the point in time they were logged to the last change measurement in SOC. This process was necessary because the rate of SOC depleted was studied with respect to road classifications. Since the logging of SOC was found to be a stepwise function, there could have been over- or under-inflated measurements of change in SOC due to carry-over between road classes. To circumvent this issue the first change in SOC for each change in road class could have been stripped from the dataset for each subject. This would have amounted to a significant loss in data. Instead, change in SOC values were backwards distributed based on distance traveled.

The process for this backwards distribution of SOC measurements is illustrated in Figure 3.9. Incremental values were calculated using $\frac{\triangle S O C}{\sum D \text { istance }}$, where $\triangle S O C$ is the change in SOC, reported by the vehicle, represent as $0.1 \mathrm{kWh}$ in Figure 3.9. Then each block of distance was multiplied by the incremental value. This way carry-over between roads will not be over- or under-inflated.

Once the data was cleaned, analysis of BEV driving behavior transpired. To categorize drivers with respect to their rate of SOC depletion, cluster analysis was used. Cluster 


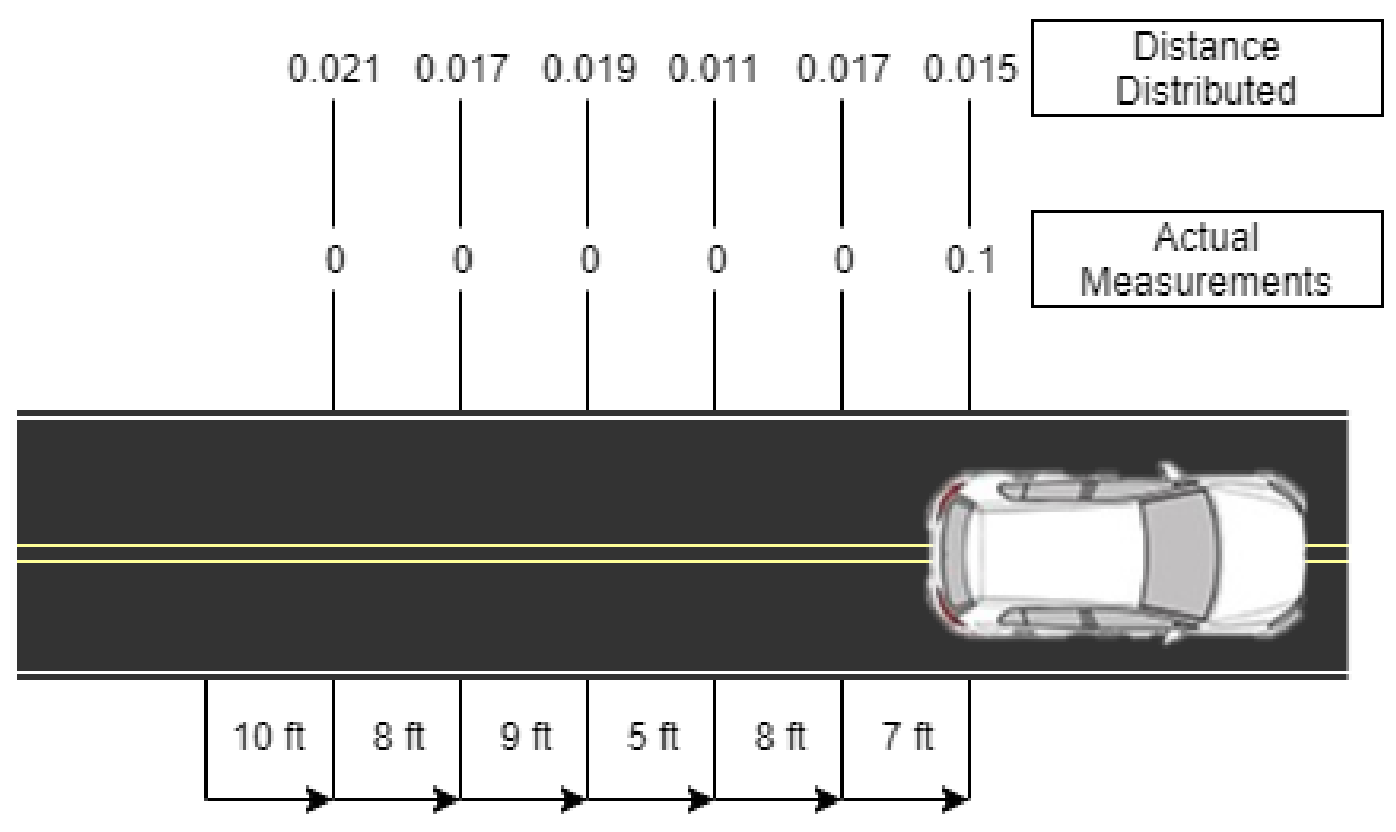

Figure 3.9: Distributed SOC Measurements

analysis is used only when categories are unknown, and the objective is to determine if an observation can be recognized as a member of a category [78]. There exist a few approaches to complete this form of analysis. K-means clustering is by far the most popular; however, it requires sample sizes greater than $200[33,78,79]$. For this reason, hierarchical clustering was used.

Hierarchical clustering is beneficial for sample sizes smaller than 50, as the decision between clusters is done through visual inspection of the separation of cluster on a dendrogram (hierarchy tree diagram) [80]. To conduct hierarchical clustering, a proximity matrix between data points was computed. The values used to compute the matrix were a subject's mean and standard deviation $\frac{\triangle S O C}{M i l e}$. Since one of the objectives of this research was to group drivers based on their rate of energy consumption, Euclidean distance was used to calculate distance in a two-dimensional plane to measure dissimilarity of clusters. The steps for using hierarchical clustering are as follows [78, 81]:

1. Start with all observations (n) belonging to their own singular cluster 
2. Combine two clusters that produce the smallest impairment to the objective function; total clusters equal to $\mathrm{n}-1$

3. Repeat step 2 until every cluster is combined into one cluster

Step two in the process requires an objective function which is responsible for measuring dissimilarity between clusters. There exist a few possible objective functions, one being single-link, which chains clusters based on the minimum distance between a single point in two clusters [78]. Complete-linkage is similar to single-link, except the maximum distance between two points in distant clusters is used to measure dissimilarity [78]. There is also average-link, which measures the average distance between all points in a cluster [78]. However, for this research the Wards objective was used. This method joins clusters based on the smallest error in the sum of squares (Equation 3).

$$
E S S=\sum_{i=1}^{n} x_{i}^{2}-\frac{1}{n}\left(\sum_{i=1}^{n} x_{i}\right)^{2}
$$

All data in the results and discussion chapter of this paper were first tested for normality using both the Anderson Darling test and the Shapiro-Wilk test. The Anderson Darling test measures the distance between the theoretical distribution and the cumulative distribution of the sample, placing a larger weight on the tails of the distribution [82]. The ShapiroWilk test factors the weight values of the covariances, based on the sample size, by the sum of squares to generate a test statistic ranging from 0-1 [83]. To test the difference between data series, if the results for the normative testing were significant a t-test was used to test the difference between the distributions. If data were not normal, a Wilcox test was used in place of a t-test.

Aggressive acceleration patterns were studied by using the safe driving region within a friction circle [84]. To generate the safe driving region vertical lines are placed on a graph at -2.5 and $2.5 \frac{\mathrm{m}}{\mathrm{s}^{2}}$ lateral acceleration, spanning a distance of $0.15 \frac{\mathrm{m}}{\mathrm{s}^{2}}$ of longitudinal acceleration from either side of the x-axis. Two horizontal lines are placed at 2.5 and 3.0 
$\frac{m}{s^{2}}$ of longitudinal acceleration spanning the same $0.15 \frac{m}{s^{2}}$ from both ends of the y-axis. The non-linear curves for enclosing the upper left region, upper right region, lower left region, and lower right region are plotted using equations $4,5,6$, and 7 respectively. The regions were defined by experimentation involving aggressive and non-aggressive drivers [84].

$$
\begin{aligned}
& a(x)=0.509 * a(y)^{2}+2.351 * a(y)+2.841 \\
& a(x)=0.509 * a(x)^{2}-2.351 * a(y)+2.841 \\
& a(x)=0.446 * a(y)^{2}-2.395 * a(y)-3.349 \\
& a(x)=0.446 * a(y)^{2}+2.395 * a(y)-3.349
\end{aligned}
$$

\subsubsection{Survey Data}

The last portion of data collected from the experiment was a questionnaire. There exist many questionnaires with respect to driving behavior. One is known as the Driving Skills Questionnaire (DSQ). The DSQ measures how an individual perceives their driving skills. The questionnaire consists of 20 questions, where subjects rate how well they believe they perform a given skill on a scale of 0 (very poor) to 10 (very good) [29].

Another questionnaire, known as the Driving Behavior Questionnaire (DBQ), has subjects rate themselves on how often they perform silly or bad driving behaviors. The questionnaire is composed of 50 questions, developed to cover the categories of slips, lapses, mistakes, unintentional violations and intentional violations. The questionnaire uses a 5point Likert scale, where participants measure how frequently an event happens to them while driving, ranging from 0 (never) to 5 (nearly all the time) [85]. 
The last questionnaire considered for the research was the DBS. This survey measures anxiety with respect to driving behavior. Subjects taking the survey will report how often they react to an anxious situation, described by each question. The questionnaire also employed a Likert scale; however, the scale ranges from 1 (never) to 7 (very frequently) [21].

The three proposed questionnaires all divulged different approaches to defining driving behavior classifications. The DSQ presented itself as an opportunity to test how perceived driving skills affect energy consumption when driving a BEV. However, while the DSQ can result in four factors, subjects tend to over inflate their driving skills [29]. The DBQ could also have been used as it can measure safe/aggressive driving practices [85]. However, these factors could already be determined via the electronic sensors equipped to the BEV $[9,34]$.

The DBS was eventually selected as the best questionnaire to include in the study. However, the DBS was not selected only as a last resort. The DBS measures driving behavior with respect to anxiety [21], and a major factor inhibiting BEV growth is range anxiety $[20,62]$. If anxiety is the responsible for BEV efficiency, then drivers can run into situations where two factors of anxiety are overwhelming one another. Anxiety can further impact anxiety, developing a vicious cycle that can be overly detrimental to an individual's health [22].

In developing the DBS, two studies were conducted, creating a 21-question survey used to rate a driver's anxiety [21]. In both studies, three factors were established to model anxiety with respect to driving behavior. The three anxiety factors determined by the DBS are outlined in Table 3.5. To ensure that the factors extracted from the DBS differ from other questionnaires, the four factors from the DSQ [29] were compared to the three factors of the DBS, showing that the factors were significantly different [21].

For completeness, all 36 questions used in developing the DBS were answered by each subject in the experiment (see Appendix C). The 21 questions essential to the DBS were 
Table 3.5: Anxiety Based Driving Factors

\begin{tabular}{|l|l|}
\hline Factor & Description \\
\hline $\begin{array}{l}\text { Anxiety Based Performance Deficits } \\
\text { (DEF) }\end{array}$ & Anxiety's impact on driving skills \\
\hline $\begin{array}{l}\text { Exaggerated Safety/Caution Behaviors } \\
\text { (CAUT) }\end{array}$ & $\begin{array}{l}\text { The ability to control anxious be- } \\
\text { haviors in complex driving situa- } \\
\text { tions }\end{array}$ \\
\hline $\begin{array}{l}\text { Anxiety-Based Aggressive/Hostile Be- } \\
\text { haviors (ANG) }\end{array}$ & $\begin{array}{l}\text { Accident related fears and eruption } \\
\text { of anger episodes }\end{array}$ \\
\hline
\end{tabular}

extracted and analyzed. By taking the average of the 7 questions that belong to the three categories of anxiety, anxiety can be measured by a low mean suggesting minimal anxiety, and a high mean suggesting heightened anxiety [21]. The means of all clusters of BEV driving behavior were compared against one another. This approach was applied in similar research, and has also been defined as the method of comparing groups against one another using the DBS [86]. Principal component analysis was used to ensure that responses to the questionnaire, taken in this research, loaded correctly on the factors outlined by the DBS. 


\section{CHAPTER 4}

\section{Results and Discussion}

This chapter provides a comprehensive analysis of the data extracted from the experiment. Once a discussion of the raw data was covered, a cluster analysis was used to generate clusters of similar driving behavior patterns. Lastly, an analysis of how the DBS can be used to understand these clusters was assessed.

\subsection{Raw Data Analysis}

\subsubsection{Analysis of SOC Consumed}

In similar experiments, results had exposed that when a sample of drivers was tasked with driving a BEV on the same route, a dissimilar amount of energy was used among the samples [17]. Since the BEV brand used in this research had not yet been utilized in any experimentation, with the extent of literature discovered, the first portion of the analysis determined if an inconsistent usage of energy existed between the subjects. For a visual perspective, a bar plot of the total consumption used by each subject was generated, which can be seen in Figure 4.1. The x-axis labels each of the subjects in the order they were tested, while the y-axis displays their total energy consumption for the entirety of the route in $\mathrm{kWh}$.

Subject 37 was the control for inefficient BEV driving and subject 38 was the control for efficient BEV driving. The efficient control used $6.41 \mathrm{kWh}$ and the inefficient control consumed $7.26 \mathrm{kWh}$ which suggested that there was a difference between the two BEV driving styles. The lower control however did not under-perform other subjects. The least amount of $\mathrm{kWh}$ used on the route was done by subject 29 , who consumed $1.21 \mathrm{kWh}$ less than efficient control. The maximal difference existed between subjects 3 and 29, amounting to a difference of $2.42 \mathrm{kWH}$. If the rate of depletion of SOC could effectively be estimated as

$\frac{M i l e s}{k W h}$, subject 29 would have been able to drive an additional 12.28 miles before consum- 
ing an equivalent amount of energy to subject 3. For the sake of visualizing this difference, subject 29 could have been able to complete an additional $47.23 \%$ of the experimental route before using a similar amount of energy to subject 3 .

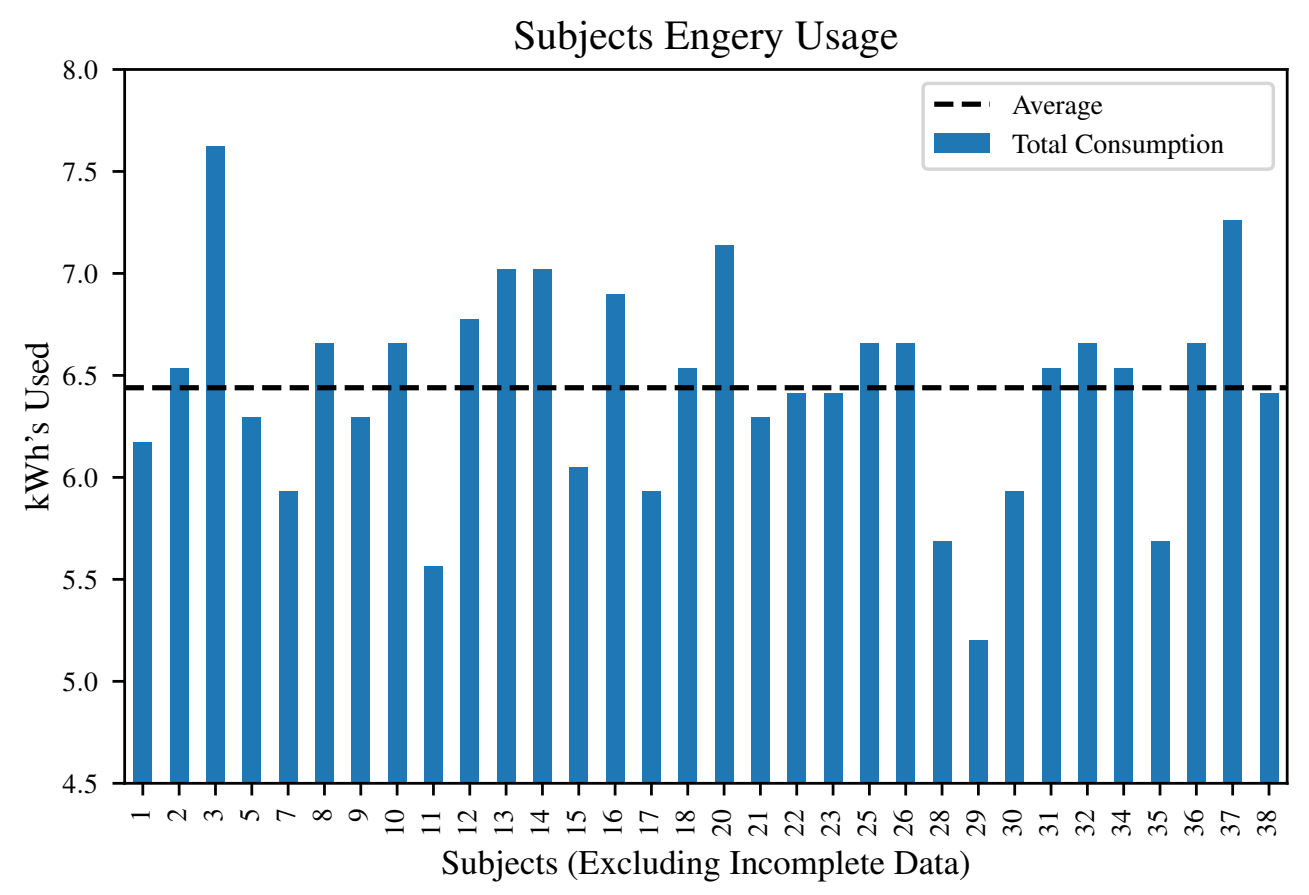

Figure 4.1: Subjects Usage of Energy During Experiment

In similar BEV driving research, it was found that subjects had a mean energy consumption of $0.21 \frac{\mathrm{kWh}}{\text { Mile }}$, with a standard deviation of $0.04 \frac{\mathrm{kWh}}{\text { Mile }}$ [17]. In this research the mean consumption was $0.25 \frac{\mathrm{kWh}}{\mathrm{Mile}}$, with a standard deviation of $0.02 \frac{\mathrm{kWh}}{\text { Mile }}$. While the mean consumption in this research differed by around $0.04 \frac{\mathrm{kWh}}{\text { Mile }}$, the difference most likely stemmed from the experimental route in this experiment being much longer, with more elevation changes. Also, the other experiment focused on routes with many traffic signals which would aid in energy recuperation from braking $[12,17]$.

\subsubsection{Road Type Analysis}

Since it had determined that road type selection for a BEV is essential for reduced energy consumption [53], a graphical representation of energy consumption by OSM road 
class was created and can be viewed in Figure 4.2a. The x-axis lists the subjects, while the $\mathrm{y}$-axis is scaled by $\frac{\mathrm{kWh}}{\mathrm{mile}}$, where each subject had 5 data points, one for each OSM road classification. While Principal Arterials (purple) and Expressways (black) were expected to be highly inefficient due to higher speed limits, Major Collectors (blue) proved to be generally the most inefficient type of road to drive on. The interaction plot in Figure 4.2b displays the inefficiency of road class Major Collector, as the 95\% confidence interval deviates significantly from all other road classes. Since the speed limits on the Major Collector class were similar to that of Minor Collector (green) and Minor Arterial (yellow), it is quite evident that other factors were having a greater impact than speed.

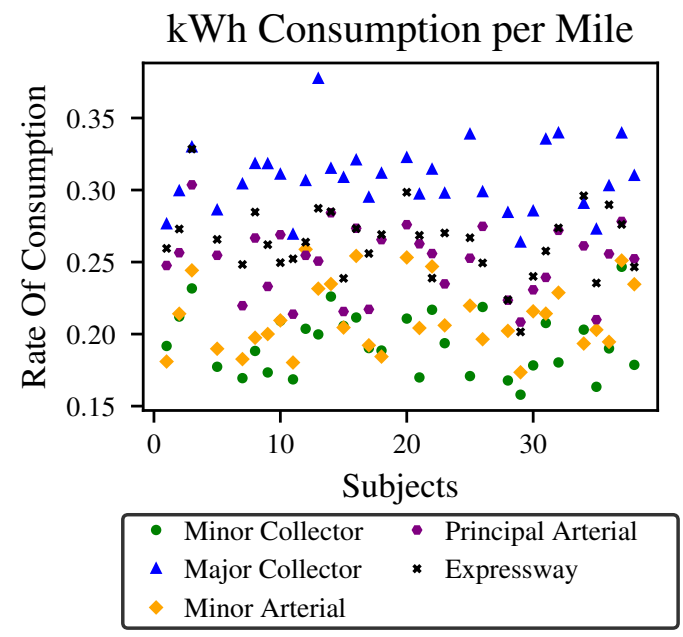

(a) Subjects Average Energy Consumption

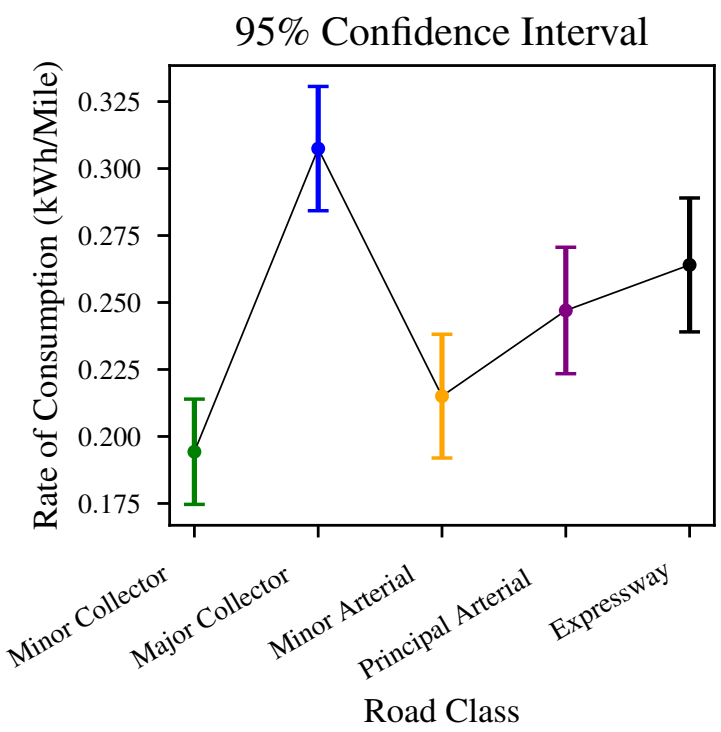

(b) $95 \%$ CI by Road type

Figure 4.2: Rate of SOC depletion by Road Type

\subsubsection{Elevation Analysis}

The inefficiency of road class Major Collector was evidence that change in elevation was a key component of BEV inefficiency [12]. Since there existed a limited number of Major Collector roads in the region, the experiment was only conducted on uphill elevation changes, as seen in Figure 4.3c. To accurately define the effect that change in elevation 
has on the rate of SOC depletion via different road classes, roadway divisions were taken between the peaks and valleys along the experimental route, so that the effect of elevation could be studied only when a subject drove uphill or downhill. Manual divisions were placed along the route and can be seen by the vertical gray lines in Figure 4.3c. To factor the rate of SOC depletion of the BEV, the rate of energy consumption was analyzed with respect to the elevation angle of a segment of road. Elevation angles are used to measure the angle of slope from a round base, using Earths radius. The elevation angle was estimated using Equation 8. The rate of SOC depletion was produced by $\frac{k W h}{\text { ElevationAngle }}$. Both negative and positive changes in elevation were separated to establish the rate at which subjects consumed energy over increasing and decreasing elevation. The elevation angles were computed using a distance held to approximately one mile, as the angle was dependent on both distance and height.

$$
\text { ElevationAngle }=\frac{180}{\pi} *\left[\frac{\text { Altitude }_{\text {start }}-\text { Altitude }_{\text {end }}}{\text { Distance }}-\frac{\text { Distance }}{2 * \text { Radius }_{\text {earth }}}\right]
$$

Figure 4.3a displays subjects' $\frac{k W h}{\text { ElevationAngle }}$ over increasing road grades. Through visual inspection, the Major Collector road class shifted to the region between Principal Arterial and Minor Arterial road classes, when comparing Figure 4.2a and 4.3a. Road classes Expressway, Principal Arterial, Minor Arterial, and Minor Collector all illustrate less consumption from Expressway-Minor Collector as expected, because they range from 55 to $25 \mathrm{MPH}$ respectively. While road class Major Collector had shifted downward, it was still one of the most energy inefficient roads to drive on. However, for the purposes of this analysis, studying the elevation angle's effect on energy consumption would not have yielded substantial results. Since change in SOC happened on average every 0.5 miles, elevation's effect on SOC was challenging to study, even when the measurements of SOC had been backwards distributed, as described by this thesis. Overall, each subject over the course of the experimental route witnessed, on average, 56 change events in SOC. When making comparisons to distance, there existed large amounts of data from which to make 


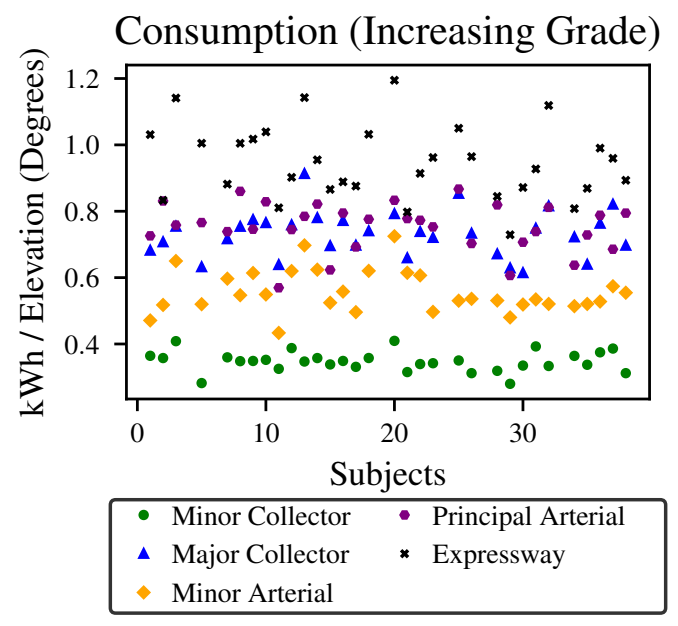

(a) Subjects' Consumption Positive Grade

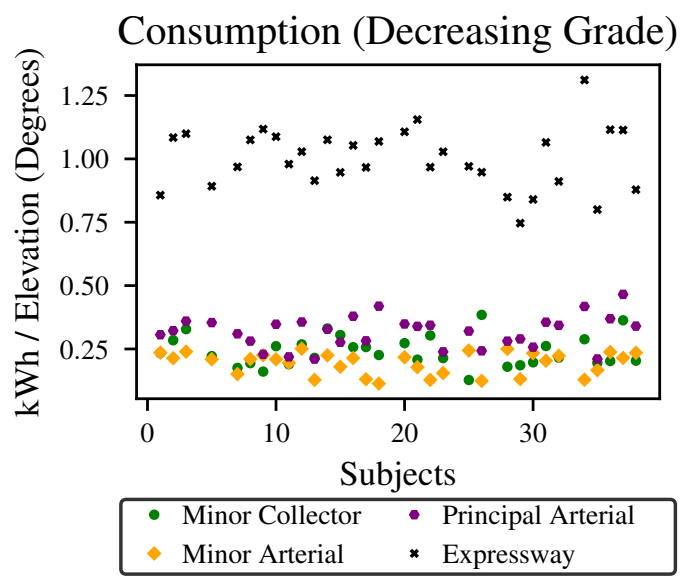

(b) Subjects' Consumption Negative Grade

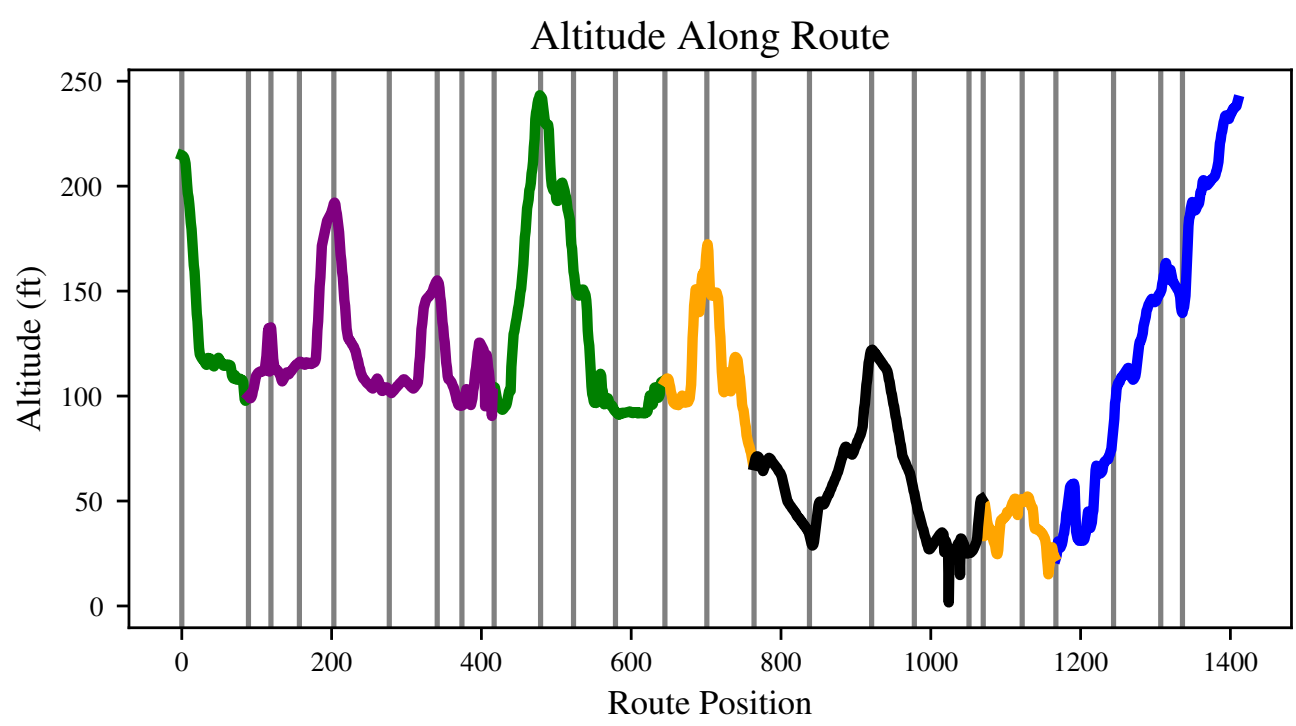

\begin{tabular}{|llll|}
\hline Minor Collector & Minor Arterial & Expressway \\
Major Collector & Principal Arterial & \\
\hline
\end{tabular}

(c) Elevation Altitude Cuts

Figure 4.3: Rate of SOC depletion by Grade

inferences. When studying the elevation angle over a road segment, there existed a total of 26 samples, 12 for downhill elevation changes and 14 for uphill elevation changes.

With so few data samples, making an accurate analysis of behavioral BEV driving with respect to elevation would not have aided in analysis. Furthermore, when broken down by road class, there were 2-3 samples for each direction of elevation. For road class Major 
Collector, there were no downhill samples, as the color blue is missing from Figure 4.3b. For this reason, analysis of BEV behavioral driving with respect to elevation was eliminated from further analysis, and driver behavior was analyzed instead on a driver's overall rate of energy consumption per mile.

\subsection{Cluster Analysis}

From the analysis of the raw data, there existed evidence that subjects were not using a similar amount of energy while traveling the same route, although some subjects appeared to show similar consumption patterns. This section first covers the process of subdividing drivers into clusters through hierarchal clustering. Next, clusters of drivers were statistically validated to ensure that clusters had unequal distributions of energy consumption. Lastly, driving parameters such as speed and acceleration were tested to determine if the clusters found had displayed aggressive behaviors, as aggressive speed and acceleration are responsible for ICE inefficiency [9].

\subsubsection{Results}

To cluster drivers based on their energy consumption profiles, hierarchical clustering was utilized. Hierarchical clustering develops a tree-structured dendrogram where clusters can be assigned by the partitions in the branches. The dendrogram from this experiment can be seen in Figure 4.4a. The height on the y-axis displays the measurement of dissimilarity between groupings of branches on the dendrogram. The largest distance existed between Cluster 1 (green) and the combination of Cluster 2 (blue) and Cluster 3 (red). Dropping to a fourth cluster would only have moved Subject 34 into a cluster of their own. Thus, a maximum of three possible clusters was analyzed.

Results of hierarchical clustering were plotted in Figure 4.4b, to display graphical separation between clusters. Cluster 1 (green) spans the region of low mean and low standard

deviation of $\frac{k W h}{M i l e}$. The combination of Clusters 2 and 3 (red) spans the region of high mean 


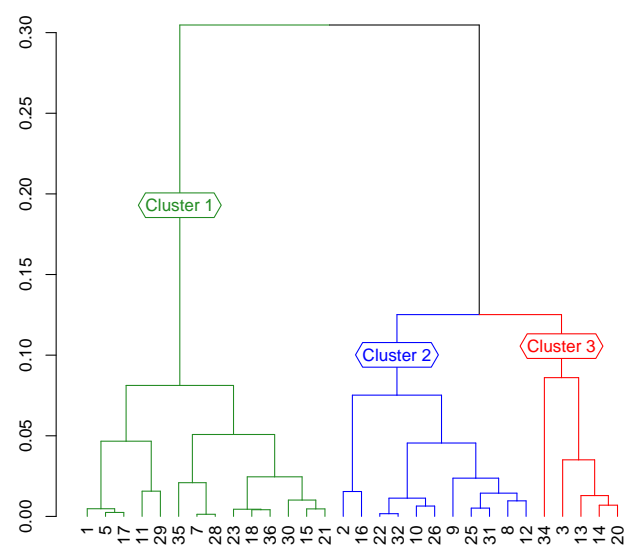

(a) Hierarchical Clusters

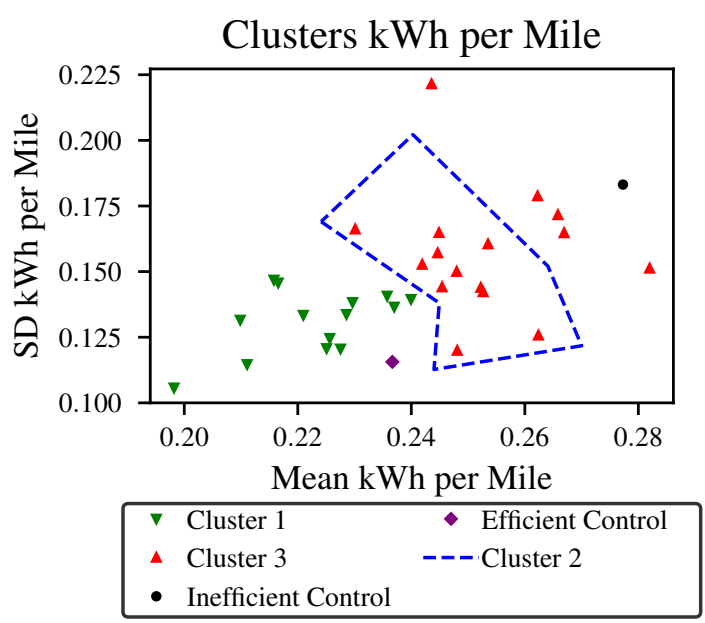

(b) Clusters Spread

Figure 4.4: Clustering Results

and high standard deviation of $\frac{k W h}{M i l e}$. If a three-cluster scenario was deemed significant, the red points surrounded by the dotted blue box in Figure 4.4 would be separated into a cluster of their own.

Two control runs were set up, driving the BEV efficiently (purple) and inefficiently (black), and their results can be seen in Figure 4.4. The inefficient control (black) appeared to fit into Cluster 3's region, as that run resulted in a high rate of energy consumption. The inefficient driving control also appeared to fit into the region defined by Cluster 1 (green), with a low mean and low standard deviation $\frac{k W h}{M i l e}$. Since three clusters were outlined in Figure 4.4 to represent increased inefficiency from Cluster 1 to Cluster 3, they will be referenced by their efficiency level for the remainder of this analysis. Cluster 1 (green) was labeled as efficient BEV drivers, Cluster 2 (blue) was labeled as moderately efficient BEV drivers, and Cluster 3 (red) was labeled as inefficient BEV drivers. However, if a two cluster model was singularly significant, moderately efficient BEV drivers would have merged with inefficient BEV drivers, and all drivers in that cluster would be labeled inefficient BEV drivers. 


\subsubsection{Cluster Validation}

Since three possible distinctions of BEV driving behavior were found, the strength of cluster's to stand on its own as significant categories of BEV driving behavior was covered. To determine statistical significance between found clusters of BEV efficiency, each clusters distribution for their rate of energy consumption was tested for normality. Both an Anderson Darling and a Shapiro Wilk test were used to test the hypothesis of normality of the cluster's distributions.

Every cluster, in a two and three cluster setup, were found to be not normal. All test statistics from the Anderson Darling and Shapiro Wilk tests were zero, meaning that the assumption of normality was rejected. For further inspection, qqplots were drawn for each cluster in a three cluster model. If data were to be considered normal, data points would have linearly trended around the fitted line in a qqplot. However, this was not the case for the data extracted from this experiment. All of the qqplots, seen in Figure 4.5, are non-linear. The curves from each qqplot suggest that the distributions were skewed to the right. The skewness of the distributions seemed truly representative of the data collected, as there were events such as traffic and variable elevation that aided in BEV efficiency, which altered the rate of energy consumption from the BEV [12]. Normal data obtained from BEV driving would more likely exist in non-complex transportation networks, as there would be no event that would hinder the rate of energy consumed. While normality could have been assumed from the implications of the central limit theorem, the data had been proven to be not normal, and further analysis was built on this fact.

Since normative testing between two samples was not used to find significance between the found clusters, a non-parametric test was used. The test used on these data was a Wilcox test, and the resulting test statistics for each type of BEV driving can be found in Table 4.1. In a two cluster scenario, both efficient and inefficient BEV driving were found to be significant, as the test statistic from the Wilcox test was zero. In a three cluster scenario, significance testing was computed for both efficient behavior and moderately efficient be- 


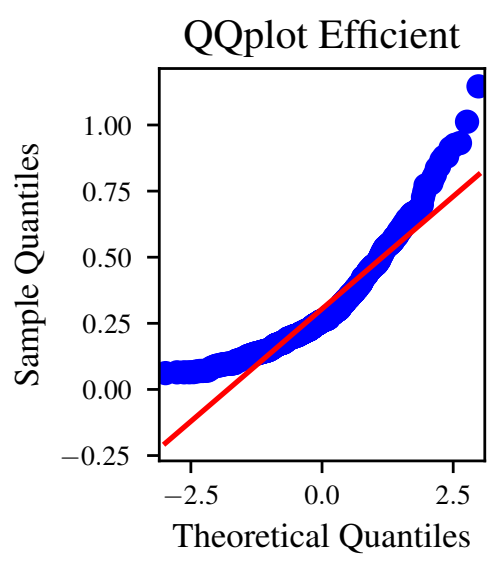

(a) Efficient BEV drivers

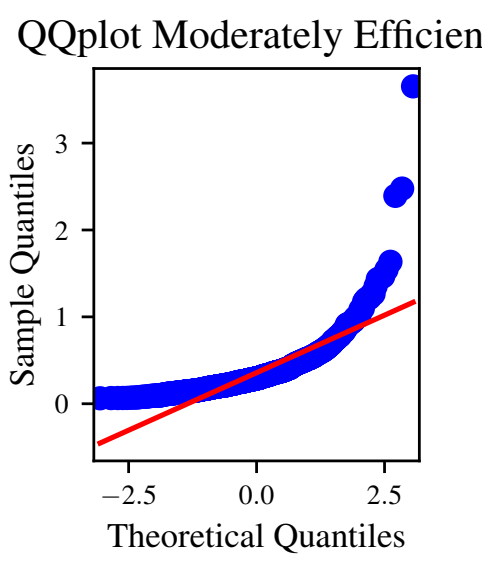

(b) Moderately Efficient BEV drivers

Figure 4.5: Cluster QQplots

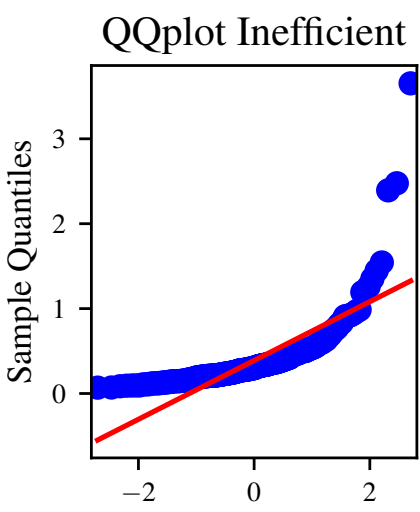

Theoretical Quantiles

(c) Inefficient BEV drivers

(c) 
Table 4.1: Cluster Statistics

\begin{tabular}{|c|c|c|c|c|c|c|}
\hline $\begin{array}{c}\text { Number } \\
\text { of } \\
\text { clusters }\end{array}$ & group & Subjects & $\begin{array}{c}\text { Data } \\
\text { Samples }\end{array}$ & $\begin{array}{c}\text { Age } \\
(\mu, \sigma)\end{array}$ & Sex & $\begin{array}{r}\text { Wilcox } \\
\text { Test }\end{array}$ \\
\hline 2 & $\begin{array}{c}\text { Efficient } \\
\text { Behavior }\end{array}$ & 14 & 699 & $(24.0,3.7)$ & $\mathrm{M}=8 \mathrm{~F}=6$ & 0.000 \\
\cline { 2 - 6 } & $\begin{array}{c}\text { Inefficient } \\
\text { Behavior }\end{array}$ & 16 & 895 & $(24.6,4.1)$ & $\mathrm{M}=9 \mathrm{~F}=7$ & \\
\hline \multirow{2}{*}{3} & $\begin{array}{c}\text { Efficient } \\
\text { Behavior }\end{array}$ & 14 & 699 & $(24.0,3.9)$ & $\mathrm{M}=8 \mathrm{~F}=6$ & \multirow{2}{*}{0.001} \\
\cline { 2 - 6 } & $\begin{array}{c}\text { Moderately } \\
\text { Efficient } \\
\text { Behavior }\end{array}$ & 11 & 603 & $(24.3,4.7)$ & $\mathrm{M}=6 \mathrm{~F}=5$ & \multirow{2}{*}{0.161} \\
\cline { 2 - 6 } & $\begin{array}{c}\text { Inefficient } \\
\text { Behavior }\end{array}$ & 5 & 292 & $(25.4,2.6)$ & $\mathrm{M}=3 \mathrm{~F}=2$ & \\
\hline
\end{tabular}

which mimics the demographics of the population, as there were more males enrolled in the experiment than females.

Since the two cluster setup was deemed significant, from this research, BEV drivers can either be categorized as efficient or inefficient. Further analysis of how strong these two clusters of behavioral BEV driving was completed by taking the same parameters they were clustered on, those being mean and standard deviation $\frac{\triangle S O C}{M i l e}$, and separating their consumption on the different road classifications defined by OSM. Figure 4.6 holds five plots for the five different road classes that the experiment was completed over. The expectation of this analysis was that the clustering regions defined earlier in Figure 4.4, should hold true when broken down by road class. The inefficient BEV driving behavior cluster should remain in the region of high mean high standard deviation $\frac{\triangle S O C}{\text { Mile }}$, while the efficient $\mathrm{BEV}$ driving behavior cluster should trend to the lower-leftmost region of the plots.

Overall, the two defined clusters of driving behavior fit into their respective regions of efficiency in Figure 4.6, where efficient BEV driving (green) is positioned in the lower left quadrant of the graphs and inefficient driving behavior (red) is positioned in the upper right 
quadrant on the graphs. However, there were a few examples of drivers who appeared to display the opposite classification of BEV driving behavior then that in which they were clustered. This rarely happened for drivers classified as efficient BEV drivers (green), as there were limited instances in Figure 4.6 where a red point is mixed in with inefficient BEV drivers (red). An instance of this can be seen in Figure 4.6a, where efficient BEV drivers number 32 and 15 are encircled by a few inefficient BEV drivers. The same happened for efficient BEV driver number 36 in Figure 4.6e. However, for the most part, efficient BEV drivers retained a similar pattern of energy consumption when driving different road classes. This was to be expected, as the efficient cluster was developed by minimizing the cluster's standard deviation of $\frac{\Delta S O C}{M i l e}$. The efficient cluster was expected to display a similar pattern on energy consumption when broken down by road class.

Inefficient BEV driving behavior, on the other hand, showed more examples where a subject's behavior appeared to be efficient when broken down by road class. Extreme examples of this were inefficient BEV drivers number 9 and 25 on road class Minor Collector (Figure 4.6a) and drivers 9 and 31 on road class Principal Arterial (Figure 4.6d). These drivers displayed efficient driving behaviors on those road classes. This was to be expected, as drivers who were categorized as inefficient BEV drivers had a much higher standard deviation in energy consumption; thus, they will display a degree of variability in energy consumption when driving a BEV.

One road class that did not hold up well was class Minor Arterial. On the Minor Arterial roads, depicted in Figure 4.6c, there was a large amount of mixing between the regions of inefficient and efficient BEV driving behavior. Both control runs also displayed a very similar pattern of consumption over this road class. Road class Minor Arterial, however, had greater traffic density and many stop signals, which provided ample opportunity to recuperate energy from the regenerative brakes. 
Clusters kWh per Mile

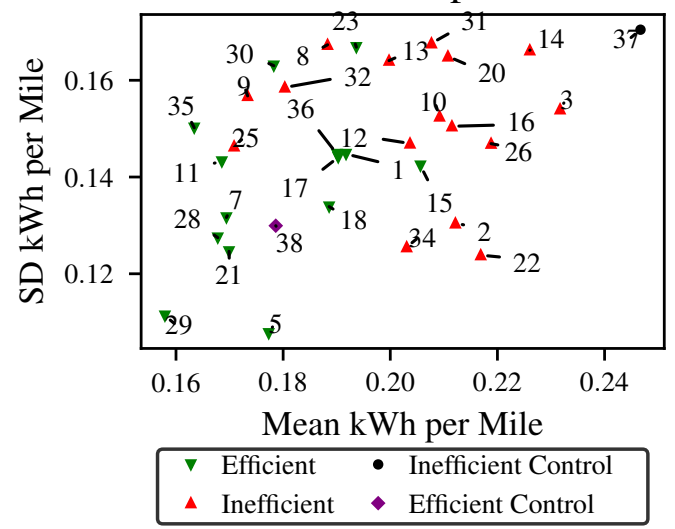

(a) Minor Collectors

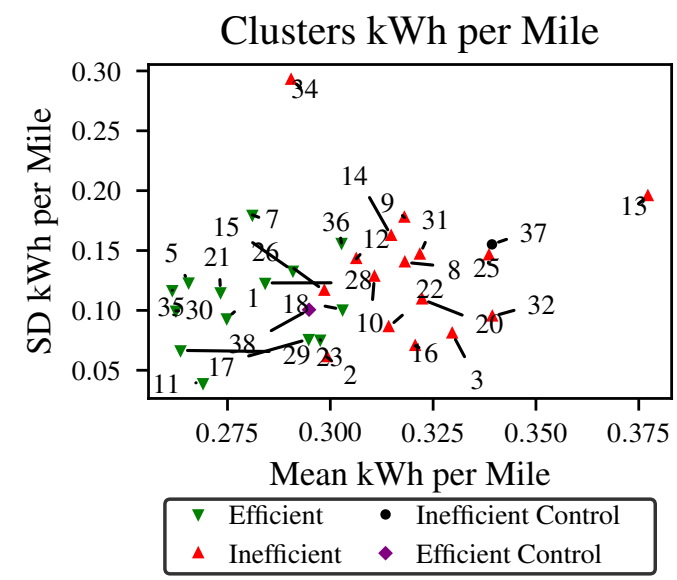

(b) Major Collectors

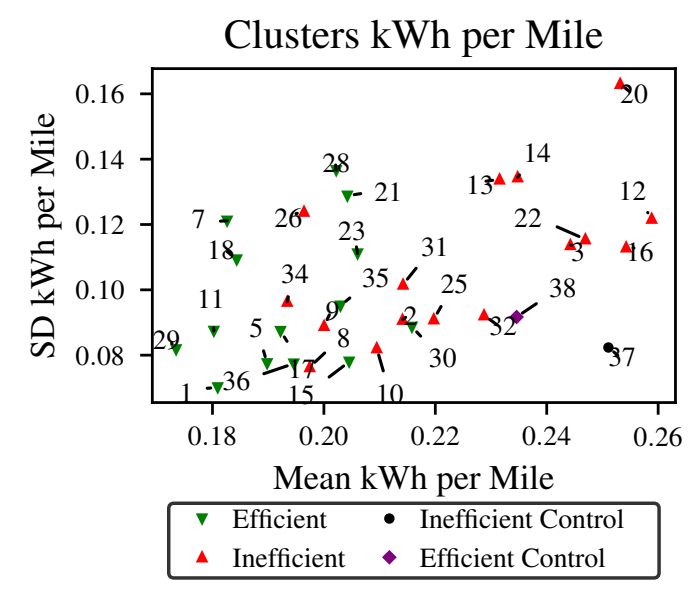

(c) Minor Arterial

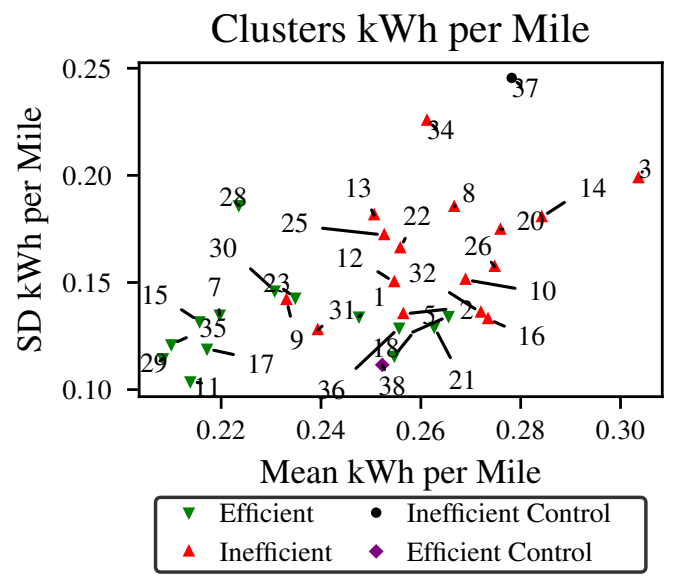

(d) Principal Arterial

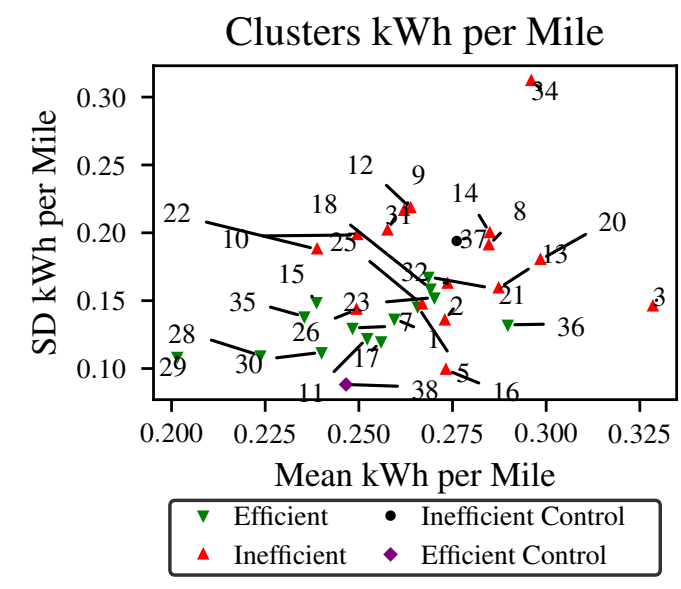

(e) Expressway

Figure 4.6: Rate of SOC depletion by Road Class 


\subsubsection{Analysis of Aggressive Driving Attributes}

Part of the analysis of this research was to determine if eco-driving of ICE vehicles is comparable to efficient driving of BEV vehicles. The last portion of analysis of data extracted from the vehicle was used to compare eco-driving to BEV driving efficiency. Ecodriving in ICE vehicles was defined as the reduction of aggressive speed and acceleration. With this in mind, acceleration data collected from an iPhone 6 s and velocity data captured from the Adifruit ${ }^{\circledR}$ Ultimate Breakout board were analyzed.

With traveling speed being a large contributing factor to inefficient driving of BEVs [16], a distinction was made between the traveling speeds of efficient and inefficient BEV drivers. Figure 4.7 shows the speed profile of each class of BEV drivers over the course of the experimental route. Data was down-sampled for visualization purposes. The spread of the standard deviation of each class of efficient BEV driving was plotted over time, which can be seen in Figure 4.7. Generally, efficient BEV driving behavior (green) results displayed much slower speeds than inefficient driving behavior (red). There was a slight overlap (brown) between the two classes of BEV driving behavior; however, for the most part it would appear that each class's distribution of speed differs. Surprisingly, there is a large degree of overlap on road class Expressway, which can be seen between time steps 78-95 in Figure 4.7. A similar separation between traveling speed of the BEV efficiency clusters would have been expected to follow suit on class Expressway, especially since this road had a high speed limit, allowing drivers to get a feel for high speed travel in a BEV. Since all of drivers in the experiment were familiar with the area, due to recruiting through the University, it is also possible that subjects could have been aware of possible penalties for speeding on that stretch of road.

While there is visual evidence from Figure 4.7 that different clusters of BEV driving efficiency traveled at different rates of speed, further statistical testing ensued to determine if inefficient BEV drivers have aggressive speeds and if efficient BEV drivers present nonaggressive speeds. Over the course of the experimental route, both groups' average speed 


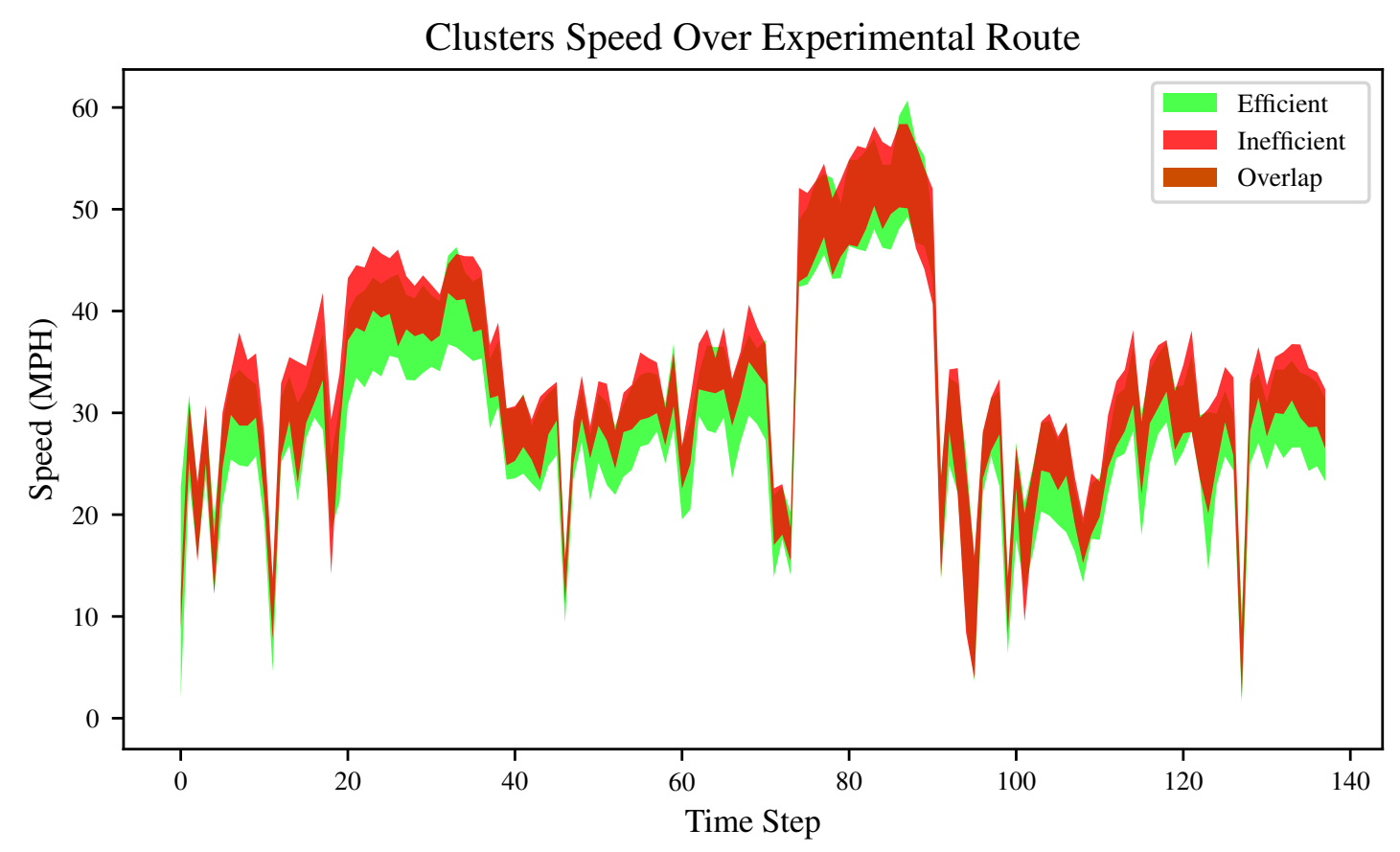

Figure 4.7: Cluster Speed

with respect to the road's speed limit was calculated by stripping off the first 100 and the last 100 samples from each road, to assess true traveling speed and curb deflation from stopping, starting, and standstill traveling events. Efficient BEV drivers, on average, traveled 1.7 MPH over the speed limit, with a standard deviation of 6.0 MPH. Inefficient BEV drivers traveled on average 4.8 MPH over the speed limit with a standard deviation of 5.5 MPH. The distributions of the deviation from the speed limit were plotted in Figure 4.8. Both distributions visually had a bell curve structure, which suggested normality.

With both classes of efficient BEV driving representing a bell curve structure, and a number of samples than 40,000 for deviation from the speed limit for each cluster, according to the central limit theorem, the data could be assumed normal. Continuing on the assumption of normality, a t-test was used to determine if the clusters of BEV driving efficiency were statistically different. The test statistic from the t-test resulted in a value of zero, meaning each class of driving efficiency drove the BEV at a different rate of speed when compared to the speed limit. For the sake of comparison to eco-driving in ICE vehi- 


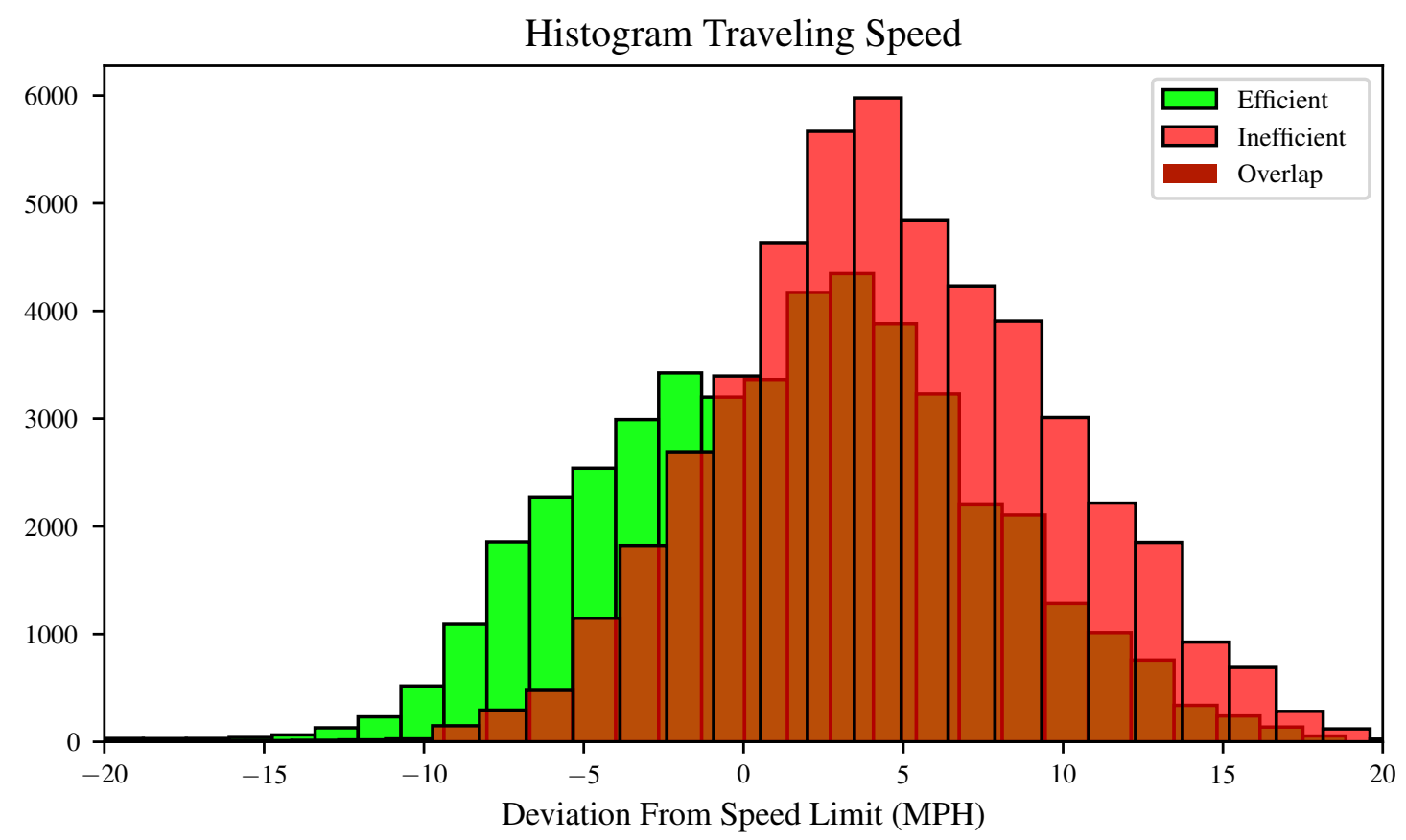

Figure 4.8: Cluster Deviation from Speed Limit

cles, efficiency of BEV driving was also affected by aggressive speeds, as inefficient BEV drivers generally drove faster than efficient BEV drivers.

The second component of eco-driving was defined as aggressive acceleration [9]. One way to determine aggressive driving was to use the safe driving region within a friction circle [84]. The acceleration results from the control runs were plotted in Figure 4.9. The $\mathrm{y}$-axis is the longitudinal acceleration of the vehicle (forward and backward acceleration), while the $\mathrm{x}$-axis is the lateral acceleration (left to right acceleration), measured in $\frac{\text { meters }}{\text { second }^{2}}$. While both control runs had a high degree of acceleration within the safe driving region, the inefficient controls plot from Figure $4.9 \mathrm{~b}$ had a greater degree of points outside the safe driving region. It was determined that safe, non-aggressive driving behavior results in fewer than $8 \%$ of points falling outside the safe driving region, and aggressive driving amounts to more than $10 \%$ of points outside of the safe driving region [84]. The efficient control had $4.07 \%$ of points outside of the region and the inefficient control had $9.53 \%$ of 
points outside the region. These results pointed to aggressive driving behaviors having an impact BEV on efficiency.

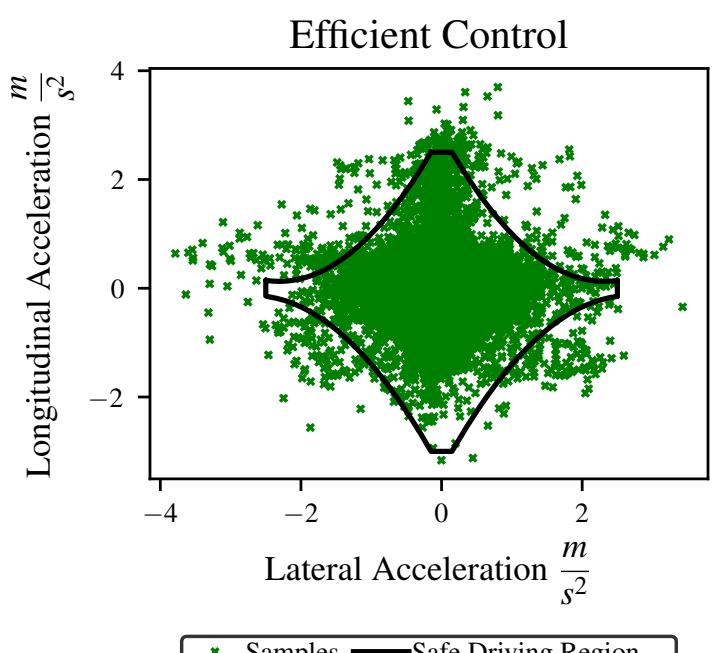

(a)

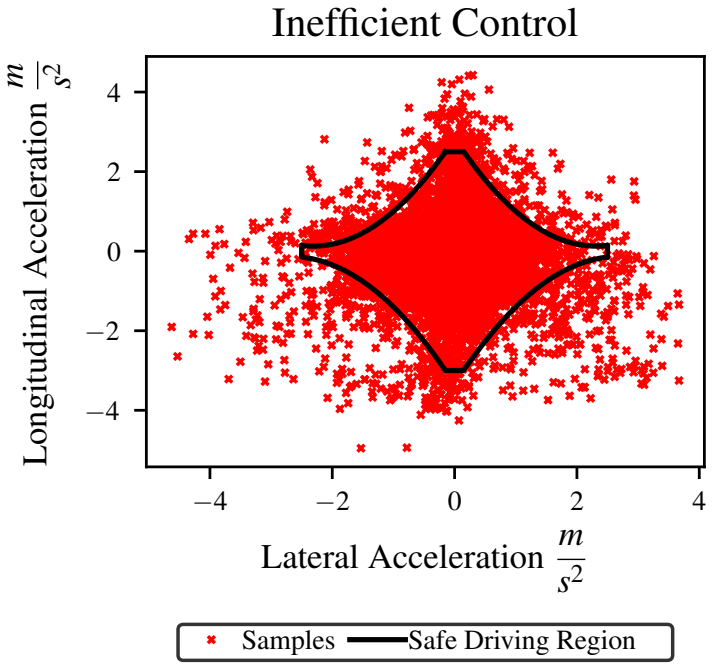

(b)

Figure 4.9: Control Runs Friction Circles

Results for both efficient and inefficient BEV driving can be seen by the box plot in Figure 4.10. Efficient BEV drivers had a much larger range of acceleration points outside the safe driving region as compared to inefficient BEV drivers. Both clusters' ranges did not expand beyond $10 \%$, which was suggested to be the threshold of aggressive driving [84]. This was most likely due to using the D1 recuperation mode, as this mode applied braking when the driver removed their foot from the gas pedal.

However, inefficient BEV drivers generally had more points outside of the safe driving region, as their median is very close to the third quartile of efficient BEV drivers in Figure 4.10. To test if these acceleration profiles differ, they were first tested for normality. The efficient cluster reported a test statistic of 0.9 for the Anderson-Darling test and 0.8 for the Shapiro Wilk test. The inefficient cluster reported 0.07 for the Anderson Darling test and 0.05 for the Shapiro Wilk test. Both could be assumed normal from these tests, even though the inefficient drivers' results showed marginal insignificance when compared to a normal distribution. 


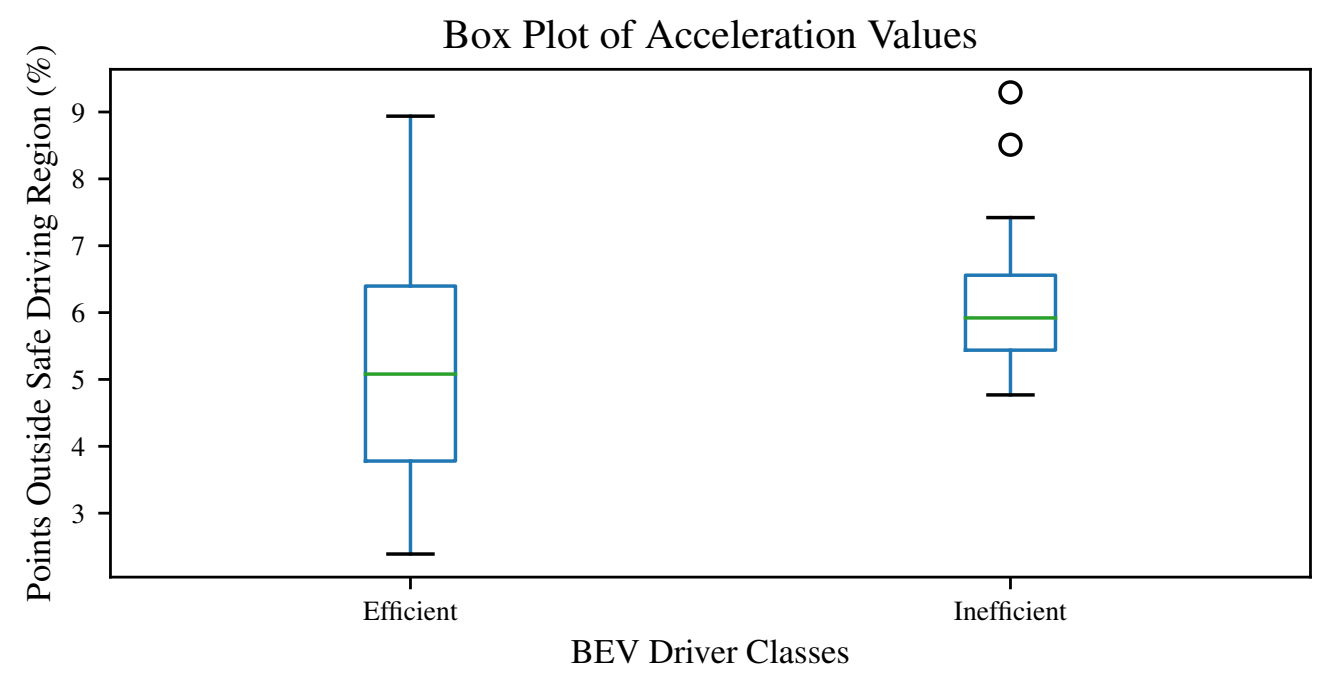

Figure 4.10: Points Outside Safe Driving Region by BEV Cluster

A t-test was used to determine whether the two cluster acceleration profiles differed. The results from the t-test determined that the clusters did in fact have different acceleration profiles, as the test statistic resulted in a value of 0.039 . While the determined thresholds of $10 \%$ for aggressive drivers and $8 \%$ for non-aggressive drivers [84] may hold true for ICE vehicles, recuperation modes on the e-Golf have altered the results in this experiment. Thus, acceleration is affecting a BEV driver's efficiency.

\subsubsection{Regression of BEV Driving Factors}

In an effort to determine the effect that the different factors explored in this research have on BEV efficiency, a hierarchical regression was constructed. To create the regression model, segments of roads were extracted over the course of the experimental route. These segments were randomly generated from the data so that they would only cover uphill, downhill, or flat elevation. The predictor used was the sum of the $\mathrm{kWh}$ consumed of the road segment.

Regression 1 is the first model considered in the hierarchal regression and can be seen in the second column of Table 4.2. Regression 1 considered only roadway characteristics, those being the total distance traveled, the change in altitude, and the speed limit. This 
model alone had a strong $R^{2}$ value $(0.9434)$, and all of the predictors were significant at a $99 \%$ confidence interval.

Regression 2 was constructed by adding in the BEV behavioral classes found in this research. This variable was defined as a binary classification where zero represents Efficient BEV drivers and one represent Inefficient BEV drivers. The addition of these variables to the model was significant, reporting a test statistic of zero and an F-value of 67.87. The inclusion of this variable also raised the $R^{2}$ of the regression to 0.9523 while increasing Sum of Squares by 0.15 .

Regression 3 was created by adding instantaneous parameters to the model. The inclusion of these parameters was also significant reporting a test statistic of zero and F-values of 10.971. However, speed limit becomes insignificant as the travel time was a better representation of speed, which was found to be a strong component of BEV inefficiency as outlined in this research and previous works [12]. The inclusion of the number of points outside the safe driving region of a friction circle was also not significant, as seen in Table 4.2. The inclusion of the instantaneous parameters only increases the Sum of Squares by 0.0743 and the $R^{2}$ values by 0.0043 .

Table 4.2: Hierarchical Regression Results

\begin{tabular}{lccc}
\hline Predictor Variables & Regression 1 & Regression 2 & Regression 3 \\
\hline Intercept & $-5.608 \mathrm{e}-02 * * *$ & $-8.051 \mathrm{e}-02 * * *$ & $-2.845 \mathrm{e}-02$ \\
Distance & $2.364 \mathrm{e}-01 * * *$ & $2.361 \mathrm{e}-01 * * *$ & $2.991 \mathrm{e}-01 * * *$ \\
Change in altitude & $1.478 \mathrm{e}-03 * * *$ & $1.490 \mathrm{e}-03 * * *$ & $1.509 \mathrm{e}-03 * * *$ \\
Speed limit & $1.787 \mathrm{e}-03 * * *$ & $1.849 \mathrm{e}-03 * * *$ & $5.308 \mathrm{e}-04$ \\
BEV Classes (1,Inefficient; 0, & & $4.273 \mathrm{e}-02 * * *$ & $3.395 \mathrm{e}-02 * * *$ \\
Efficient) & & & \\
Travel Time & & & $7.076 \mathrm{e}-04 * * *$ \\
Safe driving region $\quad$ Inside region & & & $-2.797 \mathrm{e}-04 * * *$ \\
$\quad \quad$ Outside region & 0.9434 & 0.9523 & $-5.869 \mathrm{e}-05$ \\
$R^{2} \quad 0.9566$ \\
$\Delta R^{2} \quad$ & 0.0089 & 0.0043 \\
\hline$* \mathrm{p}<0.05 ; * * \mathrm{p}<0.01 ; * * * \mathrm{p}<0.001$ & & &
\end{tabular}




\subsection{Questionnaire Results}

With two distinct clusters presenting themselves in the categories of efficient and inefficient BEV driving behavior, their results were tested against drivers' answers to the 21-question DBS. The three measures of anxiety proposed by the DBS were DEF, which measured anxiety's effect on driving skills; CAUT which measured anxiety's effect on cautious driving behaviors; and ANG, which measured anxiety in the form of hostile and aggressive driving behaviors.

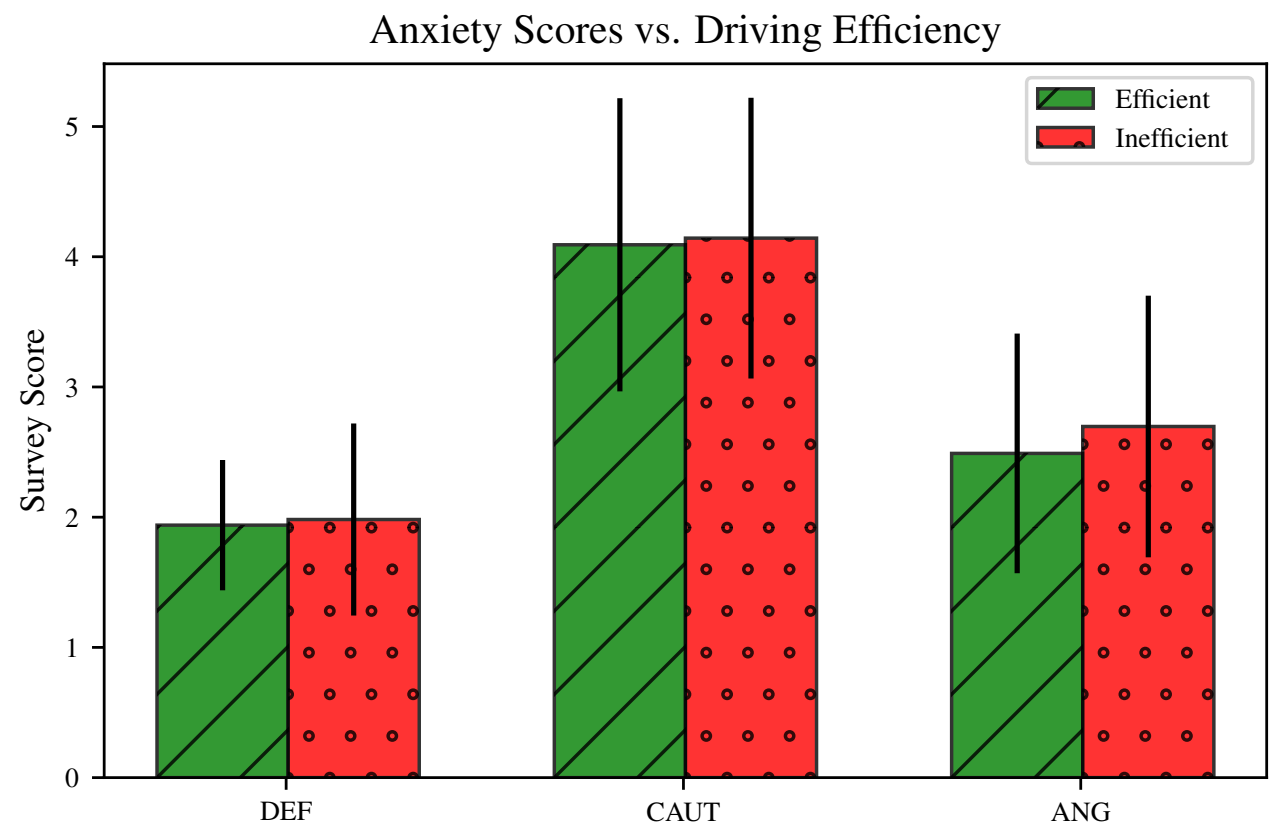

Figure 4.11: DBS 21 Anxiety Scores by Cluster

Scores for each cluster were plotted against one another to ascertain which dimensions of anxiety had an impact on BEV efficiency (see Figure 4.11). From the plot, mean answers for each of the anxiety dimensions match those reported from the DBS. However, while the mean for each level of BEV efficiency presented only a marginal shift in anxiety measures, a standard deviation of around 1 was found for each class, by each dimension of anxiety. Similar analysis had been done by comparing the results of drivers with post-traumatic stress disorder, to the sample of the DBS using normative statistical testing [86]. Results from this experiment were tested in the same way. 
However, in this experiment, results for dimensions DEF (p-value=0.613), CAUT (pvalue=0.938), and ANG (p-value=0.464) all reported insignificant measures between the clusters. These results, while insignificant, are of benefit to BEV drivers. If BEV inefficiency stemmed from anxiety-based driving, compounding range anxiety with anxiety from driving could be detrimental to an individual's health [22].

To further validate the factors proposed by the DBS, exploratory factor analysis was conducted. For this research, principal component analysis was used to further explore possible factors with the sample of drivers who participated in the BEV driving experiment. The analysis began with the construction of a scree plot. The scree plot displays the eigenvalues of the number of principal components that are added to the model, which reduce unexplainable variance.

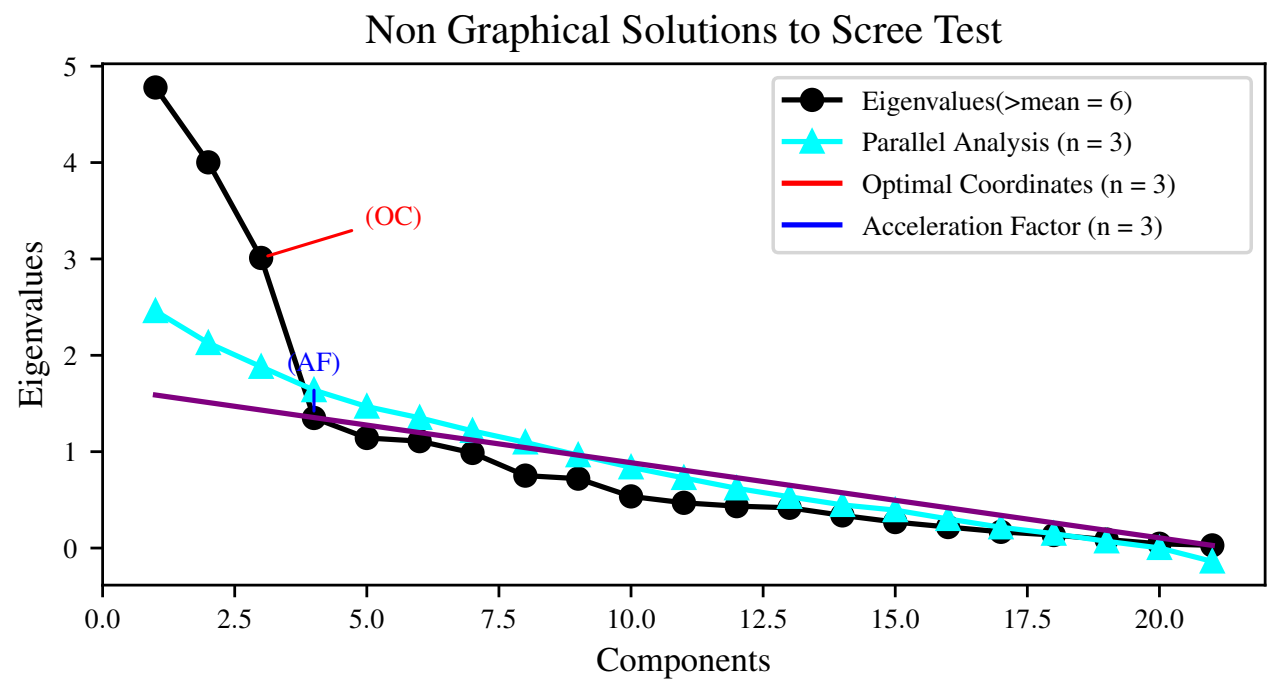

Figure 4.12: Scree Plot of Eigenvalues

The scree plot, depicted in Figure 4.12, shows the expected decrease in eigenvalues as more components are added to the model. Once the scree plot forms an elbow, less variance is explained by adding additional principal components to the model. In Figure 4.12, the elbow formed at the fourth component, which suggested that the data collected could be efficiently explained in a three, four, or five factor model. Table 4.3 displays the numerical eigenvalues from Figure 4.12, while also including the total variance explained by each 
component added, and the cumulative variance from each component added to the model. While the scree plot suggested a four factor model, this also was the case for developing the DBS [21], where a three factor model was found to be the most accurate representation of anxiety-based driving.

Table 4.3: Principal Component Analysis Variance

\begin{tabular}{|c|c|c|c|}
\hline Component & Eigenvalues & Total Variance & Cumulative Variance \\
\hline 1 & 4.779 & 0.273 & 0.273 \\
\hline 2 & 4.002 & 0.192 & 0.465 \\
\hline 3 & 3.010 & 0.122 & 0.587 \\
\hline 4 & 1.349 & 0.0649 & 0.653 \\
\hline 5 & 1.142 & 0.0647 & 0.717 \\
\hline
\end{tabular}

Additionally, the inclusion of a fourth factor only reduced unexplained variance by around half of what the previous additional component explained. Moving to a five factor model also only additionally explained $6 \%$ more variance within the model. Since the intention of this analysis was to test whether or not the same factors exist in this experiment, only a three factor model was analyzed. This method of analysis has been seen in other factor analysis experiments using the DBS [87]. Also, a three factor model was able to explain well over half of the variance that exists from the survey answers.

Results from the principal component analysis is outlined in Table 4.4. In the exploratory factor analysis completed to create the DBS, factor loadings greater than 0.3 were considered to be representative of a given factor. Factor loadings, in columns 2-4 in Table 4.4, yielded factor loadings greater than 0.41 , in line with the analysis of the DBS [21] and other studies that have done factor analysis on this survey [87]. All the factors are loaded to the same categories as the DBS, with the exception of "I pound on the steering wheel when I'm nervous." This question got loaded with DEF, which measures anxiety related to driving skills. The sample size in this experiment was not as enormous as the DBS, which had over 200 samples [21], or other similar principal component analysis studies which 
had 147 samples [87]. It is possible that with a larger sample size, all factors would have loaded correctly.

Table 4.4: Factor Loadings for the DBS

\begin{tabular}{|c|c|c|c|c|}
\hline $\begin{array}{c}\text { DBS } \\
\text { Category }\end{array}$ & Question & $\begin{array}{c}\text { Factor } \\
1\end{array}$ & $\begin{array}{l}\text { Factor } \\
2\end{array}$ & $\begin{array}{c}\text { Factor } \\
3\end{array}$ \\
\hline \multirow{7}{*}{ ANG } & $\begin{array}{l}\text { I gesture at the driver drivers who made me ner- } \\
\text { vous }\end{array}$ & 0.91 & & \\
\hline & $\begin{array}{l}\text { I try to find ways to let other drivers know that they } \\
\text { are making me nervous }\end{array}$ & 0.82 & & \\
\hline & $\begin{array}{l}\text { I let the driver who made me nervous know that I } \\
\text { m upset }\end{array}$ & 0.79 & & \\
\hline & I honk my horn at the driver who made me nervous & 0.71 & & \\
\hline & I yell at the driver who made me nervous & 0.68 & & \\
\hline & I swear use profanity while I am driving & 0.58 & & \\
\hline & I pound on the steering wheel when I $m$ nervous & & 0.41 & \\
\hline \multirow{7}{*}{$\mathrm{DEF}$} & I have trouble staying in the correct lane & & 0.84 & \\
\hline & I drift into other lanes & & 0.8 & \\
\hline & I forget to make appropriate adjustments in speed & & 0.63 & \\
\hline & I lose track of where I am going & & 0.62 & \\
\hline & I have trouble finding the correct lane & & 0.6 & \\
\hline & I forget where I am driving to & & 0.57 & \\
\hline & I have difficulty merging into traffic & & 0.45 & \\
\hline \multirow{7}{*}{ CAUT } & I try to put distance between myself and other cars & & & 0.76 \\
\hline & I try to stay away from other cars & & & 0.74 \\
\hline & $\begin{array}{l}\text { During bad weather I drive more cautiously than } \\
\text { other vehicles on the road }\end{array}$ & & & 0.69 \\
\hline & $\begin{array}{l}\text { I maintain a large distance between myself and the } \\
\text { driver in front of me }\end{array}$ & & & 0.55 \\
\hline & $\begin{array}{l}\text { I slow down when approaching intersections even } \\
\text { when the light is green }\end{array}$ & & & 0.55 \\
\hline & I decrease my speed until I feel comfortable & & & 0.54 \\
\hline & I maintain my speed in order to calm myself down & & & 0.45 \\
\hline
\end{tabular}

\subsection{Summary}

The results from this analysis show that two clusters of BEV driving efficiency statistically differ. The categories were defined as efficient and inefficient BEV driving. When they were compared to eco-driving in ICE vehicles, both aggressive speed and acceleration 
were found to affect the rate at which SOC was depleted by the subjects. Anxiety was not found to be a contributing factor to BEV efficiency, as both clusters' answers to the DBS were highly similar.

The final analysis for the effects of efficient and inefficient driving behavior can be found in Table 4.5. The first section of Table 4.5 displays each clusters mean and standard deviation $\mathrm{kWh}$ per mile which were the factors used to cluster drivers. Although efficient $\mathrm{BEV}$ driving appeared to only be slightly different than inefficient BEV driving, when analysis is expanded over a full year the impacts hold a much larger weight. The second section of Table 4.5 displays how much battery power the behavioral classes would use over the course of a year, based on the average distance drivers travel per year, which was 13,474 miles[88]. The next grouping of data shows the expected fuel bill for traveling 13,474 miles a year at a rate of $13.1 \phi / \mathrm{kWh}$, which is the national average [89]. The last group of results displays how many charging events these groupings of drivers should expect to have in a year, calculated by dividing kWh per year by the e-Golf total battery capacity of $24.2 \mathrm{kWh}$ [71]. However, in reality more charging events will happen as these numbers would assume full discharge and full recharge.

Table 4.5: Driving Estimation for BEV Driving Behavior

\begin{tabular}{|c|c|c|c|c|}
\hline \multirow{2}{*}{ Event } & \multicolumn{2}{|c|}{ Efficient BEV Driving } & \multicolumn{2}{c|}{ Inefficient BEV Driving } \\
\cline { 2 - 5 } & Mean & SD & Mean & SD \\
\hline $\mathrm{kWh} /$ mile & 0.227 & 0.129 & 0.254 & 0.165 \\
$\mathrm{kWh}$ per Year & 3063 & 1741 & 3421 & 2223 \\
Yearly Fuel Bill & $\$ 401.36$ & $\$ 228.14$ & $\$ 448.15$ & $\$ 291.33$ \\
Yearly charging Events & 126 & 72 & 141 & 92 \\
\hline
\end{tabular}




\section{CHAPTER 5 - Conclusion}

\subsection{Conclusions}

The aim of this research was to test the statistical significance between clusters of BEV driving behavior, determine whether or not the definition for eco-driving of ICE vehicles held constant for BEV driving efficiency, and also to determine if anxiety-based driving behavior influences BEV efficiency. To complete this analysis, 30 subjects agreed to voluntary participate in this research study. The participants involvement required them to drive a BEV on a specified route and complete the DBS used to measure three components of anxiety.

From the driving experiment, sensors were setup to collect measurements of the change in SOC over the experimental route. In terms of energy consumption, a variable amount of energy consumption was found between the sample of drivers. The maximal difference between the subject who used the most energy, compared to the subject who used the least energy, was equivalent to $10 \%$ of the batteries capacity. Estimating energy consumption on a per mile basis would enable the subject who consumed the least amount of energy to drive an additional $47 \%$ of the experimental route again, before consuming the equivalent amount of energy as the most inefficient subject.

Hierarchical clustering was used to group subjects into categories of efficiency with respect to their mean and standard deviation kWh's consumed per mile. The Wards objective function was used to create efficiency clusters and dissimilarity between clusters was calculated using Euclidean Distance. Based on the dendrogram developed from hierarchical clustering, three possible clusters presented themselves in the form of efficient, moderately efficient, and inefficient BEV driving. However a two clusters model was only significant, which was determined by using a Wilcox test, which proved that the two cluster model had independent distributions of energy consumption. 
Three anxiety factors were tested against the efficient and inefficient BEV driving clusters found from hierarchical clustering. Measuring anxiety was an appropriate addition to the study due to range anxiety being key deterrent of market transition to BEVs $[62,20]$. Multiple forms of anxiety compounded together can be detrimental to an individuals health [22]. This could potentially lead to increased rates of energy consumption for BEV drivers. Further validation of the results from questionnaire taken during this research was completed using principal component analysis, following similar procedures proposed by the DBS [21] and other research employing the DBS [87]. All questions, except for one, loaded correctly on the three factors of anxiety proposed by the DBS. The three components of anxiety were not found to influence BEV efficiency as the drivers in each of the two clusters answered the questionnaire similarly.

In relation to eco-driving, efficient BEV driving behavior was found to be similar. Since eco-driving was defined as the reduction of aggressive speed and acceleration [9], efficiency clusters were statistically tested against their deviation from the speed limit. Aggressive speed was found to be significantly different between the clusters of efficiency. Speed was expected to have a powerful contribution to efficient BEV driving, as speed is know to exponentially affect the rate that SOC is depleted $[12,16,90]$. Aggressive use of acceleration was also found to be a factor for BEV efficiency. Using the safe driving region of a friction circle, inefficient BEV drivers statistically had more points outside of the safe driving region as compared to efficient BEV drivers. However, the threshold of $10 \%$ for aggressive driving and $8 \%$ for non aggressive driving [84] were not determinants in this research, because the BEV was set to a recuperation mode that reduced acceleration. Thus, further analysis of the data included using a t-test to determine if inefficient BEV drivers had more points outside the safe driving region of a friction circle. It was found that the acceleration profiles between efficient and inefficient BEV drivers was significantly different. 


\subsection{Limitations}

There are, however, some limitations presented in this research. The first was sample size and age range of the subjects. While the sample size was in line with other behavioral driving research $[7,31,33,68]$, a larger sample size would have sanctioned the use of more robust clustering techniques, such as k-mean clustering [79], or latent profile analysis. An extension of the sample size into more age groups would have also enabled studying BEV driving behavior with respect to driving experience [25], as drivers who can purchase a $\mathrm{BEV}$ is not limited to age range of participants in the experiments sample.

A longer experimental drive would have also been beneficial because the sampling rate for the change in SOC was infrequent, happening every 0.5 miles on average. A higher sampling rate would have allowed for a more in depth analysis of energy consumption with respect to change in elevation and road classes. Since there was a possibility of overlap between road classes, defined by OSM, values for the change in SOC were backwards distributed based on the distance traveled. Instantaneous sampling of SOC would have eliminated this issue entirely.

Both a longer experimental drive and a larger sample size would have allowed more time to study the different eco-modes of the VW e-Golf. The BEV had four recuperation modes and three modes that limit acceleration when pressing the gas pedal [70]. Since the the experiment was limited to approximately 26 miles, and the change in measurements of SOC happened, on average every half mile, further analysis of BEV driving behavior was limited to one recuperation mode. Mode D1, light recuperation when braking was selected for the experimental drive as it adds the benefits of reduced energy consumption. Mode D1 was also chosen because comparisons between eco-driving and BEV driving behavior was completed in this research. Since manufactures of ICE vehicles are making alterations to improve efficiency, eco-modes are becoming a standard in these vehicles [48]. Future research should involve all eco-modes of BEVs to fully understand how they impact driving behavior. 
One constant from the experiment was the time of day when participants completed the experimental drive. This constant was included in the experiment to attempt to control traffic congestion. However, there are many other factors that affect traffic congestion such as accidents, holidays, weekday, etc. At the time this research was completed, there was no data publicly available to access traffic congestion. To study traffic congestion, in future analyses, it may be possible to acquire radar data from the BEVs CAN to access how far away other vehicles are and relate this information to traveling speed to determine traffic congestion.

In terms of driving anxiety, BEV efficiency was studied using the three anxiety factors defined by the DBS. To control range anxiety, drivers were informed that there was more than enoguh energy to complete the experiment. While this allowed for finer analysis of the DBS anxiety factors, this research did not cover the effect that range anxiety could have the clusters of efficiency found. So defining how range anxiety affects the BEV behavioral classes found in this research was not explored.

Lastly, another limitation of this research was that naturalist driving behaviors could not be studied. The vehicle that subjects drove was not their own, the route of travel may not have been one the subjects were accustom too, and a researcher was present during the experimental drive. When studying driving behavior, typically a vehicle is supplied to drivers so that it can be used for daily driving [20]. While participants were given time to adjust the vehicles settings, and were provided a mile travel to become comfortable driving the vehicle, naturalistic driving behavior would be better studied in a vehicle that a subject had for an extended period of time.

\subsection{Future Work}

Results from this research can branch out in various directions, within the scope of BEV energy consumption modeling. To start, the foundation supporting this research can be further expanded in understanding BEV behavioral driving. Those who have studied 
range anxiety have supplied a BEV to selected drivers for an extended period of time [62]. By supplying a BEV to drivers, behavioral patterns can be studied based on road selection, as well as vehicle comfort settings, to study behavior in uncontrolled environments. With the inclusion of the results from this research, and further research on naturalistic BEV driving behavior, courses could be developed to train drivers to drive BEVs efficiently. In a study tracking one BEV driver, minor interventions helped that driver make better overall route selections [53]. Also, the effect that range anxiety has on BEV efficiency should be explored, as drivers who fit within the classes defined by this research may change when they experience limited range.

An instantaneous estimation of SOC can be made by utilizing Coulomb Counting, Kalman Filters, or by training back propagation neural networks [91]. In future research, these methods could be applied to yield a faster sampling rate to analyze BEV behavioral driving data. Faster sampling rates could be beneficial in developing estimation techniques for how much energy will be required to travel from point $A$ to point $B$, on real road networks. The VW e-Golf used in this research provides an estimate for how many miles can be traveled based on the energy left in the battery back [70]. Many estimation methods also attempt to better quantify remaining miles given the current charge of the battery and the drivers behavior $[92,93]$. However, circular range estimation only enables drivers to know how much charge they will use when driving in a straight line, from origin to destination.

Better estimation of energy consumption and the inclusion of BEV behavioral driving can benefit routing problems as well. Most BEV routing problems give a single estimate for the rate of charge used per distance $[94,95]$. This is also the case for BEV shortest path problems [96, 97]. The inclusion of behavioral data will refine these routing techniques, allowing them to model true energy consumption with respect to driving behavior.

BEVs have the potential to develop a more sustainable society. While sales of BEVs continue to grow, these vehicles have not yet captured a prominent share of the automotive market, because potential BEV drivers are concerned with limited range. Manufactures 
can use the information from this research to develop BEV driving modes that promote efficiency, or learn the current drivers behavior and automatically alter the BEV settings to improve efficiency. Ultimately, this research was able to quantify BEV driving behavior factors that inhibit maximum traveling distance of these vehicles. New BEV drivers can learn to adopt better driving behaviors, and potential BEV drivers can learn from this material, to overcome the hurdle of transitioning from an ICE vehicle to a BEV and help advance the sustainability of society. 


\section{Appendix A - Recruitment Advertisements}

\section{WANT TO TEST DRIVE AN ELECTRIC CAR?}

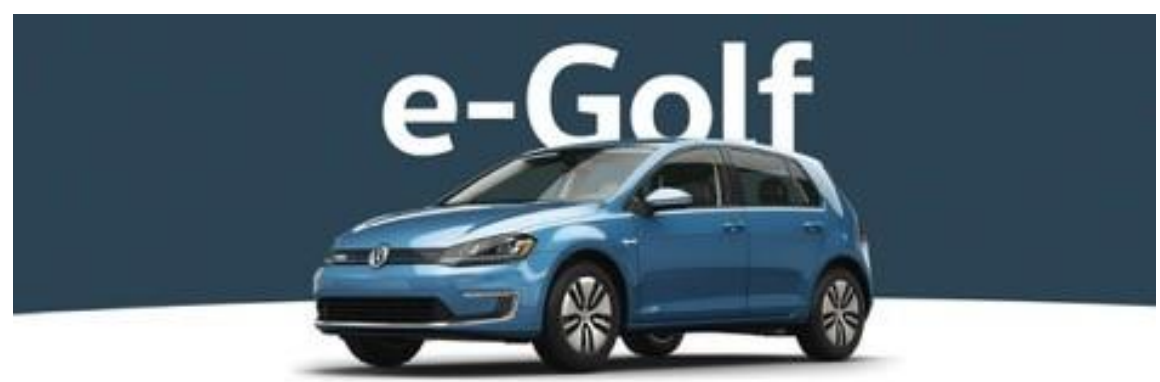

Have you always wanted to drive an electric car? Are you curious if it's the same as or different from your car? Do you want to see for yourself how quiet it is?

Well, here is you chance! Come participate in a study that is looking at how we drive EVs. This is a URI research under the supervision of Dr. Gretchen A. Macht which will help understand how people drive electric vehicles, which in turn will help arrange infrastructure better to accommodate the rising use of EVs.

Research volunteers, 18 or older, in possession of a valid American or international driver's license are being sought for an experiment beginning - . This research will be conducted at URI and routes to drive will all be around the Kingston campus.

The experiment will last just over an hour. First, you will take a questionnaire on your perceived driving habits [10 minutes]. Next, you will gain familiarity with the vehicle with a brief training session [10 minutes]. Then you will drive the car on the road on a specified route [50 minutes].

Contact Dan Kowalsky email at dan_kowalsky@my.uri.edu for more information and for recruitment. This research is affiliated with the University of Rhode Island through the MCISE department.

This research has been approved by The University of Rhode Island Institutional Review Board.

\begin{tabular}{|c|c|c|c|c|c|c|c|c|c|}
\hline 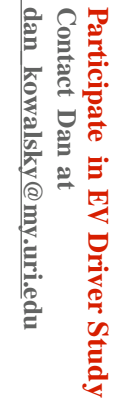 & 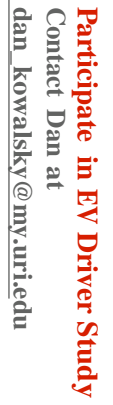 & 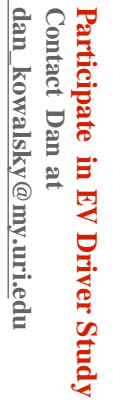 & 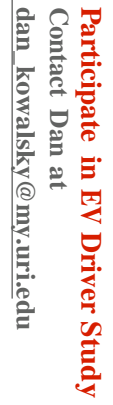 & 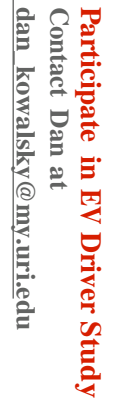 & 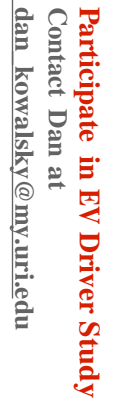 & 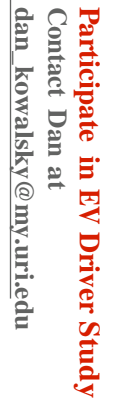 & 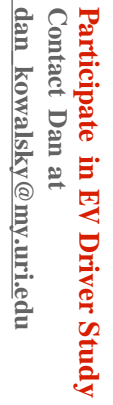 & 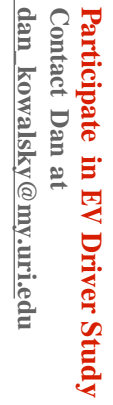 & 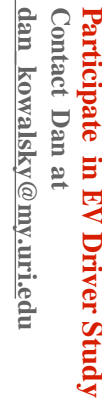 \\
\hline
\end{tabular}




\section{Want to Test Drive an Electric Car?}

Well, here is you chance! Come participate in a study that is looking at how we drive EVs. This is a URI research under the supervision of Dr. Gretchen A. Macht which will help understand how people drive electric vehicles, which in turn will help arrange infrastructure better to accommodate the rising use of EVs.

Research volunteers, 18 or older, in possession of a valid American or international driver's license are being sought for an experiment beginning - . This research will be conducted at URI and routes to drive will all be around the Kingston campus.

The experiment will last just over an hour. First, you will take a questionnaire on your perceived driving habits [10 minutes]. Next, you will gain familiarity with the vehicle with a brief training session [10 minutes]. Then you will drive the car on the road on a specified route [50 minutes].

Contact Dan Kowalsky email at dan_kowalsky@my.uri.edu for more information and for recruitment. This research is affiliated with the University of Rhode Island through the MCISE department.

This research has been approved by The University of Rhode Island Institutional Review Board. 


\section{Appendix B - Consent Form}

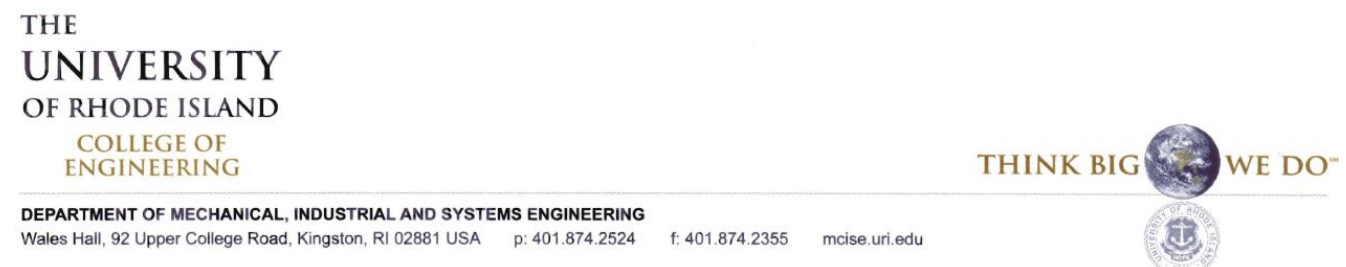

Consent Form for Research

The University of Rhode Island

Department of: Mechanical, Industrial \& Systems Engineering

Address: 92 Upper College Road, Kingston RI 02881

Title of Project: Electric Vehicle Driver Behavior

TEAR OFF AND KEEP THIS FORM FOR YOURSELF

Dear Participant

You have been invited to take part in the research project described below. If you have any questions, please feel free to call Dan Kowalsky or Dr. Macht or Dr. Sodhi, the people mainly responsible for this study.

The purpose of this study is to investigate how driver behaviour changes when combustion engine drivers start using an electric vehicle. All collected information will be stored in Pastore 333 in a locked file cabinet and digital information will be stored in computers in Pastore 254 as locked files. Only the researchers will have access to these files. No audio or video file will be collected. All the information required will be collected directly from the car. 


\section{Appendix C - Anxiety Questionnaire}

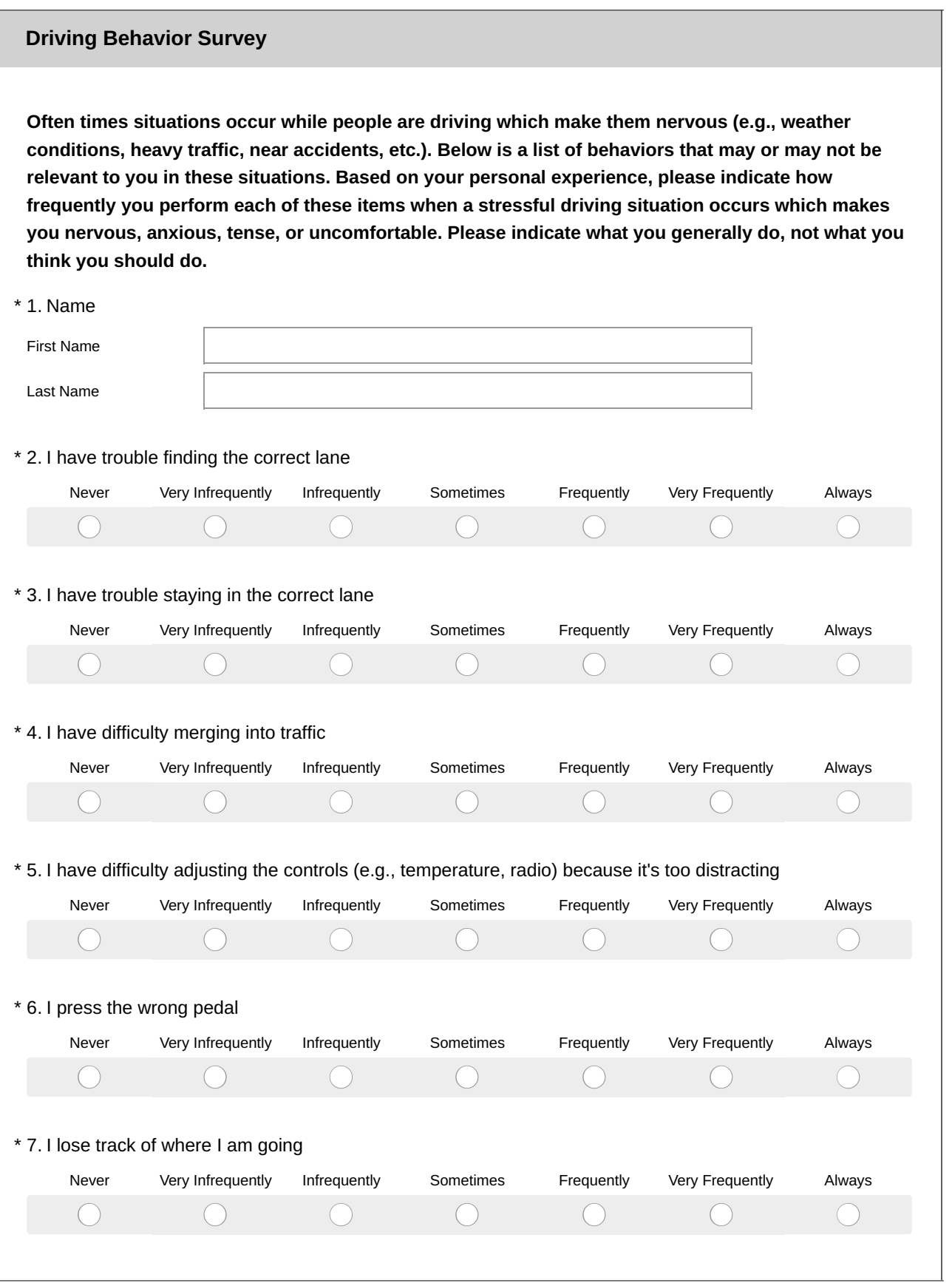




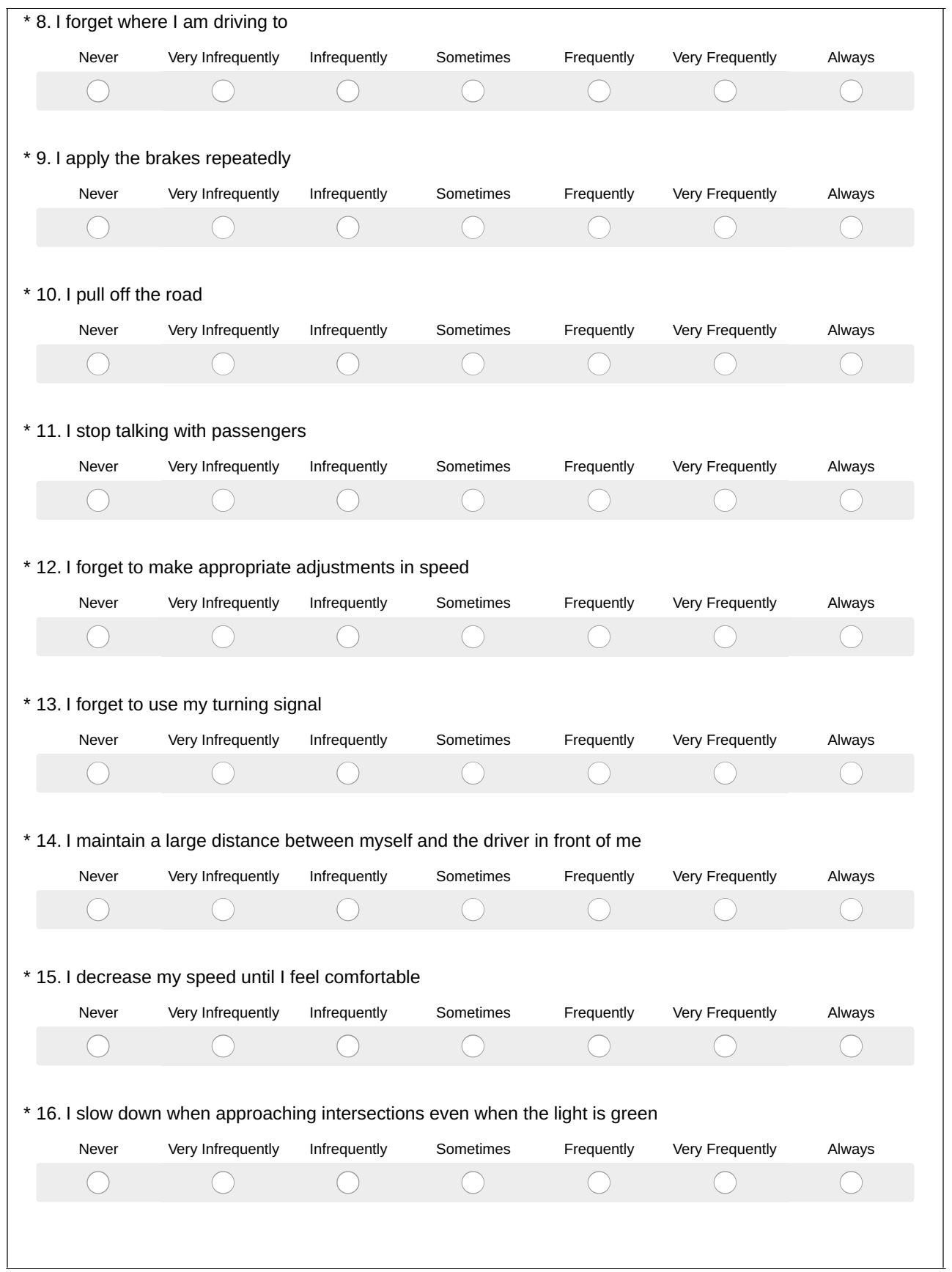




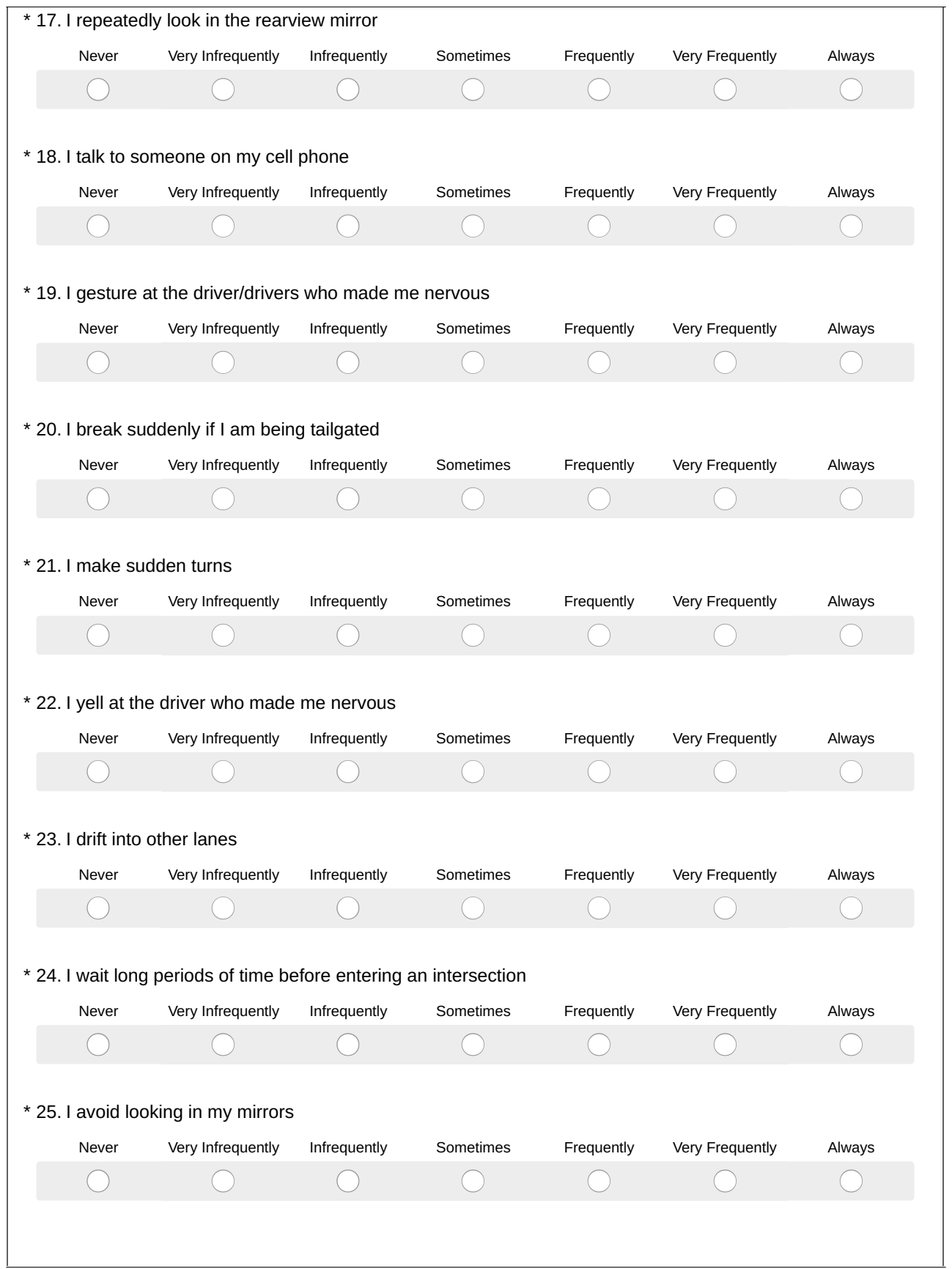




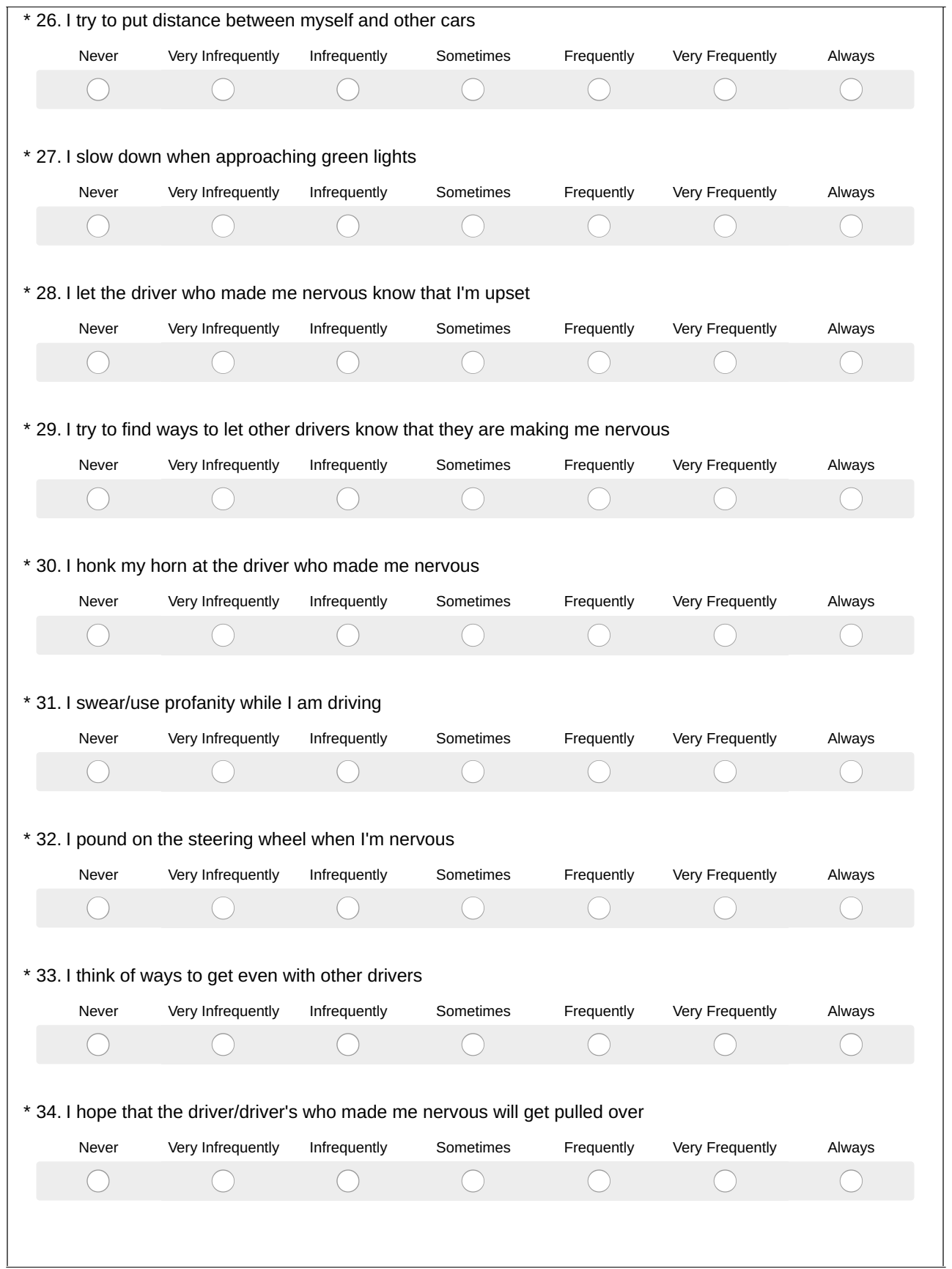




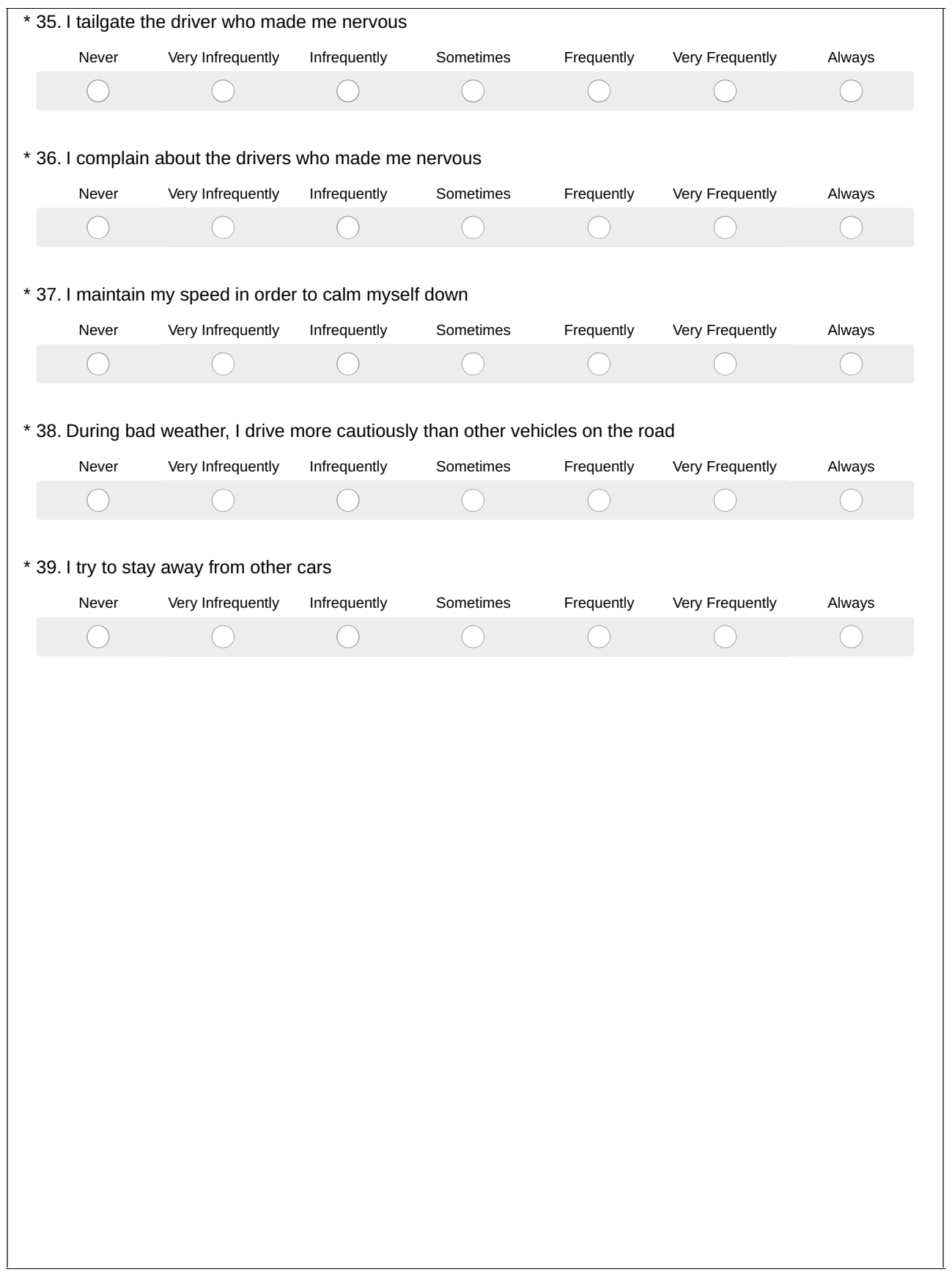




\section{BIBLIOGRAPHY}

[1] B. F. Skinner, Science and human behavior. Simon and Schuster, 1953.

[2] D. Meadows, Thinking in Systems A Primer. Earth Scan, 2008.

[3] S. Jafarpour and V. Rahimi-Movaghar, "Determinants of risky driving behavior: a narrative review." Medical journal of the Islamic Republic of Iran, vol. 28, p. 142, 12 2014.

[4] "Bureau of transportation statistics," https://www.bts.gov, 2016, [Accessed: 23- Oct2017].

[5] F. Guo and Y. Fang, "Individual driver risk assessment using naturalistic driving data," Accident Analysis \& Prevention, vol. 61, pp. 3-9, 2013.

[6] O. Taubman-Ben-Ari, M. Mikulincer, and O. Gillath, "The multidimensional driving style inventory-scale construct and validation," Accident Analysis \& Prevention, vol. 36, no. 3, pp. 323-332, 2004.

[7] D. J. Sun and L. Elefteriadou, "Lane-changing behavior on urban streets: An“invehicle" field experiment-based study," Computer-Aided Civil and Infrastructure Engineering, vol. 27, no. 7, pp. 525-542, 2012.

[8] T. Litman and S. B. Colman, "Generated traffic, implications for transport planning," Institute of Transportation Engineers. ITE Journal, vol. 71, no. 4, p. 38, 2001.

[9] J. N. Barkenbus, "Eco-driving: An overlooked climate change initiative," Energy Policy, vol. 38, no. 2, pp. 762-769, 2010.

[10] M. Sivak and B. Schoettle, "Eco-driving: strategic, tactical, and operational decisions of the driver that improve vehicle fuel economy," University of Michigan, Ann Arbor, Transportation Research Institute, 2011. 
[11] D. L. Meadows, E. I. Goldsmith, and P. Meadow, Limits to growth. CBC, 1972, vol. 381.

[12] S. Agrawal, H. Zheng, S. Peeta, and A. Kumar, "Routing aspects of electric vehicle drivers and their effects on network performance," Transportation Research Part D: Transport and Environment, vol. 46, pp. 246-266, 72016.

[13] R. Curtin, Y. Shrago, and J. Mikkelsen, "Plug-in hybrid electric vehicles," Reuters/University of Michigan, Surveys of Consumers, 2009.

[14] DOE, “All-electric vehicles," https://www.fueleconomy.gov/feg/evtech.shtml, 2011, [Accessed: 29- Oct- 2017].

[15] J. Dong, C. Liu, and Z. Lin, "Charging infrastructure planning for promoting battery electric vehicles: An activity-based approach using multiday travel data," Transportation Research Part C: Emerging Technologies, vol. 38, pp. 44-55, 2014.

[16] G. Wager, J. Whale, and T. Braunl, "Driving electric vehicles at highway speeds: The effect of higher driving speeds on energy consumption and driving range for electric vehicles in australia," Renewable and Sustainable Energy Reviews, vol. 63, pp. 158$165,92016$.

[17] A. D. Alvarez, F. S. Garcia, J. E. Naranjo, J. J. Anaya, and F. Jimenez, "Modeling the driving behavior of electric vehicles using smartphones and neural networks," IEEE Intelligent Transportation Systems Magazine, vol. 6, no. 3, pp. 44-53, 2014.

[18] T. Hiraoka, Y. Terakado, S. Matsumoto, and S. Yamabe, "Quantitative evaluation of eco-driving on fuel consumption based on driving simulator experiments," in Proceedings of the 16th World Congress on Intelligent Transport Systems, 2009, pp. 2125. 
[19] D. S. Bunch, M. Bradley, T. F. Golob, R. Kitamura, and G. P. Occhiuzzo, "Demand for clean-fuel personal vehicles in california: A discrete-choice stated preference survey," Institute of Transportation Studies, University of California, Irvine, 1991.

[20] E. Tate, M. O. Harpster, and P. J. Savagian, "The electrification of the automobile: from conventional hybrid, to plug-in hybrids, to extended-range electric vehicles," SAE international journal of passenger cars-electronic and electrical systems, vol. 1, no. 2008-01-0458, pp. 156-166, 2008.

[21] J. D. Clapp, S. A. Olsen, J. G. Beck, S. A. Palyo, D. M. Grant, B. Gudmundsdottir, and L. Marques, "The driving behavior survey: Scale construction and validation," Journal of Anxiety Disorders, vol. 25, no. 1, pp. 96-105, 12011.

[22] S. Taylor, W. J. Koch, and R. J. McNally, "How does anxiety sensitivity vary across the anxiety disorders?" Journal of anxiety disorders, vol. 6, no. 3, pp. 249-259, 1992.

[23] Y. Yang, B. Chen, L. Su, and D. Qin, "Research and development of hybrid electric vehicles can-bus data monitor and diagnostic system through obd-ii and androidbased smartphones," Advances in Mechanical Engineering, vol. 2013, p. 741240, 1 2013.

[24] D. A. Johnson and M. M. Trivedi, "Driving style recognition using a smartphone as a sensor platform," in Intelligent Transportation Systems (ITSC), 2011 14th International IEEE Conference on. IEEE, 2011, pp. 1609-1615.

[25] M. Casucci, M. Marchitto, and P. C. Cacciabue, "A numerical tool for reproducing driver behaviour: Experiments and predictive simulations," Applied ergonomics, vol. 41, no. 2, pp. 198-210, 2010.

[26] N. Rhodes and K. Pivik, "Age and gender differences in risky driving: The roles of positive affect and risk perception," Accident Analysis \& Prevention, vol. 43, no. 3, pp. 923-931, 2011. 
[27] X. Yan, E. Radwan, and D. Guo, "Effects of major-road vehicle speed and driver age and gender on left-turn gap acceptance," Accident Analysis \& Prevention, vol. 39, no. 4, pp. 843-852, 2007.

[28] R. Lawton, D. Parker, A. S. Manstead, and S. G. Stradling, "The role of affect in predicting social behaviors: The case of road traffic violations," Journal of applied social psychology, vol. 27, no. 14, pp. 1258-1276, 1997.

[29] F. P. McKenna, R. A. Stanier, and C. Lewis, "Factors underlying illusory selfassessment of driving skill in males and females," Accident Analysis \& Prevention, vol. 23 , no. 1, pp. 45-52, 1991.

[30] L. Eboli, G. Mazzulla, and G. Pungillo, "Combining speed and acceleration to define car users' safe or unsafe driving behaviour," Transportation Research Part C: Emerging Technologies, vol. 68, pp. 113-125, 2016.

[31] Z. Constantinescu, C. Marinoiu, and M. Vladoiu, "Driving style analysis using data mining techniques," International Journal of Computers Communications \& Control, vol. 5, no. 5, pp. 654-663, 2010.

[32] Gradel, T.E. and Allenby, B.R., Industrial Ecology and Sustainable Engineering. Prentice Hall, 102009.

[33] J. Wang, M. Lu, and K. Li, "Characterization of longitudinal driving behavior by measurable parameters," Transportation Research Record: Journal of the Transportation Research Board, no. 2185, pp. 15-23, 2010.

[34] Y. L. Murphey, R. Milton, and L. Kiliaris, "Driver's style classification using jerk analysis," Computational Intelligence in Vehicles and Vehicular Systems, 2009. CIVVS'09. IEEE Workshop on, pp. 23-28, 2009. 
[35] C. Beckx, L. Panis, I. Vlieger, and G. Wets, "Influence of gear-changing behaviour on fuel use and vehicular exhaust emissions," Highway and Urban Environment, pp. 45-51, 2007.

[36] B. Beusen, S. Broekx, T. Denys, C. Beckx, B. Degraeuwe, M. Gijsbers, K. Scheepers, L. Govaerts, R. Torfs, and L. I. Panis, "Using on-board logging devices to study the longer-term impact of an eco-driving course," Transportation research part D: transport and environment, vol. 14, no. 7, pp. 514-520, 2009.

[37] K. Boriboonsomsin, A. Vu, and M. Barth, "Eco-driving: pilot evaluation of driving behavior changes among us drivers," University of California Transportation Center, 2010.

[38] T. Hiraoka, Y. Terakado, S. Matsumoto, and S. Yamabe, "Quantitative evaluation of eco-driving on fuel consumption based on driving simulator experiments," in Proceedings of the 16th World Congress on Intelligent Transport Systems, 2009, pp. 2125.

[39] D. J. LeBlanc, M. Sivak, and S. Bogard, "Using naturalistic driving data to assess variations in fuel efficiency among individual drivers," University of Michigan, Ann Arbor, Transportation Research Institute, 2010.

[40] EPA, "Gas mileage tips - driving more efficiently," http://www.fueleconomy.gov/feg/ drivehabits.shtml, 2011, [Accessed: 10- Oct- 2017].

[41] — , "Many factors affect mpg," http://www.fueleconomy.gov/feg/factors.shtml., 2011, [Accessed: 10- Oct- 2017].

[42] D. Vangi and A. Virga, "Evaluation of energy-saving driving styles for bus drivers," Proceedings of the Institution of Mechanical Engineers, Part D: Journal of Automobile Engineering, vol. 217, no. 4, pp. 299-305, 2003. 
[43] S. Carrese, A. Gemma, and S. La Spada, "Impacts of driving behaviours, slope and vehicle load factor on bus fuel consumption and emissions: a real case study in the city of rome," Procedia-Social and Behavioral Sciences, vol. 87, pp. 211-221, 2013.

[44] R. Buehler, "Determinants of transport mode choice: a comparison of germany and the usa," Journal of Transport Geography, vol. 19, no. 4, pp. 644-657, 2011.

[45] C. Andrieu and G. Saint Pierre, "Comparing effects of eco-driving training and simple advices on driving behavior," Procedia-Social and Behavioral Sciences, vol. 54, pp. 211-220, 2012.

[46] EPA, "Light-duty automotive technology, carbon dioxide emissions, and fuel economy trends report overview," https:/www.epa.gov/fuel-economy-trends/ trends-report, 2016.

[47] E. Dogan, L. Steg, and P. Delhomme, "The influence of multiple goals on driving behavior: The case of safety, time saving, and fuel saving," Accident Analysis \& Prevention, vol. 43, no. 5, pp. 1635-1643, 2011.

[48] W. R. Morrow, K. S. Gallagher, G. Collantes, and H. Lee, "Analysis of policies to reduce oil consumption and greenhouse-gas emissions from the us transportation sector," Energy Policy, vol. 38, no. 3, pp. 1305-1320, 2010.

[49] F. Birol et al., "World energy outlook," Paris: International Energy Agency, vol. 23, no. 4 , p. 329, 2008.

[50] M. Tran, D. Banister, J. D. Bishop, and M. D. McCulloch, "Realizing the electricvehicle revolution," Nature climate change, vol. 2, no. 5, p. 328, 2012.

[51] "How to gasoline and electric vehicles compare," https://avt.inl.gov/sites/default/files/ pdf/fsev/compare, 2016, [Accessed: 27- Oct- 2017]. 
[52] "Alternatie fuels data center," https://www.afdc.energy.gov/fuels/, [Accessed: 15Oct- 2017].

[53] X. Wu, D. Freese, A. Cabrera, and W. A. Kitch, "Electric vehicles' energy consumption measurement and estimation," Transportation Research Part D: Transport and Environment, vol. 34, pp. 52-67, 12015.

[54] D. Meadows, Thinking in Systems A Primer. Earth Scan, 2008.

[55] X. Nian, F. Peng, and H. Zhang, "Regenerative braking system of electric vehicle driven by brushless dc motor," IEEE Transactions on Industrial Electronics, vol. 61, no. 10, 102014.

[56] K. Boriboonsomsin and M. Barth, "Impacts of road grade on fuel consumption and carbon dioxide emissions evidenced by use of advanced navigation systems," Transportation Research Record: Journal of the Transportation Research Board, no. 2139, pp. 21-30, 2009.

[57] J. G. Hayes, R. P. R. de Oliveira, S. Vaughan, and M. G. Egan, "Simplified electric vehicle power train models and range estimation," Vehicle Power and Propulsion Conference (VPPC), 2011 IEEE, pp. 1-5, 2011.

[58] T. Yuksel and J. J. Michalek, "Effects of regional temperature on electric vehicle efficiency, range, and emissions in the united states," Environmental science \& technology, vol. 49, no. 6, pp. 3974-3980, 2015.

[59] J. S. Welstand, H. H. Haskew, R. F. Gunst, and O. M. Bevilacqua, "Evaluation of the effects of air conditioning operation and associated environmental conditions on vehicle emissions and fuel economy," SAE Technical Paper, Tech. Rep., 2003.

[60] C. Walsh, S. Carroll, A. Eastlake, and P. Blythe, "Electric vehicle driving style and duty variation performance study," University of Sheffield2010, 2010. 
[61] A. Gärling, Paving the way for the electric vehicle. Vinnova, 2001.

[62] T. Franke, I. Neumann, F. Bühler, P. Cocron, and J. F. Krems, "Experiencing range in an electric vehicle: Understanding psychological barriers," Applied Psychology, vol. 61, no. 3, pp. 368-391, 2012.

[63] P. Cocron, F. Bühler, I. Neumann, T. Franke, J. F. Krems, M. Schwalm, and A. Keinath, "Methods of evaluating electric vehicles from a user's perspective-the mini e field trial in berlin," IET Intelligent Transport Systems, vol. 5, no. 2, pp. 127$133,2011$.

[64] J. Dong, C. Liu, and Z. Lin, "Charging infrastructure planning for promoting battery electric vehicles: An activity-based approach using multiday travel data," Transportation Research Part C: Emerging Technologies, vol. 38, pp. 44-55, 2014.

[65] O. Egbue and S. Long, "Barriers to widespread adoption of electric vehicles: An analysis of consumer attitudes and perceptions," Energy policy, vol. 48, pp. 717-729, 2012.

[66] “Global ev outlook 2017,” 2017, [Accessed: 15- Oct- 2017].

[67] “Office of energy resources," http://www.energy.ri.gov/transportation/ev/, [Accessed: 29- Oct- 2017].

[68] A. D. Alvarez, F. S. Garcia, J. E. Naranjo, J. J. Anaya, and F. Jimenez, "Modeling the driving behavior of electric vehicles using smartphones and neural networks," IEEE Intelligent Transportation Systems Magazine, vol. 6, no. 3, pp. 44-53, 2014.

[69] “Open street maps," http://wiki.openstreetmap.org/wiki/Key:highway, [Accessed: 23- Oct- 2017].

[70] “2015 volkswageb e-golf - owners manual,” https://carmanuals2.com/volkswagen/ e-golf-2015-owner-s-manual-88312, [Accessed: 29- Oct- 2017]. 
[71] “2015 e-golf,” https://www.vw.com/content/dam/vwcom/brochures/2015models/ MY15_e-Golf_Digital.pdf, [Accessed: 1- Oct- 2017].

[72] "Sk pang electronics," http://skpang.co.uk/catalog/ pican2-canbus-board-for-raspberry-pi-23-p-1475.html, [Accessed: 25- Oct2017].

[73] K. H. Johansson, M. Törngren, and L. Nielsen, Vehicle Applications of Controller Area Network. Boston, MA: Birkhäuser Boston, 2005, pp. 741-765.

[74] C.-M. Tseng, W. Zhou, M. Hashmi, C.-K. Chau, S. Song, and E. Wilhelm, "Data extraction from electric vehicles through obd and application of carbon footprint evaluation," EV-SYS, 62016.

[75] "Socektcan documentation," https://git.kernel.org/pub/scm/linux/kernel/git/torvalds/ linux.git/plain/Documentation/networking/can.txt, [Accessed: 29- Aug- 2017].

[76] "Breakout board documentation," https://learn.adafruit.com/adafruit-ultimate-gps/ overview, [Accessed: 01- Aug- 2017].

[77] P. Mohan, V. N. Padmanabhan, and R. Ramjee, "Nericell: rich monitoring of road and traffic conditions using mobile smartphones," in Proceedings of the 6th ACM conference on Embedded network sensor systems. ACM, 2008, pp. 323-336.

[78] M. R. Anderberg, Cluster analysis for applications: probability and mathematical statistics: a series of monographs and textbooks. Academic press, 2014, vol. 19.

[79] J. A. Hartigan and M. A. Wong, "Algorithm as 136: A k-means clustering algorithm," Journal of the Royal Statistical Society. Series C (Applied Statistics), vol. 28, no. 1, pp. 100-108, 1979.

[80] "Cluster analysis," http://www.umass.edu/landeco/teaching/multivariate/schedule/ cluster1.pdf, [Accessed: 26- Oct- 2017]. 
[81] J. H. Ward Jr, "Hierarchical grouping to optimize an objective function," Journal of the American statistical association, vol. 58, no. 301, pp. 236-244, 1963.

[82] T. W. Anderson and D. A. Darling, "A test of goodness of fit," Journal of the American statistical association, vol. 49, no. 268, pp. 765-769, 1954.

[83] S. S. Shapiro and M. B. Wilk, "An analysis of variance test for normality (complete samples)," Biometrika, vol. 52, no. 3/4, pp. 591-611, 1965.

[84] R. Vaiana, T. Iuele, V. Astarita, M. V. Caruso, A. Tassitani, C. Zaffino, and V. P. Giofrè, "Driving behavior and traffic safety: an acceleration-based safety evaluation procedure for smartphones," Modern Applied Science, vol. 8, no. 1, p. 88, 2014.

[85] J. Reason, A. Manstead, S. Stradling, J. Baxter, and K. Campbell, "Errors and violations on the roads: a real distinction?" Ergonomics, vol. 33, no. 10-11, pp. 1315$1332,1990$.

[86] J. D. Clapp, A. S. Baker, S. D. Litwack, D. M. Sloan, and J. G. Beck, "Properties of the driving behavior survey among individuals with motor vehicle accident-related posttraumatic stress disorder," Journal of anxiety disorders, vol. 28, no. 1, pp. 1-7, 2014.

[87] H. Khanipour, S. A. Tavallaii, and K. Ahmadi, "Psychometric properties of the driving behavior survey among iranian drivers," Practice in Clinical Psychology, vol. 3, no. 4, pp. 259-266, 2015.

[88] "Us department of transportation," https://www.fhwa.dot.gov/ohim/onh00/bar8.htm, [Accessed: 29- Oct- 2017].

[89] “Telegram,” http://www.telegram.com/article/20150915/NEWS/150919445, [Accessed: 29- Oct- 2017]. 
[90] R. Zhang and E. Yao, "Electric vehicles' energy consumption estimation with real driving condition data," Transportation Research Part D: Transport and Environment, vol. 41, pp. 177-187, 122015.

[91] W.-Y. Chang, "The state of charge estimating methods for battery: A review," ISRN Applied Mathematics, vol. 2013, 2013.

[92] A. Bolovinou, I. Bakas, A. Amditis, F. Mastrandrea, and W. Vinciotti, "Online prediction of an electric vehicle remaining range based on regression analysis," in Electric Vehicle Conference (IEVC), 2014 IEEE International. IEEE, 2014, pp. 1-8.

[93] J. C. Ferreira, V. Monteiro, and J. L. Afonso, "Dynamic range prediction for an electric vehicle," in Electric Vehicle Symposium and Exhibition (EVS27), 2013 World. IEEE, 2013, pp. 1-11.

[94] J. Lin, W. Zhou, and O. Wolfson, "Electric vehicle routing problem," Transportation Research Procedia, vol. 12, pp. 508-521, 2016.

[95] M. Bruglieri, F. Pezzella, O. Pisacane, and S. Suraci, "A matheuristic for the electric vehicle routing problem with time windows," arXiv preprint arXiv:1506.00211, 2015.

[96] A. Artmeier, J. Haselmayr, M. Leucker, and M. Sachenbacher, "The shortest path problem revisited: Optimal routing for electric vehicles." KI, vol. 6359, pp. 309-316, 2010.

[97] J. D. Adler, P. B. Mirchandani, G. Xue, and M. Xia, "The electric vehicle shortestwalk problem with battery exchanges," Networks and Spatial Economics, vol. 16, no. 1, pp. 155-173, 2016. 